UNIVERSIDADE DE SÃO PAULO

FACULDADE DE MEDICINA DE RIBEIRÃO PRETO

\author{
“AVALIAÇÃO ESTRUTURAL E FUNCIONAL DA \\ DEGLUTIÇÃO DE IDOSOS, COM E SEM QUEIXAS \\ DE DISFAGIA, INTERNADOS EM UMA \\ ENFERMARIA GERIÁTRICA”
}

Paula de Carvalho Macedo Issa

RIBEIRÃO PRETO

2.003 
FACULDADE DE MEDICINA DE RIBEIRÃO PRETO

\title{
“AVALIAÇÃO ESTRUTURAL E FUNCIONAL DA \\ DEGLUTIÇÃO DE IDOSOS, COM E SEM QUEIXAS \\ DE DISFAGIA, INTERNADOS EM UMA
}

ENFERMARIA GERIÁTRICA”

Paula de Carvalho Macedo Issa

\begin{abstract}
Dissertação de Mestrado apresentada à Universidade de São Paulo para obtenção do Título de Mestre em Biociências aplicada à Clínica Médica.

Orientador: Dr. Eduardo Ferriolli Colaborador: Dr. Roberto Oliveira Dantas
\end{abstract}


"Ninguém envelhece meramente porque viveu um certo número de anos. Pessoas envelhecem quando desistem de seus ideais. No fundo do coração há uma câmara de recordações e quanto mais mensagens de beleza, esperança, alegria $e$ otimismo, perseverança e coragem nela existirem, tanto mais jovem você será. Quando as mensagens forem de tristeza e o coração estiver coberto pela neve do pessimismo e pelo gelo do cinismo, então e só então, você terá envelhecido".

(DOUGLAS MC ARTHUR - “O que é envelhecer") 


\section{DEDICATÓRIAS}

Meus sonhos e minhas conquistas só fazem sentido e se concretizam pela existência de duas pessoas maravilhosas e indescritíveis, que jamais pouparam esforços para que estes sonhos se tornassem realidade e as conquistas ... fossem muito mais que uma simples realização pessoal! Dedico à vocês, papai e mamãe, este trabalho!!

Fazendo parte dessa longa caminhada, sempre presentes, irmãs, amigas, cúmplices e confidentes, divido com vocês, Cláudia e Renata, a conclusão dessa 


\section{AGRADECIMENTOS}

Ao Senhor Pai, por ter respondido aos meus apelos, dando-me força e entusiasmo nos momentos de cansaço e desânimo. Obrigada por estar presente, iluminando-me e afagando-me no silêncio das madrugadas.

Aos meus pais, José Antônio e Cármen. Obrigada por serem o que são! Esse trabalho tem muito de vocês. Mamãe, incansavelmente, na busca dos voluntários idosos. Papai, nas correções e perguntas intrigantes. Agradeço-os, imensamente.

As minhas irmãs, Cláudia e Renata, pelo incentivo na concretização desse estudo, sempre com sugestões e opiniões construtivas durante a execução dos exames. Assim como vocês são um ‘pedacinho’ de mim, este trabalho também tem um ‘pedacinho' de vocês.

Aos pacientes da enfermaria, onde passei poucos e grandiosos momentos à beira do leito ouvindo suas histórias de vida antes que terminássemos nossa avaliação. Sem vocês, esse trabalho não teria sido iniciado; sem vocês, esse trabalho não teria sido concluído.

A todos que participaram do grupo controle de jovens - residentes da geriatria, aprimorandas do setor de fonoaudiologia, amigos, funcionários da medicina nuclear, meus primos Carlos e Alessandra, meus cunhados Rodrigo e André, meu namorado Denny - o meu muitíssimo obrigada!

A todos os voluntários idosos pela disposição em colaborarem na constituição do nosso grupo controle. 
Aos funcionários da Divisão de Clínica Médica Geral e Geriatria do Hospital das Clínicas pela compreensão, gentileza em aguardar alguns procedimentos para que eu finalizasse as avaliações e, principalmente, auxílio no manuseio dos pacientes.

A todos da medicina nuclear, pela abertura e disposição que me foi dispendida.

À Marie Secaf e ao Samuel, que foram tolerantes, curiosos e indispensáveis na concretização das cintilografias. Vocês são especiais.

Ao meu orientador, Prof. Dr. Eduardo Ferriolli, que sempre tentou me passar calma, tranqüilidade e confiança nos momentos de muito nervosismo. Pessoa de personalidade bem oposta a minha não poderia ter sido melhor escolhida para que desempenhasse seu papel. Agradeço também o carinho a mim disposto em um momento de grande tristeza pessoal.

Ao Prof. Dr. Roberto Oliveira Dantas, pela disponibilidade em me orientar sobre o desenvolvimento da pesquisa, fornecendo-me referências, textos e, principalmente, conhecimento.

Ao Prof. Dr. Troncon que, indiretamente, acompanhou esse trabalho e dividiu, gentilmente, o espaço na medicina nuclear. Obrigada pelas sutis dicas e ensinamentos extremamente úteis para o desenvolvimento dessa pesquisa. O senhor, foi também meu mestre não só na pesquisa mas, e, principalmente, como ser humano. Sinceramente, eu o admiro!

As minhas aperfeiçoandas, Anna Flávia e Fabiane, por terem me ajudado, incondicionalmente, nos momentos de ausência. Com certeza, vocês ficarão guardadas no meu coração. Obrigada.

As colegas do Setor de Fonoaudiologia, pelo incentivo, troca de informações e conhecimentos. 
Especialmente, agradeço às amigas, Luciana Voi, Ana Paula André e Lílian, que compartilharam as dúvidas, incertezas, desânimos e desabafos. Agradeço as sugestões, opiniões e incentivo.

A todas fonoaudiólogas da equipe de disfagia, Danielle, Lílian, Adriana e Ana Paula Duca, pela compreensão da ausência, mau humor e stress nos ambulatórios.

A minha companheira de trabalho, Danielle Ramos, que sempre se colocou à disposição para que eu pudesse me ausentar nos atendimentos, respondendo prontamente a todas minhas solicitações.

Ao Prof. Gerson que, sempre atento aos números estatísticos, nos dá suporte para concluirmos os trabalhos.

Ao Dráulio pela prontidão em realizar o vídeo da cintilografia, ilustrando minha apresentação.

À Tereza Bilton pelos comentários extremamente pertinentes durante a leitura da dissertação.

Ao amigo Beto Leão pela arte da capa, trazendo-me à lembrança tão significantes pessoas em minha vida.

Ao vovô Edgard, não podendo incluí-lo em minhas experiências que por tão jovem nos ter deixado, o meu carinho.

Aos meus avós, Alexandrina, Issa e Julia declaro o respeito que sinto por vocês, exaltando-os numa conquista muito importante em minha vida. Aonde quer que estejam... ficam minhas saudades! 


\section{SUMÁRIO}

Pág.

\begin{tabular}{|c|c|}
\hline \\
\hline Abstract & \\
\hline \multicolumn{2}{|l|}{ Listas } \\
\hline \multicolumn{2}{|l|}{ Introdução } \\
\hline 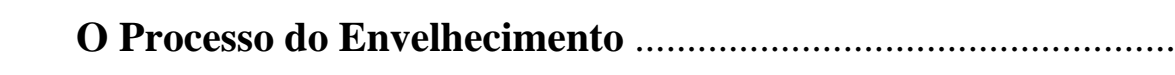 & 2 \\
\hline (n) & 6 \\
\hline Envelhecimento e Desordens da Deglutição ................................. & 10 \\
\hline Objetivos ................................. & 22 \\
\hline Material e Método ........................... & 24 \\
\hline Resultados & 34 \\
\hline Discussão & 54 \\
\hline Conclusão & 76 \\
\hline 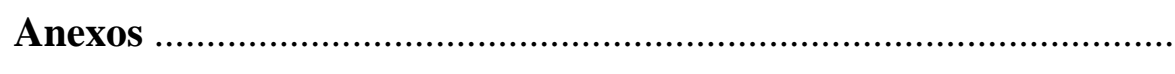 & 78 \\
\hline  & 84 \\
\hline Bibliografia Consultada ..................... & 94 \\
\hline Apêndice & \\
\hline
\end{tabular}


RESUMO 
Os mecanismos fisiológicos sofrem mudanças durante o processo de envelhecimento. Dentre as alterações que ocorrem naturalmente durante esse processo, existem os problemas de deglutição.

A integridade da deglutição não só garante a manutenção do estado nutricional do paciente mas também protege o trato respiratório contra acidentes como aspiração de conteúdo da orofaringe; por outro lado, suas alterações, muitas vezes somadas a processos patológicos, levam a complicações nutricionais e infecciosas, favorecendo a ocorrência de outras doenças e podendo, até mesmo, levar a quadros irreversíveis.

O presente estudo teve por objetivo avaliar a fase orofaríngea da deglutição de pacientes idosos internados na enfermaria da Divisão de Clínica Médica Geral e Geriatria do Hospital das Clínicas da Faculdade de Medicina de Ribeirão Preto da Universidade de São Paulo, com ou sem queixas de dificuldade de deglutição, através da avaliação clínica fonoaudiológica e do estudo cintilográfico da deglutição, correlacionando-os.

Para tanto, foram avaliados 30 pacientes idosos internados, com idades entre 66 e 94 anos, idade média de 80 anos, selecionados aleatoriamente, sem se considerar suas doenças e a presença ou não de queixas de disfagia, sendo excluídos os pacientes gravemente comprometidos, cujo estado impossibilitava a avaliação clínica e objetiva da deglutição.

Além disso, obteve-se dois grupos controle, sendo um constituído por jovens, com idades variando de 21 a 30 anos, idade média de 25 anos e o outro foi constituído por idosos, com idades variando de 60 a 80 anos, idade média de 70 anos. Os voluntários dos grupos controle foram cuidadosamente triados antes da participação no estudo para assegurar que eles não apresentassem histórias de dificuldades para a deglutição e/ou condições médicas que pudessem influenciar a deglutição ou performance motora orofacial e/ou que usassem medicamentos depressores do sistema nervoso central.

Para a avaliação funcional da deglutição, os participantes do estudo deglutiram dois bolos de alimentos de $5 \mathrm{ml}$ cada, nas consistências líquida e pastosa. No estudo cintilográfico foram adicionados aos dois bolos, um marcador de radioatividade de fitato coloidal ligado ao tecnécio $\left({ }^{99 \mathrm{~m}} \mathrm{Tc}\right)$. Os dados da avaliação 
foram analisados no computador através do protocolo de aquisição da gama-câmara (vision DST) quanto ao trânsito e resíduo oral, trânsito, clearance e resíduo faríngeo e entrada no esôfago proximal.

O estudo permitiu concluir que idosos doentes sem queixa de dificuldade de deglutição e sem a presença de doenças que cursam com a disfagia, não apresentam diferença significativa dos parâmetros observados quando comparados com idosos saudáveis; pessoas idosas deglutem mais lentamente quando comparadas com pessoas mais jovens, entretanto essa lentificação permite que idosos deglutam mais seguramente. As mudanças no hábito alimentar de idosos devem ser questionadas por profissionais que trabalham com a população geriátrica e a avaliação fonoaudiológica clínica da deglutição deve fazer parte da definição do diagnóstico diferencial em quadros que sugiram dificuldades de deglutição e, principalmente deve ser imprescindível naqueles que apresentem patologias que cursam com a disfagia; a técnica cintilográfica é sensível a sutis mudanças relacionadas ao trânsito, clearance e resíduo alimentar. 
ABSTRACT 
Physiological mechanisms change during the aging process. Among the changes that occur naturally during this process, there are the problems of swallowing.

Swallowing integrity not only warrants the maintenance of the patient's nutritional status, but also protects the respiratory system against accidents like the aspiration of oropharyngeal contents. On the other hand, changes in the swallowing process, often added by other diseases, induces nutritional and infectious complications, favoring the occurrence of other diseases and, even, irreversible clinical pictures.

The present study aimed to assess the oropharyngeal phase of swallowing of older persons admitted to the wards of the Division of General Internal Medicine and Geriatric Medicine of the Internal Medicine Department of the School of Medicine of Ribeirão Preto - University of São Paulo, independently of the presence or absence of swallowing complaints, through phonoaudiological clinical evaluation and cintilographic study of swallowing.

Thirty elderly patients were studied, with age ranging from 66 to 94 years old, mean age 80 years, randomly selected, without being taken into consideration specific diseases and the presence or absence of swallowing complaints. Severely compromised Patients, whose health status made impossible adequate evaluation, were excluded.

Two control groups were composed, one of young volunteers, aged from 21 to 30 years, mean age 25 years and one of elderly volunteers, with age ranging from 60 to 80 years old, mean age 70 years. Volunteers of the control groups were carefully evaluated before participation, to make sure that they did not have swallowing difficulties and/or clinical conditions that could influence swallowing and oral and facial motor performance and did not take medications with central nervous system actions.

For functional assessment of swallowing, the study participants swallowed two boluses of $5 \mathrm{ml}$ each, in liquid and syrup consistence. In the cintilographic study, a radioactive tracer $\left({ }^{99 \mathrm{~m}} \mathrm{Tc}\right.$ colloidal phytate) was added to the boluses. Data were analyzed through the gamma-camera acquisition protocol (vision DST) for oral 
transit and residual, pharyngeal transit, clearance time and residual and time for proximal esophagus entrance.

The study allowed us to conclude that older patients without swallowing complaints and without diseases that cause dysphagia, do not show significant differences of the observed parameters when compared to healthy older persons. Older persons swallow slower when compared to younger persons, however this delay allows them to swallow safer. Changes in dietary habits of older persons should be questioned by professionals that work with geriatric populations and clinical phonoaudiological assessment of swallowing must be part of the assessment process of situations where difficulties for swallowing appeared, being absolutely necessary for those that present diseases that courses with dysphagia. The cintilographic technique is sensitive to subtle changes in transit, clearance and food residuals. 


\section{LISTA DE FIGURAS}

Pág.

Figura 1 - Voluntário sentado em frente à gama-câmara (posição adequada para a avaliação da deglutição)

Figura 2 - Voluntário sentado em frente à gama-câmara (opção para a avaliação de pacientes em cadeira de rodas)

Figura 3 - Delimitação das ROIs referentes às áreas estudadas (boca, faringe e esôfago proximal) 


\section{LISTA DE QUADROS}

Pág.

Quadro 1 - Caracterização das queixas (dados de anamnese) dos três pacientes que referiram disfagia .................................................................... 35

Quadro 2 - Referência quanto à alimentação dos 27 pacientes sem queixa de disfagia (dados de anamnese) ........................................................... 36

Quadro 3 - Avaliação estrutural da deglutição dos 30 pacientes estudados ......... 37

Quadro 4 - Avaliação funcional da deglutição dos 30 pacientes estudados ........ 40 


\section{LISTA DE TABELAS}

Pág.

Tabela 1: Comparação entre os grupos de jovens, idosos saudáveis e doentes para a consistência líquida

Tabela 2: Comparação entre os grupos de jovens, idosos saudáveis e doentes para a consistência pastosa

Tabela 3: Comparação da fase oral entre as consistências (bolos) no grupo de jovens

Tabela 4: Comparação da fase faríngea entre as consistências (bolos) no grupo de jovens

Tabela 5: Comparação da entrada no esôfago proximal entre as consistências (bolos) no grupo de jovens

Tabela 6: Comparação da fase oral entre as consistências (bolos) no grupo de idosos saudáveis

Tabela 7: Comparação da fase faríngea entre as consistências (bolos) no grupo de idosos saudáveis

Tabela 8: Comparação da entrada no esôfago proximal entre as consistências (bolos) no grupo de idosos saudáveis

Tabela 9: Comparação da fase oral entre as consistências (bolos) no grupo de idosos doentes

Tabela 10: Comparação da fase faríngea entre as consistências (bolos) no grupo de idosos doentes

Tabela 11: Comparação da entrada no esôfago proximal entre as consistências (bolos) no grupo de idosos doentes 


\section{LISTA DE GRÁFICOS}

Pág.

Gráfico 1: Curva de atividade durante a deglutição do bolo na consistência liquida por um jovem

Gráfico 2: Curva de atividade durante a deglutição do bolo na consistência líquida por um voluntário idoso

Gráfico 3: Comparação entre os grupos de jovens, idosos saudáveis e idosos doentes para a consistência líquida quanto aos resíduos oral e faríngeo .

Gráfico 4: Comparação entre os grupos de jovens, idosos saudáveis e idosos doentes para a consistência líquida quanto aos tempos de trânsito, clearance e entrada no esôfago proximal

Gráfico 5: Comparação entre os grupos de jovens, idosos saudáveis e idosos doentes para a consistência pastosa quanto aos resíduos oral e faríngeo . 45

Gráfico 6: Comparação entre os grupos de jovens, idosos saudáveis e idosos doentes pra a consistência pastosa quanto aos tempos de trânsito, clearance e entrada no esôfago proximal

Gráfico 7: Comparação entre os tempos de trânsito oral e faríngeo, clearance faríngeo e tempo de entrada no esôfago proximal durante a deglutição dos bolos líquido e pastoso no grupo de jovens

Gráfico 8: Comparação entre os resíduos oral e faríngeo na deglutição dos bolos líquido e pastoso no grupo de jovens

Gráfico 9: Comparação entre os tempos de trânsito oral e faríngeo, clearance faríngeo e tempo de entrada no esôfago proximal durante a deglutição dos bolos líquido e pastoso no grupo de idosos saudáveis

Gráfico 10: Comparação entre os resíduos oral e faríngeo na deglutição dos bolos líquido e pastoso no grupo de idosos saudáveis

Gráfico 11: Comparação entre os tempos de trânsito oral e faríngeo, clearance faríngeo e tempo de entrada no esôfago proximal durante a deglutição dos bolos líquido e pastoso no grupo de idosos doentes 
Gráfico 12: Comparação entre os resíduos oral e faríngeo na deglutição dos bolos líquido e pastoso no grupo de idosos doentes .... 


\section{INTRODUÇÃO}




\section{PROCESSO DO ENVELHECIMENTO}

O envelhecimento é um processo natural e inerente à vida. Desde que nascemos, estamos em processo de envelhecimento. Neste é observada a redução da reserva funcional dos vários órgãos e sistemas do organismo, enfraquecimento dos mecanismos de defesa frente às variações do ambiente e maior incidência de algumas afecções. Estes fatores fazem com que a abordagem diagnóstica e terapêutica desses indivíduos seja merecedora de especial atenção (NASI et al, 1998; RIBEIRO, 1999).

A deterioração funcional em idosos ativos, previamente não comprometidos, pode ser um sinal precoce e sutil de doença. Conseqüentemente, problemas de mobilidade, cognição, continência e nutrição requerem uma abordagem cuidadosa e direcionada, acrescendo-se a avaliação funcional à clínica tradicional (BESDINE, 1995).

É durante esse processo que surge uma infinidade de doenças que irão comprometer, direta ou indiretamente, a qualidade de vida desses indivíduos. GORMAN et al (1994), descreveram que os pacientes idosos são suscetíveis a todas as doenças que mais comumente afetam adultos mais jovens. Entretanto, na maneira em que são acometidos por elas e na sua recuperação é que se ressaltam as diferenças dessas faixas etárias. As manifestações clínicas nos idosos podem diferir, significativamente, das observadas em pessoas mais jovens (NASI et al, 1998).

No sistema nervoso, com o advento do envelhecimento, há uma significativa redução do número de neurônios, diminuição da reserva de oxigênio e do fluxo sangüíneo. Mudanças que não fazem parte desse processo natural, mas que são mais freqüentemente encontradas no envelhecimento, são a perda dos poderes psíquicos já adquiridos, sobretudo a cognição (demência), hemorragia cerebral, insuficiência cérebro vascular crônica e doença de Parkinson (ALBERTO, 1998).

As doenças vasculares cerebrais nos pacientes idosos são, provavelmente, as patologias neurológicas mais comuns nesta faixa etária. Admite-se que nos Estados Unidos 200.000 óbitos ocorram anualmente por causa de doenças vasculares cerebrais (AMANCIO, 1975). 
As patologias orgânicas que são, freqüentemente, encontradas no processo do envelhecimento, se somadas a outras alterações, poderão desencadear novas patologias e complicações. Dentre as alterações mais freqüentes nos idosos, existem as relacionadas com o aparelho digestivo (ausência de dentes, problemas de nutrição, constipação, incontinência, entre outras). Também podem ocorrer alterações nas vias respiratórias, onde o pulmão do idoso sofre uma série de alterações anátomofuncionais, tais como a diminuição do seu volume, do seu peso. Podem ocorrer doenças como a bronquite crônica, enfisema, pneumonia que, com um quadro de disfagia, muitas vezes não detectado, poderiam ser agravadas (ALBERTO, 1998).

Além de complicar doenças como as referidas, a disfagia pode ser a causa direta de desnutrição. Isso a torna objeto de grande interesse na medicina geriátrica (BILTON et al, 1999).

Com o avanço da idade, mudanças difusas na extensão do músculo, motilidade e coordenação do esôfago, assim como diminuição na discriminação sensorial, predispõem indivíduos à disfagia. Na ausência de condições mórbidas, essas mudanças são bem compensadas, permanecendo indetectáveis para médicos e pacientes. Entretanto, no cenário de uma doença aguda ou progressiva, o paciente pode, rapidamente, perder essa habilidade de compensar mudanças na deglutição relacionadas à idade (SCHINDLER \& KELLY, 2002).

Como todas as estruturas do organismo envelhecem, a cavidade oral apresenta uma série de modificações que dão origem a queixas comuns, facilitam a presença de determinadas doenças, e produzem alterações funcionais. Todos os tecidos da cavidade oral sofrem atrofia e perda da elasticidade, desde a mucosa, passando pelos tecidos subjacentes e de sustentação, pelas estruturas musculares, inclusive do palato, atingindo as estruturas ósseas. A produção da saliva diminui quantitativamente (ALENCAR e CURIATI, 1998).

LEEMING et al (1975), descreveram que alterações relacionadas à boca são comuns no envelhecimento, como o surgimento de varicosidades dos vasos da mucosa, em geral debaixo da língua; xerostomia com ressecamento da boca por respiração bucal ou por ingestão insuficiente de líquidos ou secreção da parótida diminuída; mudanças do gosto, que pode ser alterado por diversas razões. A simples perda da sensação gustativa pode ser causa importante de desnutrição, podendo 
resultar em perda de peso. Por fim, são comuns as perdas dentárias, sendo importante a presença de alguns elementos dentários para possíveis adaptações de próteses.

Nos idosos, ocorrem uma variedade de mudanças que pioram a função da deglutição. Algumas dessas mudanças são efeito direto do processo de envelhecimento, mas muitas outras aparecem de processos utilizados para tratar várias condições médicas (PLANT, 1998), como, por exemplo, o uso de medicamentos que alteram essa função.

Vários fatores estão relacionados à deglutição, como os hábitos de higiene pessoal. No que diz respeito à higiene oral, muitas vezes não é dada a devida importância pelos idosos. Essa má higiene pode levar a perda de dentes, cáries, necessidade do uso de próteses, que muitas vezes tornam-se mal adaptadas por emagrecimento ou ausência de ajustamento em decorrência da própria ausência de percepção de sua má adaptação (com a perda de sensores existentes na cavidade oral).

A saúde oral é importante para a saúde geral devido à ocorrência de doenças estomatológicas. Por causa de má higiene, acaba havendo mudanças e alterações no sistema estomatognático como um todo, trazendo malefícios durante a função da mastigação e, consequentemente, na deglutição. Além disso, condições sistêmicas podem ter um forte impacto na função e saúde oral. Problemas orais com o avanço da idade são mais freqüentemente atribuídos a doenças preveníveis do que à idade por si só (SHAY \& SHIP, 1995).

A perda dos dentes leva à perda sensorial do periodonto e mucosa, assim os outros receptores existentes informarão os movimentos mastigatórios, pois com a colocação de dentes artificiais, a mastigação será diferente. O uso da prótese exige uma programação neuromuscular, que se dá por meio de um processo de aprendizagem para que se desenvolva uma mastigação adequada a essa prótese.

As dificuldades na mastigação, deglutição e fala em idosos desdentados também estão relacionadas à dor durante a função por inadequação das próteses devido à falta de requisitos para uma boa adaptação da mesma. Nesses idosos, são evidentes alterações em decorrência da modificação da neuromusculatura, podendo ocorrer perda da tonicidade, mandíbula em posição protrusiva, lábios contraídos, inserções musculares modificadas em virtude do processo de absorção alveolar, 
contração permanente dos músculos do mento e lábio inferior, diminuição da dimensão vertical e alteração da musculatura da língua, entre outros (CUNHA e ZUCCOLOTTO, 1999).

As lacunas na dentadura, assim como seu mal posicionamento e os locais de pressão, são causas de alimentação deficiente e de erros alimentares que não deveriam passar desapercebidos (SCHNEIDER, 1985).

Todos esses fatores, somados, podem levar a um impacto social, afastando o idoso de seu meio, e podendo levar à recusa da alimentação, que passa a não ser mais um ato prazeroso e sim, causador de desconforto. Assim, isso trará conseqüências que refletirão diretamente no processo de envelhecimento.

MORLEY (1993), descreveu que, de uma perspectiva patofisiológica, anorexia e perda de peso são considerados devidos a causas sociais, psicológicas, médicas e relacionadas à idade. Dentro da causa social, o isolamento pode ter um importante papel em levar a uma redução na ingestão da comida. Como causa psicológica, a depressão pode estar presente atipicamente e a perda de peso não é um sintoma raro em pessoas idosas. A disfagia pode levar à perda de peso. Esses problemas são extremamente comuns entre pessoas idosas e ainda são raramente tratados. Em geral, estar abaixo do peso ou perdendo peso é problema com conseqüências médicas mais graves para pessoas idosas do que o sobrepeso. O autor ainda afirma que é importante que médicos prestem uma atenção mais cuidadosa a mudanças no peso que ocorrem em pacientes idosos, pois, apesar da importância da má nutrição protéica em pessoas idosas, poucos estudos têm sido feitos sobre essa ocorrência.

Uma simples mudança de hábito alimentar, isolamento ou uma queixa subjetiva devem ser considerados relevantes e observados prontamente como indício de alteração ou provável doença.

É importante tratar alguma anormalidade morfológica antes da disfunção ser constatada. Usualmente, as anormalidades morfológicas são mais fáceis de serem manejadas que a disfunção. É importante a compreensão da queixa dos pacientes e o de resultados de exames prévios, com revisão correta e descritiva desses resultados, podendo-se concluir se os achados explicam ou não os sintomas dos pacientes (EKBERG \& OLSSON, 1997). 
Considerando-se as queixas da alimentação como foco primário da atividade social e interpessoal, desordens da deglutição podem ter um impacto negativo na saúde, status nutricional e qualidade de vida (ROBBINS et al, 1992).

\section{DISFAGIA}

A deglutição é resultante de um complexo mecanismo neuromotor, cuja absoluta coordenação em cada e entre suas fases, resultará no efetivo transporte do alimento até o esôfago (MACEDO-FILHO, 1998).

É um processo contínuo, mas, para melhor compreensão, pode ser dividido em 3 fases: a oral, a faríngea e a fase esofágica. A fase oral é, principalmente, voluntária. Comidas sólidas são trituradas pelos dentes e a saliva mistura-se com o alimento, lubrifica a comida triturada e permite que fragmentos, na textura apropriada para a deglutição, já lubrificados, sejam moldados dentro de um bolo. Após isso, há o transporte do bolo para a faringe. É na fase oral também, que se inicia o processo de absorção dos nutrientes (SHAY \& SHIP, 1995; LOGEMANN, 1990; ZOHAR et al, 1998). O reflexo palatal previne a comida de entrar na nasofaringe. Diferentes texturas são deglutidas diferentemente. Os alimentos são contidos dentro da cavidade oral por uma criação de pressão subatmosférica, e através da força da língua contra o palato duro, o alimento é propelido para dentro da faringe em duas outras fases.

Durante a primeira fase, a língua é moldada dentro de um sulco longitudinal pelos músculos longitudinal superior e genioglosso. Este sulco torna-se um espaço tubular quando o palato duro e a língua ficam em contato. O dorso da língua é forçado para cima pela contração do músculo lingual transverso. O líquido é forçado para trás e para dentro da faringe. A segunda fase se inicia com os dentes se ocluindo, a contração do milohióide, e a suspensão do assoalho bucal. A parte 
posterior da língua é forçada para trás dentro da faringe, empurrando o fluido e/ou o sólido para dentro da faringe.

A fase faríngea é um mecanismo reflexo controlado por receptores localizados na parede posterior da faringe, pelas tonsilas e a base da língua, os quais são estimulados por fluidos ou comida.

As aberturas pertencendo à via aérea, à nasofaringe e à laringe devem ser fechadas quando a comida passa através do sistema alimentar para prevenir a passagem do bolo para dentro da via aérea. Isso resulta da ação do esfíncter nasofaringeal e laríngeo. A respiração tem inibição reflexa e é seguida pelo fechamento velofaríngeo, fechamento glótico e elevação laríngea com deslocamento anterior (ZOHAR et al, 1998).

SHAY \& SHIP (1995), acrescentaram, ainda, que três tarefas fisiológicas essenciais são realizadas pela cavidade oral: o início da alimentação, a produção da fala e a proteção contra bactérias.

DODDS et al (1990a), subdividiram a deglutição em quatro fases: fase preparatória, fase oral, fase faríngea e fase esofágica. A fase preparatória envolve a mastigação de um bolo alimentar e o mistura com a saliva. O bolo alimentar é moldado (formado) e posicionado na língua prontamente para a deglutição. Durante a fase oral, o bolo é propelido da cavidade oral para dentro da faringe. A fase faríngea envolve o transporte do bolo alimentar da orofaringe para dentro do esôfago. LOGEMANN (1990), descreveu que o estímulo exato necessário e mecanismos sensoriais usados no disparo da deglutição faríngea não são claramente definidos.

A deglutição normal requer controle neuromuscular fino de estruturas na cavidade oral, faringe, laringe e esôfago para que a comida seja reduzida a uma consistência apropriada e que possa ser transportada da boca ao estômago (LOGEMANN, 1990).

Qualquer interrupção no processo da deglutição pode ocasionar dificuldades, a chamada disfagia que, em algumas condições, pode ser a primeira manifestação clínica da doença (FEIJÓ \& RIEDER, 2003).

Vários são os fatores envolvidos na deglutição. Podem ser importantes o tamanho da partícula e a quantidade de fluido na boca, em parte da saliva e outra do alimento, bem como o gosto e a forma do alimento (SILVA-NETTO, 2003). 
Os sintomas mais freqüentes de alterações nas fases oral e faríngea da deglutição incluem dificuldade de iniciar a deglutição, disfagia cervical, regurgitação nasal, tosse e engasgos. Anormalidades funcionais nas fases preparatória e oral da deglutição são causadas por movimentos anormais de língua e, ocasionalmente, pela alteração no tecido mole da língua ou cavidade oral, incluindo uma dificuldade em formar o bolo ou mantê-lo acima da língua. Normalmente, a fase oral da deglutição passa por uma tranqüila transição a uma rápida fase faríngea com transporte do bolo através da faringe. Em alguns pacientes, entretanto, a fase faríngea á atrasada, mas uma vez iniciada, é normal.

Um número de fatores podem contribuir para alteração no transporte do bolo na fase faríngea: ausência ou redução do movimento hióide, ausência ou redução do movimento laríngeo, movimento palatal inadequado, atraso ou ausência da fase faríngea, aumento unilateral de resíduo em valécula e/ou seios piriformes, movimentos anormais de epiglote, penetração e/ou aspiração laríngea e abertura anormal do esfíncter esofágico superior. Nesse último, a incompleta abertura pode prejudicar o transporte do bolo, levando a um excessivo resíduo faríngeo, e causando aspiração tardia. O movimento anterior lento do hióide pode contribuir para uma abertura incompleta desse esfíncter, mas isso, raramente, ocorre como um achado isolado (DODDS et al, 1990b).

Danos neurológicos ou estruturais e muitas outras doenças podem causar anormalidades em um ou mais dos eventos fisiológicos nos estágios oral e faríngeo da deglutição, criando problemas (LOGEMANN, 1990).

O termo disfagia refere-se à sensação da comida “espetando" em sua passagem da boca ao estômago. Pode ocorrer na fase oral, faríngea e esofageana (no esôfago superior ou no corpo do esôfago).

Disfagia orofaríngea pode ser resultado de um número de problemas locais, neurológicos ou musculares. Alteração estrutural local como a disfunção do esfíncter esofágico superior ou divertículo faringoesofágico, ocorre quando a habilidade de transferir a comida da boca ao esôfago é prejudicada. Disfagia esofageana é o resultado de qualquer obstrução mecânica (como tumor) do órgão ou alteração na motilidade que afeta a própria função muscular do esôfago. Tipicamente, a disfagia obstrutiva mostra-se como a dificuldade na deglutição de sólidos, progredindo ao 
líquido no curso da doença. A disfagia que resulta de disfunção neuromuscular, tipicamente, é apresentada com problemas na deglutição de líquidos e sólidos (GORMAN et al, 1994).

\section{BRANDT (1986); HOLLINSHED (1994); CASTELL (1995);} MARCHESAN (1995); NASI et al (1998), descreveram que a disfagia consiste na dificuldade de deglutir, em perda na progressão ordenada do alimento da boca para o estômago. Trata-se de um sintoma de uma doença em curso, podendo ocorrer em qualquer idade e se dar de forma imprecisa, lenta ou ambas. Pode ser classificada pela sua localização: alterações orofaríngeas, da boca até o esfíncter cricofaríngeo (disfagia orofaríngea ou alta), alterações esofágicas, abaixo do esfíncter cricofaríngeo (disfagia esofágica ou baixa).

A incoordenação do mecanismo da deglutição pode resultar em aspiração de alimentos ou regurgitação nasal. Assim, a disfagia orofaríngea, geralmente, é associada com tosse após a deglutição, dificuldade respiratória, infecção pulmonar (BRANDT, 1986), comprometendo tanto a parte respiratória do indivíduo como a sua nutrição (SANTINI, 1999).

HOLLINSHED (1994), descreveu que existem muitas causas da disfagia como problemas neurológicos, musculares e da placa motora (acidente vascular cerebral (A.V.C.), traumas cranioencefálicos, doença de Alzheimer, outras demências, doença de Parkinson, distrofia muscular, miastenia gravis, entre outras), pós-operatórios e traumáticos, doenças congênitas, inflamatórias, degenerativas, etc. Quando estes são evidentes, a disfagia, muitas vezes, é vista como problema de importância secundária.

Em outros casos, a disfagia pode causar aspirações silenciosas que não são percebidas e, com isso, a comida ou saliva entram no canal aéreo e, em seguida, nos pulmões. A princípio isto não causa nenhum sintoma mas, ao longo do tempo, pode ocorrer edema pulmonar ou crescimento de germes patológicos, que causam pneumonia. A aspiração pode ter conseqüências graves e até mesmo fatais (MARCHESAN, 1995).

Estudos sobre os fatores que alteram a deglutição demostram a necessidade de se suspeitar que haja uma doença em curso quando o paciente apresenta sintomas dessa natureza. Hoje, sabe-se que, através de diagnóstico fonoaudiológico, alterações 
de deglutição decorrentes da idade e das provenientes de outras doenças podem ser diferenciadas (CUNHA e ZUCCOLOTTO, 1999).

\section{ENVELHECIMENTO E DESORDENS DA DEGLUTIÇÃO}

LOGEMANN (1990), relata que poucas investigações acerca da deglutição têm sido extendidas a observações em idosos com marcas de envelhecimento mais evidentes.

EKBERG \& FEINBERG (1991), descreveram que os parâmetros da deglutição em pessoas idosas sem disfagia não têm sido adequadamente descritos; entretanto, afirmaram que os problemas de deglutição aumentam com o passar da idade. A maioria dessas pessoas têm uma alteração funcional em uma das fases oral, faríngea e/ou esofágica.

Poucos dados sobre o efeito da idade na deglutição são disponíveis. Portanto, não é claro quais problemas são normativos, se ocorrem mudanças na fisiologia relacionadas com a idade ou se eles refletem processo de doenças ou causas iatrogênicas (ex.: medicação, cirurgia), que ocorrem com freqüência aumentada em pessoas idosas (ROBBINS et al, 1992).

O efeito da idade na deglutição é controverso. Embora a idade, por si só, provavelmente, cause sutis mudanças quantitativas nas fases oral e faríngea da deglutição, cada mudança deve ser completamente elucidada e medida (DODDS et al, 1990b).

A alteração da deglutição e mecanismos de proteção das vias aéreas no idoso podem causar um problema clínico maior pela criação de um ciclo vicioso de aspiração e má nutrição e pode aumentar a necessidade de cuidados com a saúde do idoso. A idade pode afetar a função motora do aparato da deglutição e produzir disfagia. (GORMAN et al, 1994; FARRELL \& FRIEDMAN, 2001). 
Para SCHINDLER \& KELLY (2002), a disfagia torna-se cada vez mais um problema comum com o avanço da idade. A dificuldade no diagnóstico da disfagia na população idosa é multifatorial. As causas ou origens são diversas, e seu manejo se estende a numerosas especialidades médicas e cirúrgicas. Depressão, disfunção cognitiva e mudanças no comportamento podem retardar o reconhecimento da disfagia em pacientes idosos por seus cuidadores. Assim, problemas da deglutição são, freqüentemente, insidiosos em seu início e podem não se manifestarem, clinicamente, por anos e até décadas. Em algum período de tempo, estratégias compensatórias são aprendidas, mascarando mudanças fisiológicas normais que enfraquecem a integridade da deglutição com a idade.

FEIJÓ e RIEDER (2003), relatam que, embora os sintomas de disfagia sejam comuns entre todas as faixas etárias, sua presença aumenta com a idade. Entre eles podem-se citar alguns dos mais freqüentes que acompanham os distúrbios da deglutição: hesitação para deglutir, sensação do bolo ou dor na região da hipofaringe, tosse após ingestão do alimento, regurgitação nasal do conteúdo ingerido, pigarro freqüente, desconforto torácico à deglutição, perda de peso, pneumonias de repetição, intolerância a sólidos e/ou líquidos, constante perda de saliva pela boca, alterações da voz após a alimentação, necessidade de ingerir líquidos após alimentos sólidos.

Dentre as alterações que ocorrem naturalmente durante o envelhecimento não advindas de danos neurológicos ou estruturais - existem os problemas de deglutição decorrentes de mudanças na fisiologia das estruturas envolvidas nesse processo: aumento de tecido adiposo e conectivos da língua, atrofia do osso alveolar e perda de dentes, redução da habilidade mastigatória afetando a preparação do bolo alimentar, posição da laringe mais baixa com elevação e abaixamento mais lentos, atraso no disparo de deglutição na fase faríngea, lentificação da motilidade faríngea aumentando o tempo do trânsito alimentar nessa fase da deglutição, aumento do tempo de abertura do cricofaríngeo, redução no peristaltismo esofágico (COOK et al, 1994; LOGEMANN, 1990; ROBBINS, 1992; GROHER, 1999; WEETCH, 2001).

NILSSON et al (1996); NASI (1998); GROHER (1999); FARRELL \& FRIEDMAN (2001); FEIJÓ e RIEDER (2003), acrescentaram que a queixa da disfagia é mais freqüente em idosos em conseqüência dos efeitos do processo de 
envelhecimento no mecanismo da deglutição, havendo mudanças fisiológicas de intensidade, força e resistência dos músculos e coordenação que, quando associadas, interagem nesse mecanismo, descompensando-o. Dentre as mudanças, são citados: problemas de mastigação por deficiência da arcada dentária ou por próteses inadequadas; diminuição do volume de saliva; denervação senil do esôfago; presença de afecções associadas que comprometem a atividade motora visceral (neuropatias, miopatias, diabetes, etc.); e uso de medicamentos que, potencialmente, podem comprometer a atividade muscular dos órgãos envolvidos na deglutição (bloqueadores de canais de cálcio, nitratos, etc.). Fatores bastante importantes na defesa do órgão estão prejudicados em pacientes idosos (piora do poder de clareamento esofágico, redução do efeito protetor da saliva por diminuição do volume e alterações de seu teor).

Além dos fatores já citados em decorrência do processo de envelhecimento, vários autores citam as diversas causas de disfagia em idosos, decorrentes de doenças, freqüentemente, presentes nessa faixa etária, como doenças neurológicas (acidente vascular encefálico, demência multiinfarto, doença de Parkinson, esclerose lateral amiotrófica, doença de Alzheimer, tumores de tronco encefálico, poliomiosite); causas secundárias a problemas de cabeça e pescoço (neoplasias de boca, lesões cirúrgicas envolvendo cabeça e pescoço, falta de peças dentárias ou dentes cariados e/ou quebradiços, traqueostomia, doença da tireóide, radiação ou lesão pós-cirúrgica de cabeça e pescoço, infecções virais por herpes ou citomegalovírus), causas esofágicas (esofagites, divertículos, carcinomas, espasmo esofágico, acalasia, escleroderma) e induzidas por medicamentos (BRANDT, 1986; ROLANDELLI \& ULLRICH, 1994; GROHER, 1999; FARRELL \& FRIEDMAN, 2001; FEIJÓ e RIEDER, 2003).

SCHINDLER \& KELLY (2002), retrataram que as causas mais comuns de disfagia em idosos são os A.V.C., sendo que 45 a 65\% dos pacientes que sofrem A.V.C. apresentam dificuldades de deglutição dentro dos primeiros 6 meses do evento; a doença neuromuscular, como a doença de Parkinson, também é comum em idosos e, freqüentemente, resulta em disfagia pois afeta e dificulta a fala e deglutição, sendo multifatorial, significativamente afetada pela rigidez e bradicinesia, produzindo atraso na fase preparatória oral, transporte oral e esofágico; menos 
comum é a esclerose lateral amiotrófica, tipicamente presente na $6^{\mathrm{a}}$ década da vida e que, freqüentemente, causa disfagia.

Além disso, o processo de envelhecimento precipita mudanças da função pulmonar e predispõe o paciente à perda de elasticidade pulmonar que pode afetar o tempo de interação entre deglutição e respiração, pois estas funções compartilham as mesmas estruturas. Junto às mudanças na posição do pulmão pela degeneração da coluna cervical e torácica, a capacidade vital dos idosos (e, assim, provavelmente a capacidade de tossir e proteger as vias aéreas) é reduzida (GROHER, 1999).

Geralmente, o processo de envelhecimento não causa episódios de disfagia; entretanto, há evidências de que o desempenho da deglutição em pessoas idosas saudáveis é diferente do desempenho da deglutição em pessoas mais jovens. Cada estágio da deglutição - oral, faríngeo e esofágico - sofre modificações durante esses processos, podendo contribuir para o aparecimento de sintomas disfágicos. Dessa forma, apesar do "envelhecimento" fisiológico, isoladamente, não causar a disfagia, deixa o mecanismo da deglutição mais vulnerável a distúrbios causados por pequenas alterações de saúde em indivíduos mais susceptíveis (FERRIOLLI et al, 1996; GROHER, 1999; FARRELL \& FRIEDMAN, 2001; FEIJÓ \& RIEDER, 2003).

Existem outros inúmeros fatores que envolvem o indivíduo como um todo podendo levá-lo a possíveis alterações de deglutição, desde fatores psicossociais, perceptuais, intelectuais a afecções nas estruturas envolvidas no processo de deglutição.

Alterações nos níveis de atenção e de acuidade visual do idoso, paralelamente à freqüente utilização de próteses dentárias que impedem a sensibilização do palato e, por conseguinte, determinam redução da capacidade de percepção de agentes agressivos eventualmente ingeridos (espinhos de peixe, pedaços de ossos, etc), podem ocasionar traumatismos no trato digestivo, e em especial, no esôfago (NASI et al, 1998).

Fatores sociais, físicos e psicossociais contribuem para uma má nutrição em idosos. ROLANDELLI \& ULLRICH (1994), descreveram que aproximadamente $30 \%$ de idosos americanos vivem sozinhos, e $25 \%$ vivem livres e precisam de assistência com suas atividades de vida diária. Esse isolamento social pode levar a uma ingestão nutricional imprópria. Prejuízos físicos incluem dentição ruim, 
diminuição na gustação e sensibilidade tátil e disfagia. Causas psicossociais produzindo anorexia são a depressão, abuso de substâncias crônicas e alterações cognitivas. Dificuldades financeiras também contribuem para uma ingestão pobre de nutrientes em idosos. Má nutrição secundária pode existir devido à coexistência de doenças múltiplas confrontando com o estado nutricional.

Pacientes com problemas de alimentação secundários a dificuldades cognitivas podem comer, esporadicamente, por certos períodos. Os tempos de refeição são, freqüentemente, irregulares e muitos desses pacientes perdem peso progressivamente. Pacientes com disfagia primária, freqüentemente requerem um período mais prolongado de alimentação e eles, gradualmente, adaptam-se através de estratégias como deglutições múltiplas, mordidas menores e mastigação prolongada (SCHINDLER \& KELLY, 2002).

Pessoas idosas, especialmente quando deprimidas podem, ocasionalmente, queixar de dificuldade para iniciar a deglutição, provavelmente em parte devido a uma inibição cortical (BRANDT, 1986).

Tipicamente, o idoso perde acima de $60 \%$ de suas papilas gustativas com um declínio concomitante na sensibilidade dos quatro sabores básicos. Como resultado eles, freqüentemente, gostam menos da comida e perdem seu apetite (FARRELL \& FRIEDMAN, 2001).

As mudanças na coluna cervical e torácica em virtude do processo de envelhecimento podem afetar a integridade da deglutição, embora não seja comum esta correlação. A obstrução faríngea por osteófitos cervicais pode causar disfagia orofaríngea (GROHER, 1999).

SHAY \& SHIP (1995), descreveram que o distúrbio oromotor mais freqüentemente relatado em idosos é a alteração da mastigação. Embora a fase oral da deglutição não seja submetida a mudanças com o passar da idade, condições não usuais e estressantes dessas perturbações podem dar lugar a alguns riscos de engasgos e aspiração (CURIATI, 1998).

O osso mandibular e uma elevada força mastigatória contribuem para uma mastigação mais eficiente, sendo possível o consumo de comidas de diversas consistências, sem restrições nas dietas. No idoso, como descrito, há uma modificação nessas estruturas em decorrência, entre outras, da perda dos dentes, 
havendo necessidade de adaptação de próteses dentárias. Sabe-se que a qualidade da dentadura contribui para o sucesso mastigatório, sendo assim, a força mastigatória máxima de idosos que possuem próteses poderá ser insuficiente, causando uma habilidade funcional deficitária. Alguns mecanismos compensatórios podem explicar a variabilidade e particularidade da diferença de ingestão de alimentos mais consistentes em idosos sem dentaduras quando comparados com idosos protetizados, pois a redução da força e efetividade mastigatória podem levar a restrições na dieta (HEATH, 1982; PLANT, 1998).

Estudo de WAYLER et al (1984), reforçou a importância da integridade dentária como um melhor regulador da performance mastigatória. Os autores realizaram uma série de investigações, empreendendo atenção aos tecidos no efeito da perda dos dentes, recolocação protética versus performance mastigatória e aceitabilidade da comida. Concluíram que pessoas com o comprometimento da dentição natural, apesar de um significante prejuízo na habilidade mastigatória em relação a pessoas com dentição intacta ou com comprometimento parcial, ainda têm a função mais efetiva do que pessoas com uma ou duas próteses dentárias totais. O estudo também indicou que, uma vez que um número crítico de dentes estão ausentes, ocorrem alterações significantes em processos perceptuais, refletindo na aceitabilidade da comida. Todos os achados do estudo sugeriram que pessoas com perda parcial dos dentes, com e sem substituição dos mesmos, podem se auto impor certas restrições de dietas comprometendo seu estado nutricional.

É comum pacientes idosos se apavorarem com a deglutição com medo de aspirar a comida (ROSSMAN, 1986).

Essa situação pode levar à diminuição da alimentação, devido a dificuldade de ações motoras - mais lentificadas ou descoordenadas no processo de mastigar e engolir - havendo, também, a escolha de alimentos mais moles, quase sempre por problemas dentários, redução no número de refeições por dia. Assim, o indivíduo modifica sua forma de comer para evitar engasgos freqüentes (MARCHESAN, 1995; RIBEIRO, 1999).

ANDERSON (1971), descreveu que o estado de dentição afeta a seleção da comida por pessoas idosas, através do estudo de padrões de ingestão de comida antes da preparação da boca para a colocação de prótese dentária total e, novamente, três a 
cinco meses após a prótese ser adaptada. Os achados sugeriram que os padrões de alimentação dessas pessoas modificam mais do que se pensava e que muitas, se tivessem suas próteses melhor adaptadas, comeriam outras comidas nutricionalmente mais importantes.

Alguns sujeitos mais frágeis parecem mastigar por muitos minutos sem serem capazes de formar o bolo na base da língua (ROSSMAN, 1986).

A perda dos dentes, cáries dentais e doenças periodontais, também levam a mudanças na sensibilidade, dor e prejuízo na mastigação e dificuldades na fala. $\mathrm{Na}$ ausência de dentes (com ou sem dentadura), a discriminação de partículas de comida, devido a alterações de percepções táteis e texturais, podem trazer prejuízos, alterando a deglutição e predispondo um indivíduo a episódios de aspiração.

As doenças periodontais são freqüentes entre os idosos, devido à presença de fatores orais múltiplos, doenças sistêmicas e medicações serem mais prevalentes nessa faixa etária e terem uma influência adversa na saúde periodontal. Essas doenças são diretamente associadas com halitose, sangramento gengival, mobilidade dentária e perda dos dentes. Esses resultados podem levar a mudanças na escolha da comida alterando a ingestão alimentar, alterações na mastigação e deglutição e, freqüentemente, nas relações interpessoais (SHAY \& SHIP, 1995).

LANGMORE et al (1998), em seus estudos concluíram que o número de perdas de dentes associado à freqüência de escovação dos mesmos e à dependência para os cuidados de higiene oral, foi significativamente associado com pneumonia. Esses achados foram consistentes com a impressão clínica dos autores de que a higiene oral deficitária é comum em pacientes hospitalizados e que vivem em casas de repouso. Os autores ainda referiram que a pneumonia aspirativa é a maior causa de morbidade e mortalidade entre esses idosos. Vários fatores de risco para pneumonia têm sido identificados, incluindo a disfagia, mas não há estudos comparando riscos relativos em categorias diferentes.

Outras mudanças que cursam com o processo de envelhecimento são observadas e afetam, direta ou indiretamente, a função da deglutição.

A redução do olfato e paladar podem levar o sujeito a aceitar comidas brandas e não apetitosas. Algumas pessoas com saliva reduzida ou espessa podem ter a boca seca, aumentando a dificuldade na deglutição (WEETCH, 2001). 
Muitos outros idosos queixam-se de redução no reconhecimento da comida e prazer durante a alimentação, assim como alteração no olfato e gustação (SHAY \& SHIP, 1995).

Com a idade, a discriminação sensorial na cavidade oral, progressivamente, diminui, e a disfagia e a aspiração são mais prováveis de ocorrer. Entretanto, ainda não é esclarecido se alterações sensoriais da laringe e da faringe relacionadas à idade existem, e se estas contribuem para a disfagia e aspiração. Em estudo realizado por MARTIN et al (1994), foi concluído que há uma progressiva diminuição da capacidade sensorial na laringofaringe com o aumento da idade. Afirmaram, em seus estudos, que a disfunção sensória na laringofaringe como um fator de risco para o desenvolvimento da disfagia e aspiração não tem sido descrito, sendo surpreendente este fato, pois a função sensorial é responsável pela metade dos componentes fisiológicos no diagnóstico das desordens da deglutição e nas alterações nos mecanismos de proteção das vias aéreas.

LANGMORE et al (2002), descreveram que idosos residentes em casas de repouso têm condições médicas crônicas que, gradualmente, levam a “descompensações” das condições funcionais, nutricionais e de clearance pulmonar. Disfagia e aspiração de secreções, comida, líquido ou material do refluxo gástrico são complicações comuns em condições médicas crônicas encontradas nessa população e a gravidade e freqüência da aspiração podem, gradualmente, piorar seus estados de deterioração, com piora do estado nutricional. Um evento adverso repentino pode aumentar, dramaticamente, a quantidade de aspiração ou a capacidade de resistir à infecção, levando à descompensação repentina. É de conhecimento que a idade avançada também está associada com redução da imunidade, sendo a pneumonia aspirativa um problema sério para os idosos institucionalizados, levando, freqüentemente, à hospitalização.

EKBERG \& OLSSON (1997), expõem que a disfunção faríngea e esofageana são muito prevalentes em idosos.

Dados conflitantes existem nas mudanças fisiológicas no esôfago que ocorrem com a idade. A atividade esfinctérica esofageana superior pode ser afetada pelo avanço da idade, com redução na pressão basal e relaxamento prolongado. A 
amplitude e duração da contração faríngea nessa população também é aumentada (FARRELL et al, 2001; SCHINDLER \& KELLY, 2002).

GORMAN et al (1994), descreveram que sintomas relacionados com a disfunção esofageana são particularmente comuns em idosos. Um diagnóstico acurado pode ser mais difícil devido ao fato dos sintomas da doença do esôfago poderem ser obscuros ou atribuídos a outros problemas coexistentes. A diminuição na pressão do esfíncter esofágico inferior (E.E.I.) no repouso e um atraso de relaxamento após a deglutição é notável em pacientes acima de 62 anos, isto é, embora a extensão e pressão de relaxamento estejam preservadas, a resposta do esfíncter na deglutição é alterada. É rara a disfunção esofageana, clinicamente significante, como uma conseqüência isolada da idade, estando esta, geralmente, associada a outras comorbidades. O relaxamento incompleto do E.E.I. pode trazer dificuldades na deglutição, enquanto o enfraquecimento do esfíncter pode permitir o refluxo de alimento e ácido gástrico (WEETCH, 2001).

NASI et al (1998), descreveram que na fase esofageana da deglutição em idosos existem alterações motoras (distúrbios de peristaltismo do órgão e incoordenação dos esfíncteres) que são decorrentes do processo de envelhecimento do órgão.

Além dos aspectos descritos sobre as alterações de deglutição em idosos correlacionando-os às fases orofaríngea e esofágica, citamos outros fatores que também são comuns nessa faixa etária, levando a efeitos deletérios na função da deglutição: o uso de medicamentos.

Os medicamentos representam um papel importante na predisposição à disfagia em idosos. Os efeitos adversos das medicações costumam interferir no mecanismo normal da deglutição e os mecanismos pelos quais os medicamentos podem produzir disfagia são variados (LOGEMANN, 1990). Sabe-se que tanto a quantidade, quanto certos tipos de medicamentos são mais utilizados por idosos. Alguns fármacos reduzem o funcionamento da musculatura involuntária, diminuindo a motilidade esofágica e as pressões do esfíncter esofágico inferior. Outros, como medicamentos antidepressivos, antiespasmódicos, anti-hipertensivos, broncodilatadores, anticolinérgicos, anti-histamínicos, sedativos, hipnóticos e diuréticos, freqüentemente, ressecam a cavidade oral e a mucosa faríngea. O efeito 
mais comum causado pelo uso de medicamentos induzindo à disfagia é a xerostomia. Essa interfere no paladar por falta de saliva e também inibe o início da preparação do bolo alimentar e da subsequente resposta à deglutição. Esses problemas são mais prováveis de serem causados por doenças sistêmicas e seus tratamentos do que por seqüelas da idade (SHAY \& SHIP, 1995; WEETCH, 2001; SCHINDLER \& KELLY, 2002; FEIJÓ e RIEDER, 2003).

Pacientes com xerostomia não são apenas propensos a cáries mas também mais suscetíveis à perda de estruturas dentárias, da erosão química e abrasão mecânica, pois a saliva é um fluido complexo com constituintes que promovem um significado efetivo na proteção contra micróbios potencialmente prejudiciais e irritantes. Encontra-se uma grande tendência para acúmulo de placa e aumento na inflamação gengival, se não for despendida uma atenção extra na higiene oral. Sem uma lubrificação adequada, a comida é retida e impactada em volta dos dentes, causando uma dificuldade na alimentação e tornando-a desagradável, aumentando a formação de placas. Isso é evidente em pessoas com xerostomia (MANDEL, 1989).

O caminho mais simples para compreender a função da saliva é examinar o efeito na boca quando ela é pouco fornecida. Na população idosa, tem-se um aumento da incidência da disfunção das glândulas salivares, causada por doença sistêmica ou focal, desordens imunológicas, radiação, quimioterapia e também pelos efeitos de centenas de medicações (MANDEL, 1989; SHAY \& SHIP, 1995).

Freqüentemente, muitos medicamentos que alteram ou deprimem a atividade do sistema nervoso central podem causar disfagia em pacientes idosos. O nível de alerta é importante no tônus muscular global e coordenação, o qual inclui a habilidade na deglutição. Ansiolíticos como benzodiazepínicos, comumente utilizados para desordens do sono, são, freqüentemente, metabolizados lentamente em pacientes idosos, podendo levar a desordens da deglutição. Álcool, encontrado na preparação de muitos medicamentos, tem um efeito idêntico e predispõe a refluxo gastroesofágico através do relaxamento do esfíncter esofágico inferior. Antihistamínicos, antieméticos com fenotiazina, anticonvulsivantes, antipsicóticos e lítio prejudicam a função cognitiva e o nível de alerta. O tratamento da esquizofrenia na população geriátrica leva a efeitos colaterais, dificultando a função da deglutição. Anticolinérgicos variáveis e depressores da atividade do SNC, medicamentos 
neurolépticos podem causar sintomas extrapiramidais que se manifestam como movimentos hiperfuncionais involuntários (discinesia) da musculatura oral e faríngea. Rigidez e espasmo da musculatura faríngea também podem ser resultado do uso de neurolépticos que bloqueiam os receptores de dopamina e que também podem levar ao parkinsonismo induzido por drogas em 12 a 45\% dos pacientes.

Um número de prescrições freqüentes em pacientes idosos causam disfunção esofageana. O efeito mais comum que afeta o esôfago é a diminuição do tônus do esfíncter esofágico inferior, com refluxo gastroesofágico resultante. Teofilina, nitrato, bloqueadores de canal de cálcio e benzodiazepínicos são medicamentos comuns associados com a doença do refluxo gastroesofágico em pacientes idosos.

Finalizando, vários estudos foram feitos descrevendo as alterações durante a função da deglutição ocorridas no processo de envelhecimento. Contudo, não são totalmente descritos os efeitos relativos a essas alterações e o impacto que causam na vida do sujeito, assim como, fatores existentes que não são considerados normais em pessoas mais jovens e que na população idosa, apesar de serem diferentes, são considerados normais, isto é, funcionais para essa faixa etária.

Embora as dificuldades com a deglutição estejam presentes em um percentual alto de indivíduos idosos, quando consideramos os efeitos da idade no processo de deglutição é fundamental que se diferenciem as modificações mórbidas das normais, uma vez que esta população está mais exposta a doenças que, como vimos, podem afetar direta ou indiretamente a deglutição (FEIJÓ e RIEDER, 2003).

LANGMORE et al (1998), realizaram uma variedade de avaliações em 189 idosos de clínicas não hospitalares. Essas avaliações incluíram a avaliação das fases orofaríngea e esofageana da deglutição, condições de alimentação, condições funcionais, médicas e condições orais/dentais. Foi concluído que a disfagia é um importante risco para pneumonia aspirativa mas, geralmente, não é suficiente para causar pneumonia sem que outros fatores de risco também estejam presentes.

EKBERG \& FEINBERG (1991), avaliaram 56 pessoas com idade média de 83 anos que não tinham sintomas de disfagia ou dificuldades para se alimentarem. Encontraram apenas 6 pacientes com função da deglutição normal. A disfunção esofageana estava presente em 36\% dos pacientes (20 pacientes). 
EKBERG \& OLSSON (1997), relataram que em indivíduos normais o tempo da fase oral e faríngea é seguramente coordenado, e é, usualmente, um tempo de não mais que 0,5 segundo entre o ponto no qual o bolo passa o istmo faucial e inicia o movimento anterior do osso hióide.

STEELE et al (1997), utilizaram como instrumento de triagem, a observação de 349 idosos residentes em uma casa de repouso, onde 6 assistentes observaram durante 6 semanas uma lista de problemas relacionados à alimentação/deglutição, para determinar a prevalência de dificuldades durante a alimentação, incluindo mas não limitado à disfagia. Um aumento da prevalência de dificuldades na alimentação foi relatado na presença de prejuízo cognitivo e em graus diferentes de comprometimento. Os autores concluíram que problemas na alimentação de pessoas idosas em ambiente de cuidados institucionais são complexos e ocorrem em uma freqüência alta. Há uma prevalência de dificuldades, sendo observada em 87\% dos residentes, demonstrando uma mudança forçada em seus hábitos alimentares.

CALHOUN et al (1992), estudaram a sensibilidade oral em 60 adultos saudáveis. Suas idades variaram de 23 a 96 anos, divididos em 5 categorias com um mínimo de 10 sujeitos em cada uma, denominando-os: adultos jovens (20 a 34 anos), jovens de meia idade (35 a 49 anos), idosos de meia idade (50 a 64 anos), adultos maduros (65 a 80 anos) e idosos (acima de 80 anos). Concluíram que, com a idade, há um declínio generalizado na sensibilidade epitelial. A propriocepção por movimento passivo da língua permanece com a idade, demonstrando apenas um leve decréscimo (não estatisticamente significante) após os 80 anos. No estudo da cavidade oral demonstraram um leve decréscimo na habilidade proprioceptiva na sensação da temperatura. Houve um alto grau de variabilidade individual no declínio dos parâmetros sensoriais, com algumas pessoas dentro dos 80 a 90 anos mantendo respostas idênticas ao grupo de idade mais jovem. As mudanças encontradas nesse estudo poderiam afetar a deglutição e a fala. A habilidade de detecção de temperatura estável implica que uma pessoa idosa não é mais provável de ingerir acidentalmente uma comida que está muito quente do que seu correspondente mais jovem. O declínio variável na habilidade estereognóstica, e declínio em dois pontos de discriminação sensitiva sugerem que a identificação do tamanho, forma e consistência da ingestão de material pode ser reduzida. Então, a formação do bolo 
alimentar e movimento deve ser menos competente do que em uma pessoa mais jovem. O retorno proprioceptivo sobre a língua, lábios e posição do palato deve ser também prejudicado, causando um declínio na precisão da articulação.

Preconiza-se que uma queixa comum de pacientes idosos, a disfagia, não deve ser ignorada, porque ela é, realmente, um sintoma e, muito raramente, pode ser simulada. A localização pelo paciente do ponto (local) da dificuldade na deglutição é, notavelmente, precisa, mas isso não pode ser completamente confiável porque os idosos apresentam, por vezes, histórias imprecisas (ROSSMAN, 1986).

Como descrito, problemas de deglutição são comuns em idosos, e sua freqüência aumenta significantemente com a presença de doenças. Em pacientes hospitalizados, apesar da presença de diversos fatores de risco aqui mencionados, raramente é realizada a avaliação da deglutição na ausência de queixas objetivas de disfagia. Por esta razão, este estudo foi realizado com a intenção de se verificar a existência de alterações da deglutição em idosos internados em uma enfermaria geriátrica, independentemente, da presença ou ausência de queixas. A hipótese era de que muitos problemas não referidos poderiam ser detectados, e sua significância clínica avaliada.

\section{OBJETIVOS}

\section{OBJETIVO GERAL}

Avaliar a fase orofaríngea da deglutição de idosos admitidos na enfermaria de clínica médica geral e geriatria, independente da presença de queixa de dificuldade de deglutição (disfagia). 


\section{OBJETIVOS ESPECÍFICOS}

- Avaliar a presença ou não de queixas de disfagia entre idosos internados em uma enfermaria de geriatria.

- Avaliar a presença de alterações clínicas da deglutição em idosos internados numa enfermaria geriátrica, através de avaliação fonoaudiológica estruturada, independente da presença de queixa.

- Avaliar a fase orofaríngea da deglutição de idosos internados em uma enfermaria geriátrica por método cintilográfico, comparando-a à de idosos saudáveis e jovens.

- Correlacionar os resultados da avaliação clínica com a avaliação cintilográfica. 
MATERIAL E MÉTODO 


\section{SUJEITOS E CONTROLES}

Nossa casuística foi constituída por 30 pacientes internados na enfermaria da Divisão de Clínica Médica Geral e Geriatria do Hospital das Clínicas da Faculdade de Medicina de Ribeirão Preto da Universidade de São Paulo, sendo 17 mulheres e 14 homens, com idade média de 80 anos (variação de 66 a 94 anos), e dois grupos controle: um grupo de 10 idosos saudáveis (5 mulheres e 5 homens) com idade média de 70 anos (variação de 60 a 80 anos) e um grupo de 20 jovens (11 mulheres e 9 homens) com idade média de 25 anos (variação de 21 a 30 anos). Os voluntários dos grupos controle foram cuidadosamente triados antes da participação no estudo para assegurar que eles não apresentassem história de dificuldades para a deglutição e/ou condições médicas que pudessem influenciar a deglutição ou performance motora orofacial e/ou que usassem medicamentos depressores do sistema nervoso central, corticóides, colinérgicos e anticolinérgicos. Dessa forma, todos os voluntários controle foram julgados como se apresentassem estruturas e funções normais.

Foram incluídos no estudo pacientes internados, com idade mínima de 60 anos, independentemente de suas doenças e da presença ou não de queixas de disfagia, sendo a seleção aleatória. Os pacientes excluídos foram os gravemente comprometidos, cujo estado impossibilitava a avaliação clínica e objetiva da deglutição, entre eles os dependentes de oxigenação mecânica, os restritos à dieta enteral ou com comprometimento cognitivo grave.

Os pacientes avaliados apresentaram as seguintes doenças: demência (6), acidente vascular cerebral (3), outras doenças neurológicas (2), diabetes (3), doença cardio vascular (22), outras doenças crônicas (15), depressão (6), desnutrição (4), doença pulmonar obstrutiva crônica (3) (apêndice 1). Todos se alimentavam por via oral, sem restrições a qualquer consistência alimentar.

Foi oferecido uma carta de informação da pesquisa aos pacientes e voluntários, sendo esclarecido todo o procedimento da avaliação, tendo todos os 
participantes assinado o termo de consentimento. O estudo foi analisado pelo Comitê de Ética em Pesquisa, sendo aprovado no processo HCRP nº 3766 / 2001.

Os pacientes foram submetidos a uma avaliação clínica inicial à beira do leito, com a aplicação de um protocolo para a avaliação estrutural e funcional da deglutição. O protocolo foi constituído de cinco partes. Na primeira parte foram coletados dados de identificação do paciente como nome, data de nascimento, idade e data da internação. A segunda parte consistiu da obtenção de eventuais queixas, assim como o tempo em que as mesmas estavam presentes. No terceiro item obtevese dados de anamnese como hipóteses diagnósticas médicas, história clínica para caracterização da queixa da deglutição, quando presente.

A quarta e a quinta partes, finalmente, relacionavam-se à avaliação clínica da deglutição propriamente dita dos 30 pacientes internados, dividindo-se em estrutural e funcional. Estas avaliações, por sua especificidade, serão descritas em maior detalhe.

Na avaliação estrutural, foi observado o estado do paciente (sonolento, alerta ou outro); a compreensão e a expressão da linguagem oral foram avaliadas durante a entrevista dirigida observando-se as respostas do paciente e relacionando-as à presença adequada, ou não, de compreensão oral, assim como possíveis alterações de fala e linguagem; avaliação do órgãos fonoarticulatórios, sendo estes avaliados através da observação da presença de dentes e estado de conservação dos mesmos, uso de próteses dentárias, sua adaptação e retirada, ou não, no momento da internação; presença de ulcerações em cavidade oral; alterações de saliva (avaliação subjetiva); condições de higienização oral; deglutição espontânea de saliva ou escape da mesma para fora da cavidade oral; força de língua avaliada com auxílio de uma espátula de madeira onde era solicitado que o paciente realizasse uma força contrária à realizada pela examinadora e, depois, que realizasse força de elevação de língua contra a espátula que a deprimia no assoalho bucal; mobilidade de língua para deglutição com a solicitação de realização de movimentos de língua nos quatro “pontos” (lateralização de um lado e do outro, elevação e depressão com língua protruída); sensibilidade extra-oral, sendo solicitado que o paciente referisse a região dos lábios superiores, inferiores e da face que eram tocadas pela examinadora; sensibilidade de palato mole, através do toque do palato pela espátula de madeira; 
abertura da mandíbula durante a avaliação da cavidade oral; avaliação da tosse com a solicitação da mesma. Além disso, foram caracterizados os hábitos alimentares apresentados pelo paciente como tipo de alimentação, se houve modificação, ou não, quanto à consistência alimentar, postura durante a alimentação, presença de resíduos em cavidade oral após a deglutição e uso de manobras compensatórias para a realização da função (manobras posturais de mudança de cabeça, deglutição de esforço ou múltiplas).

Para a avaliação funcional foram utilizados dois bolos de alimento, nas consistências líquida e pastosa, ambos com volume de $5 \mathrm{ml}$, oferecidos em uma seringa graduada. Para o líquido foi utilizada a água e, para o pastoso, utilizou-se uma “papa” (alimento na consistência pastosa), que foi preparada pela diluição de $15 \mathrm{ml}$ de espessante alimentar Thick \& Easy ${ }^{\circledR}$ em $50 \mathrm{ml}$ de água. Além disso, adicionou-se suco em pó, visando a melhor aceitação pelo paciente. Nessa avaliação também foram observados alguns dados questionados na avaliação estrutural e, agora, confirmados durante a função da deglutição, como a postura do paciente e abertura da boca durante o oferecimento dos alimentos, presença de reflexos patológicos como o reflexo de mordida, vedamento labial adequado, manobras compensatórias, resíduos na cavidade oral após a deglutição, presença de engasgos, tosse e fadiga antes, durante e após a deglutição. Antes, durante e após o oferecimento dos alimentos, foi realizada a ausculta cervical para obtenção de possíveis sinais clínicos sugestivos de estase de alimento e/ou saliva em orofaringe, penetração e/ou aspiração laríngea, mudança do padrão respiratório, caracterizando-a como normal na ausência de sinais e alterada na presença destes.

Destaca-se aqui que, quando o paciente não colaborava ou não abria a boca para a avaliação, os itens cuja observação foi impossibilitada foram referidos, nos resultados, como “impossível avaliar” (tabela 3).

Após a avaliação clínica, com a obtenção dos dados estruturais e funcionais, concluiu-se se havia alteração, ou não, ou seja, se a avaliação clínica da deglutição apresentava-se normal ou alterada. Posteriormente, os sujeitos foram submetidos a avaliação cintilográfica da deglutição.

Para uma análise comparativa, também realizamos a avaliação clínica estrutural nos voluntários idosos. 


\section{TÉCNICA CINTILOGRÁFICA}

Os pacientes e voluntários foram estudados sentados em frente a uma gamacâmara (Sopha Vision DST, Sopha Medical Vision America, Twensburg, Ohio, USA) (figuras 1 e 2) equipada com um colimador de baixa energia, alta sensibilidade e um aparelho para detectar emissões de ${ }^{99 \mathrm{~m}} \mathrm{Tc}$. Todas as imagens foram armazenadas no computador do equipamento, sendo adquiridas 20 imagens por segundo em um tempo de 20 segundos de aquisição (400 imagens).

Uma marca com tecnécio foi presa na cartilagem cricóide dos pacientes e voluntários para a distinção da transição entre faringe e esôfago (determinada por palpação externa, pois sabe-se que o esôfago se inicia na cartilagem cricóide, terminando no fundo do estômago). A gama-câmara foi, então, posicionada de modo a incluir as regiões orofaríngea e esofageal no campo de visão.

Para a análise do estudo dinâmico foram oferecidos os dois bolos de alimentos já descritos, com o volume de $5 \mathrm{ml}$. Ao alimento na consistência líquida foi adicionado um marcador de radioatividade de $37 \mathrm{MBq}$ de fitato coloidal ligado ao ${ }^{99 m}$ Tc e, à “papa”, adicionou-se 55,5 MBq.

Primeiramente, foi oferecido o líquido para se excluir prováveis resíduos que o alimento pastoso poderia deixar. Os participantes do estudo foram instruídos a manterem o bolo na cavidade oral, suportando a cabeça reta, tentando não mexê-la e, então, deglutir quando a examinadora lhes desse o comando. Este era emitido, aproximadamente, dois segundos após o início da aquisição de imagens. Em seguida, foi oferecido o segundo bolo. Entre um oferecimento e outro, os participantes foram orientados a deglutir “seco” para que limpassem possíveis resíduos.

Como já referido, as imagens foram gravadas no computador do equipamento sendo feitas as análises dos exames posteriormente. 


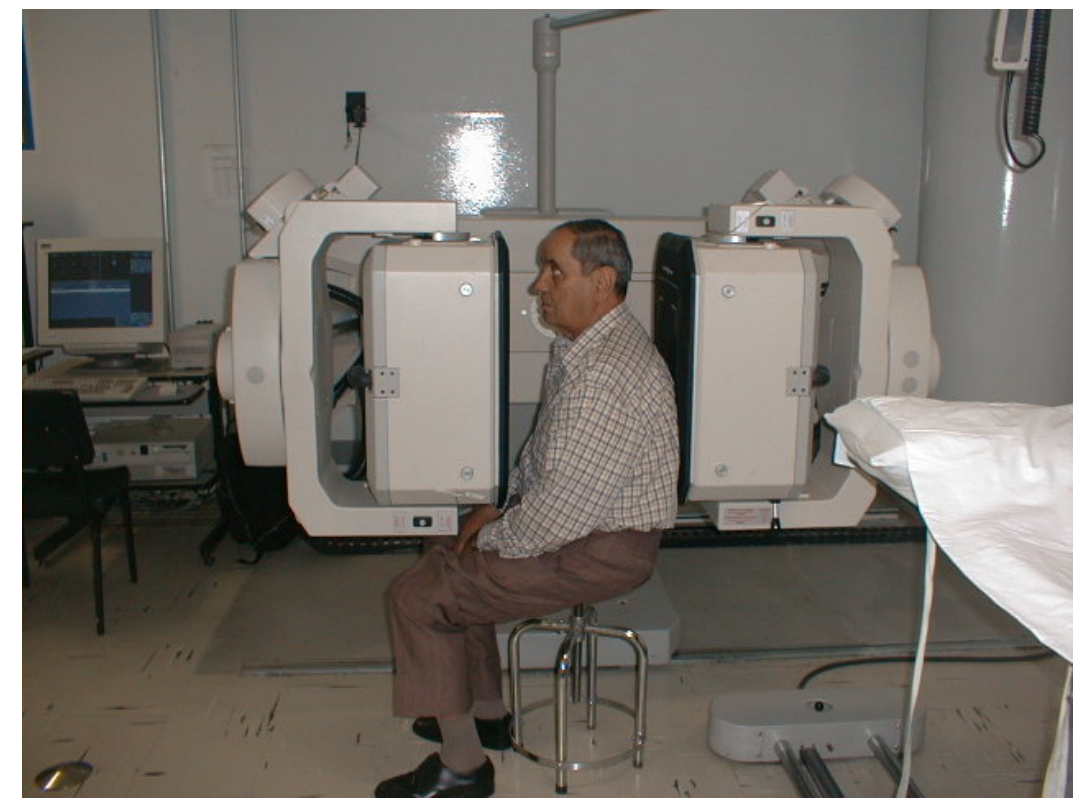

Figura 1 - Voluntário sentado em frente à gama-câmara (posição adequada para a avaliação da deglutição).

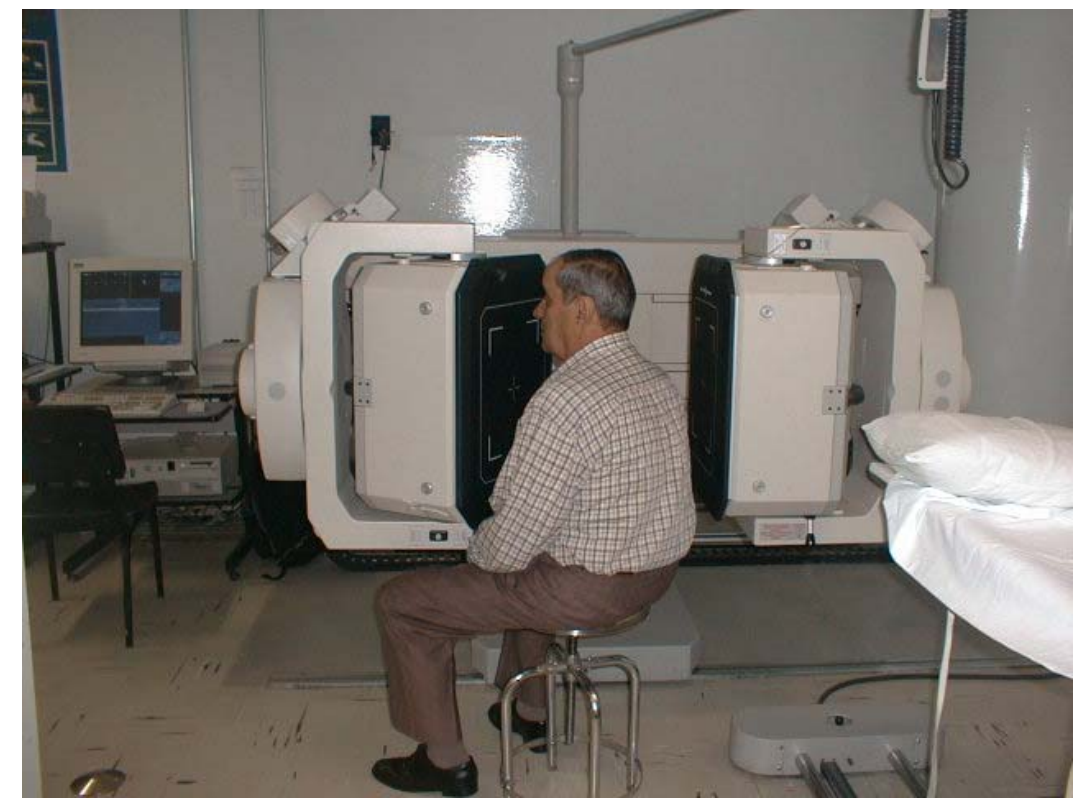

Figura 2 - Voluntário sentado em frente à gama-câmara (opção para avaliação de pacientes em cadeiras de roda) 


\section{ANÁLISE DOS DADOS}

Para a análise dos dados obtidos, estes foram divididos em resultados da avaliação clínica fonoaudiológica e, posteriormente, análise dos dados de avaliação objetiva (cintilografia).

\section{AVALIAÇÃO CLÍNICA FUNCIONAL}

Após a aplicação do protocolo de avaliação clínica da deglutição realizado à beira do leito nos pacientes internados, realizou-se uma análise descritiva dos itens constituintes do mesmo. Quando houve presença de queixa de disfagia, procurou-se caracterizá-la. Em sua ausência, seguia-se para o próximo subitem do protocolo. Independentemente da queixa, perguntava-se ao paciente como era sua alimentação.

Posteriormente a esta entrevista com o paciente, onde o mesmo deveria referir sobre sua alimentação, dava-se continuidade à avaliação estrutural através da observação de fatores relacionados à função da deglutição que, direta ou indiretamente, a influenciam e à avaliação funcional.

\section{AVALIAÇÃO CINTILOGRÁFICA}

Os dados foram analisados no computador, através do Protocolo de Aquisição Dinâmica da gama-câmara (vision DST). Para tal, foram determinadas as áreas de 
interesse referentes à boca, faringe e esôfago proximal (“Region of Interest” - ROI). O procedimento utilizado foi: delimitação da marca (área horizontal) e boca (área delimitada durante a retenção do bolo na cavidade oral), região entre boca e marca (referente à faringe: área vertical, entre a boca e a marca na cartilagem cricóide) e abaixo da marca, em uma área vertical da marca na cartilagem cricóide ao meio do esôfago (Figura 3). Uma curva do tempo de atividade foi constituída para cada ROI.

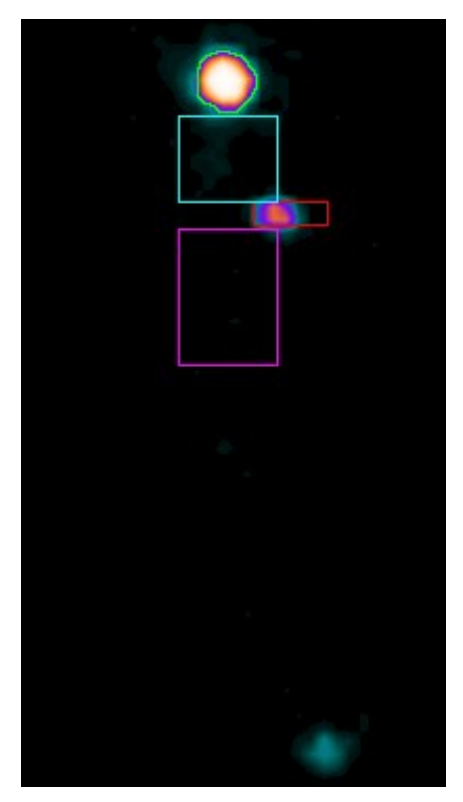

Figura 3 - Delimitação das ROIs referentes às áreas estudadas (boca, faringe e esôfago proximal)

O estudo foi completado com a obtenção dos dados compilados em uma tabela, para cada consistência, quanto ao trânsito e resíduo oral; trânsito, clearance e resíduo faríngeo e entrada no esôfago proximal.

O tempo de trânsito oral foi determinado como sendo o intervalo entre o início e o esvaziamento oral em segundos (queda da radioatividade na boca), o resíduo oral foi definido como a porcentagem de radioatividade permanecendo na boca. O trânsito faríngeo consistiu no intervalo entre o término do esvaziamento oral e a conclusão do esvaziamento faríngeo em segundos; o clearance faríngeo no tempo total de exposição faríngea ao bolo representando o intervalo entre a chegada do bolo dentro da ROI faríngea e a saída do bolo da ROI, em segundos, e o resíduo na faringe 
foi definido como a porcentagem de radioatividade permanecendo na faringe. Definiu-se como entrada no esôfago proximal, o tempo em que o bolo entra na ROI do esôfago em segundos.

Os gráficos 1 e 2 ilustram as curvas de atividade durante a deglutição de um bolo na consistência líquida, por um voluntário jovem e um idoso, respectivamente.

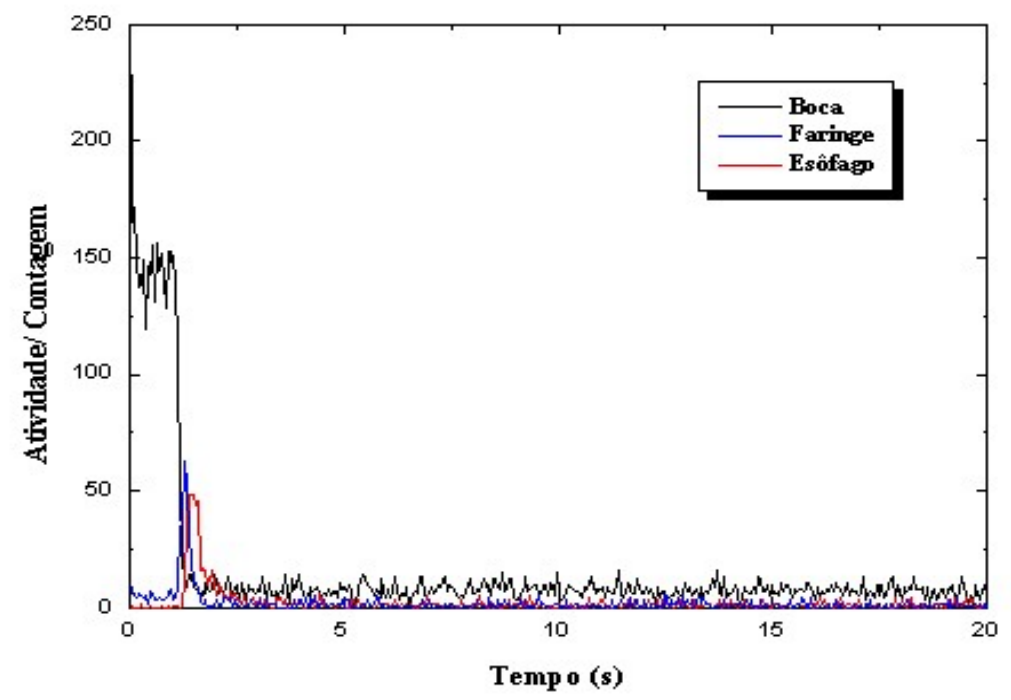

Gráfico 1: Curva de atividade durante a deglutição do bolo (água) por um jovem

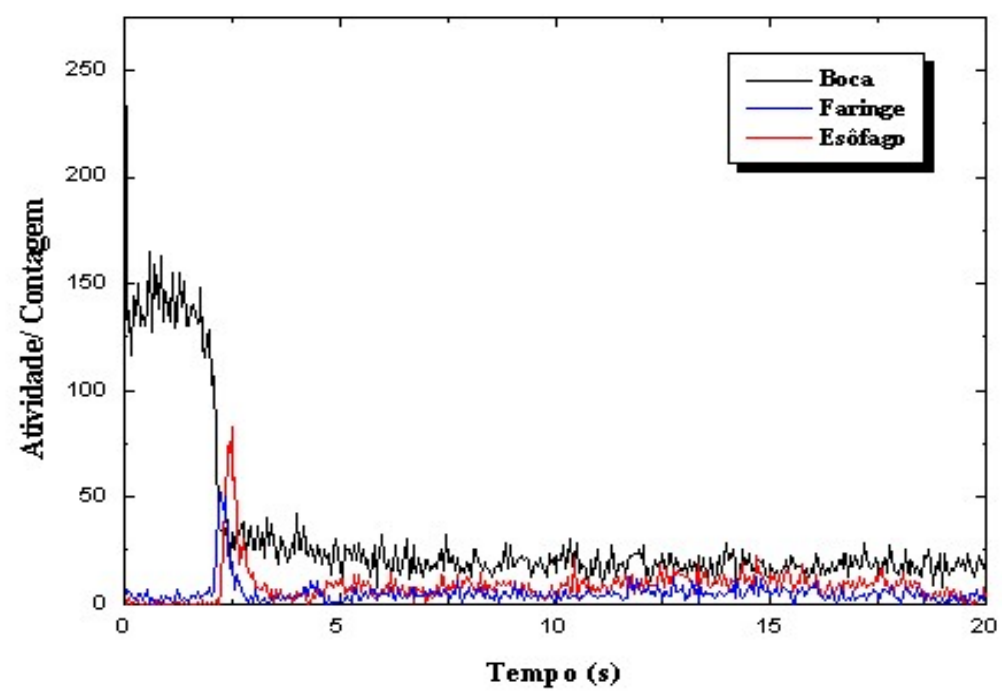

Gráfico 2: Curva de atividade durante a deglutição do bolo (água) por um idoso 
Para a análise estatística dos dados em amostras não pareadas foram utilizados testes não-paramétricos de Kruskal-Wallis, utilizando-se Comparações Múltiplas de Dunn, quando os dados foram estatisticamente significantes, no Programa Graph Pad In Stat Software, San Diego, California USA, versão 3.0 para windows 95 .

Para a análise de amostras pareadas, relação entre as consistências em cada grupo avaliado, utilizou-se o teste não-paramétrico de Wilcoxon.

Em todas as tabelas são fornecidos valores da média, desvio padrão e mediana. Foram considerados significativos valores de $\mathrm{p}<0,05$. 


\section{RESULTADOS}




\section{AVALIAÇÃO CLÍNICA}

O quadro 1 apresenta a caracterização das queixas dos pacientes. Estes, muitas vezes, referiram alterações no hábito alimentar e apetite. Entretanto, a maioria não correlacionava estas queixas a possíveis dificuldades de alimentação e deglutição, considerando-as irrelevantes ou, até mesmo, normais. Dos 30 pacientes avaliados, apenas $3(10 \%)$ apresentaram queixa de disfagia (ou foi referida pelo acompanhante) com as seguintes descrições quanto às suas dificuldades: "Tenho dificuldade para engolir pão, bolacha, comprimido. Não tinha dificuldade para engolir antes, mas foi piorando”; “A deglutição piorou no segundo A.V.C.”; “O alimento pára no peito, sinto falta de ar. Engasgo até com água”.

QUADRO 1- CARACTERIZAÇÃO DAS QUEIXAS (DADOS DE ANAMNESE) DOS TRÊS PACIENTES QUE REFERIRAM DISFAGIA

\begin{tabular}{|l|c|}
\hline \multicolumn{1}{|c|}{ Descrição } & Sim \\
\hline Aumento no tempo para se alimentar & $3 / 3$ \\
\hline Mudança da consistência alimentar & $1 / 3$ \\
\hline Dificuldade para iniciar a deglutição & $1 / 3$ \\
\hline Necessidade de deglutir mais de uma vez & $1 / 3$ \\
\hline Sobra resíduos na boca após deglutir & $1 / 3$ \\
\hline Refluxo nasal & $0 / 3$ \\
\hline Sensação de alimento parado & $2 / 3$ \\
\hline Perda de peso & $3 / 3$ \\
\hline Presença de pigarro depois que come ou bebe algo & $0 / 3$ \\
\hline Presença de tosse antes, durante ou após a deglutição & $0 / 3$ \\
\hline Mudança na voz após a deglutição & $1 / 3$ \\
\hline Apresenta infecções respiratórias freqüentes & $0 / 3$ \\
\hline Ocorreram quadros de pneumonia & $1 / 3$ \\
\hline
\end{tabular}

Os pacientes que apresentaram a queixa faziam uso de medicamentos antihipertensivos, antidepressivos, ansiolíticos, laxativos. Dois pacientes referiram 
apresentar outras doenças como hipertensão arterial sistêmica e “água no pulmão”, o terceiro negou a presença de outras doenças.

Os pacientes com queixa de disfagia apresentavam como hipótese diagnóstica médica: paralisia supranucelar progressiva, síndrome pseudobulbar, síndrome paraneoplásica, síndrome depressiva e osteoporose, A.V.C.

Os pacientes que referiram não apresentar queixas quanto a dificuldades de deglutição, relataram alguns aspectos relevantes quando perguntados sobre a alimentação. Estes estão listados no quadro 2.

QUADRO 2 - REFERÊNCIA QUANTO À ALIMENTAÇÃO DOS 27 PACIENTES SEM QUEIXA DE DISFAGIA (DADOS DE ANAMNESE)

\begin{tabular}{|l|c|}
\hline \multicolumn{1}{|c|}{ Descrição } & Pacientes \\
\hline Falta de apetite e perda de peso & 6 \\
\hline Perda de peso & 4 \\
\hline Comida fria para, às vezes volta para a boca, chego até a vomitar & 1 \\
\hline Tenho apenas um pigarro (engulo e melhora) & 1 \\
\hline Presença de vômitos e gastrite (motivo da internação) & 1 \\
\hline De vez em quando fica alimento parado, acontece uma vez por semana & 1 \\
\hline Dor ao deglutir devido a machucado na língua & 1 \\
\hline Estava apresentando náuseas ao me alimentar. Hoje não tenho mais & 1 \\
\hline Às vezes eu engasgo & 1 \\
\hline Como pouco, mas como igual & 1 \\
\hline A boca ficou machucada porque comi abacaxi, está ruim para comer & 1 \\
\hline Recusa a alimentar-se & 1 \\
\hline Não souberam descrever algo & 7 \\
\hline Total & 27 \\
\hline
\end{tabular}

Quando era referido "perda de apetite”, alguns dos pacientes complementavam: "fico com o alimento parado na boca e não engulo”, "estou com queimação no estômago e sinto dificuldade para comer carnes porque não tenho dentes”, “não tenho fome” (pacientes com miocardiopatia chagásica, hipertensão arterial, dislipidemia, coagulopatia, pneumonia).

Os pacientes com perda de peso que referiram terem sido internados para investigar a causa dessa perda (não correlacionando a quaisquer dificuldades mesmo 
com perguntas dirigidas), apresentavam como diagnósticos miocardiopatia chagásica, hipertensão arterial sistêmica e taquiarritmia ventricular, úlcera gástrica e neoplasia gástrica e de esôfago em investigação. Outro referiu perda de peso após cirurgia (hérnia no estômago). Por fim, o último paciente referiu que a perda de peso estava ocorrendo há algum tempo e apresentava, como diagnóstico, síndrome demencial, hipertensão arterial, derrame pleural.

Os dados da avaliação estrutural são apresentados no quadro 3 para melhor visualização e posterior discussão dos mesmos.

O quadro 3 nos permite observar que os valores quando somados, em porcentagem, dos dados de avaliação, não totalizam 100\%; isto corresponde ao fato dos pacientes apresentarem um ou mais dos aspectos avaliados, por exemplo, uso de próteses.

QUADRO 3 - AVALIAÇÃO ESTRUTURAL DA DEGLUTIÇÃO DOS 30 PACIENTES ESTUDADOS

\begin{tabular}{|c|c|c|c|c|}
\hline Aspecto Avaliado & \multicolumn{2}{|l|}{ Descrição } & Pacientes & (\%) \\
\hline \multirow[t]{3}{*}{ Estado do paciente } & \multicolumn{2}{|l|}{ Sonolento } & 3 & 10,0 \\
\hline & \multicolumn{2}{|l|}{ Alerta } & 26 & 86,7 \\
\hline & \multicolumn{2}{|l|}{ Confusional } & 1 & 3,3 \\
\hline \multirow[t]{2}{*}{ Compreensão } & \multicolumn{2}{|l|}{ Adequada } & 24 & 80,0 \\
\hline & \multicolumn{2}{|l|}{ Alterada } & 6 & 20,0 \\
\hline \multirow[t]{2}{*}{ Expressão } & \multicolumn{2}{|l|}{ Adequada } & 25 & 83,3 \\
\hline & \multicolumn{2}{|l|}{\begin{tabular}{|l|} 
Alterada \\
\end{tabular}} & 5 & 16,7 \\
\hline \multirow{5}{*}{ Dentição } & \multicolumn{2}{|l|}{ Presença } & 6 & 20,0 \\
\hline & \multicolumn{2}{|c|}{ Falta de elementos dentários } & 4 & 13,3 \\
\hline & \multicolumn{2}{|c|}{ Bom estado de conservação } & 2 & 6,7 \\
\hline & \multicolumn{2}{|c|}{ Mau estado de conservação } & 4 & 13,3 \\
\hline & \multicolumn{2}{|c|}{ Ausência } & 24 & 80,0 \\
\hline \multirow[t]{5}{*}{ Prótese dentária } & \multicolumn{2}{|l|}{ Não usa } & 9 & 30,0 \\
\hline & \multicolumn{2}{|l|}{ Parcial inferior } & 2 & 6,7 \\
\hline & \multicolumn{2}{|l|}{ Parcial superior } & 0 & 0,0 \\
\hline & \multicolumn{2}{|l|}{ Total inferior } & 12 & 40,0 \\
\hline & \multicolumn{2}{|l|}{ Total superior } & 18 & 60,0 \\
\hline \multirow[t]{4}{*}{ Adaptação da prótese } & \multirow[t]{2}{*}{ Bem adaptada } & Inferior & 5 & 16,7 \\
\hline & & Superior & 15 & 50,0 \\
\hline & \multirow[t]{2}{*}{ Mal adaptada } & Inferior & 9 & 30,0 \\
\hline & & Superior & 3 & 10,0 \\
\hline
\end{tabular}




\begin{tabular}{|c|c|c|c|}
\hline \multirow{2}{*}{$\begin{array}{llll}\text { Retirada } & \text { da } & \text { prótese } & \text { na } \\
\text { internação } & & & \end{array}$} & Sim & 1 & 3,3 \\
\hline & Não & 20 & 66,7 \\
\hline \multirow[t]{2}{*}{ Ulcerações na cavidade oral } & Sim & 3 & 10,0 \\
\hline & Não & 27 & 90,0 \\
\hline \multirow[t]{3}{*}{ Saliva } & Pouca & 3 & 10,0 \\
\hline & Normal & 27 & 90,0 \\
\hline & Excessiva & 0 & 0,0 \\
\hline \multirow[t]{4}{*}{ Condições de higienização } & Paciente realiza sozinho (a) & 19 & 63,3 \\
\hline & Higiene com supervisão & 7 & 23,3 \\
\hline & Não realiza higiene oral & 0 & 0,0 \\
\hline & Cuidador realiza a higiene & 4 & 13,3 \\
\hline \multirow[t]{2}{*}{ Deglutição espontânea de saliva } & Sim & 30 & 100,0 \\
\hline & Não & 0 & 0,0 \\
\hline \multirow[t]{2}{*}{ Oclusão de lábios } & Sim & 29 & 96,7 \\
\hline & Não & 1 & 3,3 \\
\hline \multirow[t]{5}{*}{ Força de língua } & 1/3 posterior & 2 & 6,7 \\
\hline & $1 / 3$ médio e $1 / 3$ posterior & 18 & 60,0 \\
\hline & $\begin{array}{l}\text { 1/3 anterior, } 1 / 3 \text { médio e } 1 / 3 \\
\text { posterior }\end{array}$ & 2 & 6,7 \\
\hline & Ausência & 2 & 6,7 \\
\hline & Impossível avaliar & 6 & 20,0 \\
\hline \multirow[t]{4}{*}{ Mobilidade para a deglutição } & Sim & 23 & 76,7 \\
\hline & Não & 0 & 0,0 \\
\hline & Reduzida (alterada) & 4 & 13,3 \\
\hline & Impossível avaliar & 3 & 10,0 \\
\hline \multirow[t]{3}{*}{ Sensibilidade } & Sim & 24 & 80,0 \\
\hline & Não & 0 & 0,0 \\
\hline & Alterada & 6 & 20,0 \\
\hline \multirow[t]{2}{*}{ Abertura de mandíbula } & Sim & 30 & 100,0 \\
\hline & Não & 0 & 0,0 \\
\hline \multirow[t]{3}{*}{ Sensibilidade de palato mole } & Sim & 22 & 73,3 \\
\hline & Não & 6 & 20,0 \\
\hline & Impossível avaliar & 2 & 6,7 \\
\hline \multirow[t]{3}{*}{ Tosse } & Sim & 30 & 100,0 \\
\hline & Não & 0 & 0,0 \\
\hline & Insuficiente & 0 & 0,0 \\
\hline \multirow[t]{2}{*}{ Freqüência da alimentação } & Normal & 29 & 96,7 \\
\hline & Reduzida & 1 & 3,3 \\
\hline \multirow[t]{2}{*}{ Tempo da refeição } & Normal & 27 & 90,0 \\
\hline & Aumentado & 3 & 10,0 \\
\hline Postura durante a alimentação & Sentado & 30 & 100,0 \\
\hline \multirow[t]{2}{*}{ Usa manobras compensatórias } & Sim & 0 & 0,0 \\
\hline & Não & 30 & 100,0 \\
\hline
\end{tabular}




\begin{tabular}{|l|l|c|c|}
\hline \multirow{3}{*}{ Resíduo na cavidade oral } & Sim & 6 & 20,0 \\
\cline { 2 - 4 } & Não & 18 & 60,0 \\
\cline { 2 - 4 } & Sem dados & 6 & 20,0 \\
\hline \multirow{3}{*}{ Presença de engasgos } & Sim & 1 & 3,3 \\
\cline { 2 - 4 } & Não & 23 & 76,7 \\
\cline { 2 - 4 } & Sem dados & 2 & 20,0 \\
\hline Presença de tosse & Sim & 22 & 73,7 \\
\cline { 2 - 4 } & Não & 6 & 20,0 \\
\cline { 2 - 4 } & Sem dados & 2 & 6,7 \\
\hline Presença de fadiga & Sim & 6 & 73,3 \\
\cline { 2 - 4 } & Não & 20,0 \\
\cline { 2 - 4 } & Sem dados & & \\
\hline
\end{tabular}

Quanto à avaliação clínica funcional da deglutição, os dados obtidos estão descritos no quadro 4. Considera-se como sinais clínicos sugestivos de alteração da deglutição, a ausculta cervical alterada antes e após a deglutição, mudança de qualidade vocal, uso de manobras compensatórias durante a deglutição, presença de estase alimentar, engasgos, tosse e fadiga, quando apresentados concomitantemente, não sendo necessária a presença de todos os sinais para caracterizá-la.

Dos pacientes avaliados, 83,3\% não apresentaram alterações de deglutição durante a avaliação clínica. Dentre estes, apenas um dos pacientes apresentou a queixa inicial de dificuldade, não sendo constatada posteriormente, quando oferecido o alimento. Dos demais cinco pacientes que a apresentaram alterada, dois apresentaram queixas de dificuldades de deglutição.

Em 63,3\% dos pacientes, oferecemos o alimento com estes em posição sentada, na cadeira ou na cama, e 36,7\% destes tinham maiores dificuldades, sendo avaliados no leito, com a cabeceira da cama elevada.

Na ausculta cervical, 86,7\% dos pacientes a apresentaram normal antes e após o oferecimento do alimento e $13,3 \%$ a apresentaram alterada nos dois momentos. Apenas dois pacientes apresentaram ausculta cervical alterada antes do oferecimento do alimento, sendo que assim a mantiveram depois.

Quanto à avaliação da qualidade vocal, 90,0\% dos pacientes não apresentaram mudança após o oferecimento do alimento e 10\% ficaram alteradas, sendo que estes mesmos pacientes apresentaram avaliação funcional da deglutição alterada. 
Durante o oferecimento do alimento, observamos que $96,7 \%$ dos pacientes apresentam abertura de boca voluntariamente, sendo que houve necessidade de auxílio na abertura bucal de um paciente que apresentava um quadro demencial mais avançado, estando confuso. Nenhum dos pacientes apresentou reflexo patológico de mordida, sendo observado vedamento labial adequado durante a deglutição.

QUADRO 4 - AVALIAÇÃO FUNCIONAL DA DEGLUTIÇÃO DOS 30 PACIENTES ESTUDADOS

\begin{tabular}{|c|c|c|c|}
\hline Aspecto avaliado & Observação & Pacientes & $(\%)$ \\
\hline \multirow[t]{2}{*}{ Postura durante o oferecimento } & Sentada & 19 & 63,3 \\
\hline & Cabeceira da cama elevada & 11 & 36,7 \\
\hline \multirow{2}{*}{$\begin{array}{l}\text { Ausculta cervical sem a oferta } \\
\text { do alimento }\end{array}$} & Normal & 26 & 86,7 \\
\hline & Alterada & 4 & 13,3 \\
\hline \multirow{2}{*}{$\begin{array}{llll}\begin{array}{l}\text { Qualidade } \\
\text { deglutição }\end{array} & \text { vocal } & \text { após } & \text { a } \\
\end{array}$} & Sem alteração & 27 & 90,0 \\
\hline & Com alteração & 3 & 10,0 \\
\hline \multirow{2}{*}{$\begin{array}{l}\text { Ausculta cervical com a oferta } \\
\text { do alimento }\end{array}$} & Normal & 26 & 86,7 \\
\hline & Alterada & 4 & 13,3 \\
\hline \multirow{2}{*}{ Abre a boca voluntariamente } & Sim & 29 & 96,7 \\
\hline & Não & 1 & 3,3 \\
\hline \multirow[t]{3}{*}{ Apresenta reflexo de mordida } & Sim & 0 & 0,0 \\
\hline & Não & 30 & 100,0 \\
\hline & Sem dados & 0 & 0,0 \\
\hline \multirow[t]{3}{*}{ Vedamento labial adequado } & Sim & 30 & 100,0 \\
\hline & Não & 0 & 0,0 \\
\hline & Sem dados & 0 & 0,0 \\
\hline \multirow{2}{*}{$\begin{array}{l}\text { Apresenta movimentação } \\
\text { compensatória ao deglutir }\end{array}$} & Sim & 2 & 6,7 \\
\hline & Não & 28 & 93,3 \\
\hline \multirow{2}{*}{$\begin{array}{l}\text { Estase de alimento em cavidade } \\
\text { oral }\end{array}$} & Sim & 3 & 10,0 \\
\hline & Não & 27 & 90,0 \\
\hline \multirow[t]{2}{*}{ Apresentou engasgos } & Sim & 1 & 3,3 \\
\hline & Não & 29 & 96,7 \\
\hline \multirow[t]{2}{*}{ Apresentou tosse } & Sim & 4 & 13,3 \\
\hline & Não & 26 & 86,7 \\
\hline \multirow[t]{2}{*}{ Apresentou fadiga } & Sim & 1 & 3,3 \\
\hline & Não & 29 & 96,7 \\
\hline \multirow[t]{2}{*}{ Avaliação clínica funcional } & Normal & 25 & 83,3 \\
\hline & Alterada & 5 & 16,7 \\
\hline
\end{tabular}

Quanto aos dados referidos pelos pacientes através de perguntas dirigidas sobre a alimentação, foram também observados no momento da avaliação funcional, 
onde obtivemos que 93,3\% não apresentaram movimentação compensatória ao deglutir e 6,7\% mudança de postura de cabeça para trás e para frente; 10,0\% apresentaram estase de alimento em cavidade oral após a deglutição e 90,0\% não apresentaram; 96,7\% não apresentaram tosse ou fadiga e 13,3\% as apresentaram. Os pacientes que demonstraram alterações nestes aspectos, concluímos que apresentaram alteração na avaliação clínica da deglutição.

\section{AVALIAÇÃO CINTILOGRÁFICA DA DEGLUTIÇÃO}

Inicialmente, todos os dados adquiridos no computador, através do Protocolo de Aquisição Dinâmica da gama-câmara (vision DST), foram compilados em uma tabela, para cada grupo (apêndice 2) e consistência, quanto ao trânsito e resíduo oral; trânsito, clearance e resíduo faríngeo e entrada no esôfago proximal.

O paciente 15 não deglutiu o alimento no tempo máximo de aquisição, padronizado no exame, não sendo possível obter os dados. O mesmo ocorreu para a consistência pastosa, no paciente 1. O paciente 9, na deglutição do bolo pastoso, deglutiu após os 20 segundos sendo prejudicada a análise do trânsito na boca. As outras variáveis foram analisadas.

A tabela 1 apresenta as médias, desvios padrão e medianas do tempo de trânsito e resíduo oral, trânsito, clearance e resíduo faríngeo e entrada no esôfago proximal para a consistência líquida. Os tempos de trânsito, clearance e entrada no esôfago proximal são apresentados em segundos e o resíduo, em porcentagem. 
Tabela 1 - COMPARAÇÃO ENTRE OS GRUPOS DE JOVENS, IDOSOS SAUDÁVEIS E DOENTES PARA A CONSISTÊNCIA LÍQUIDA

\begin{tabular}{|c|c|c|c|c|c|c|c|}
\hline Grupos & $\begin{array}{l}\text { Trâ } \\
\text { ora }\end{array}$ & $\begin{array}{l}\text { sito } \\
\text { (s) }\end{array}$ & $\begin{array}{l}\text { Resíduo } \\
\text { oral (\%) }\end{array}$ & $\begin{array}{l}\text { Trânsito } \\
\text { oral (s) }\end{array}$ & $\begin{array}{c}\text { Clearance } \\
\text { oral (s) }\end{array}$ & $\begin{array}{c}\text { Resíduo } \\
\text { faríngeo (\%) }\end{array}$ & $\begin{array}{l}\text { Entrada no } \\
\text { esôfago } \\
\text { proximal (s) }\end{array}$ \\
\hline \multirow[t]{3}{*}{ Jovens } & 20 média & 0,55 & 7,84 & 0,44 & 0,71 & 5,04 & 0,20 \\
\hline & $\mathrm{DP}$ & 0,28 & 5,35 & 0,09 & 0,18 & 3,74 & 0,07 \\
\hline & med. & 0,45 & 5,92 & 0,45 & 0,70 & 3,73 & 0,20 \\
\hline \multirow{3}{*}{$\begin{array}{c}\text { Idosos } \\
\text { saudáveis }\end{array}$} & 10 média & 0,61 & 17,56 & 0,46 & 0,81 & 10,86 & 0,37 \\
\hline & DP & 0,26 & 10,15 & 0,13 & 0,18 & 8,53 & 0,16 \\
\hline & med. & 0,62 & 14,03 & 0,50 & 0,80 & 7,01 & 0,35 \\
\hline \multirow{3}{*}{$\begin{array}{l}\text { Idosos } \\
\text { doentes }\end{array}$} & 29 média & 0,71 & 14,88 & 0,48 & 0,90 & 12,45 & 0,47 \\
\hline & DP & 0,39 & 12,72 & 0,16 & 0,34 & 7,75 & 0,51 \\
\hline & med. & 0,65 & 10,48 & 0,45 & 0,80 & 11,72 & 0,30 \\
\hline $\mathrm{P}$ & \multicolumn{2}{|c|}{0,2692 (ns) } & $0,0116(*)$ & 0,6922 (ns) & 0,1028 (ns) & $0,0011\left(^{*}\right)$ & $<0,0001\left(^{*}\right)$ \\
\hline
\end{tabular}

Ao compararmos os grupos para a consistência líquida, observamos que há diferença estatisticamente significante quanto aos resíduos e o tempo de entrada no esôfago proximal.

Quando aplicado o teste de comparações múltiplas de Dunn em relação ao resíduo oral, observou-se que a diferença estatisticamente significante encontrava-se entre os grupos de jovens e idosos saudáveis $(\mathrm{p}<0,05)$.

Para o resíduo faríngeo, embora haja nítida tendência de aumento do mesmo no grupo de idosos saudáveis (gráfico 3), houve diferença estatisticamente significante somente entre os grupos de jovens e idosos doentes, sendo a diferença não significativa para os demais grupos. Houve diferença significante entre os grupos para a entrada no esôfago proximal e, quando comparados entre si, os valores foram significativos para os grupos de jovens vs idosos saudáveis $(p<0,01)$ e jovens vs idosos doentes ( $\mathrm{p}<0,001)$, não sendo significativo entre idosos saudáveis vs idosos doentes (p > 0,05) (gráfico 4). 
Gráfico 3: Comparação entre os grupos de jovens, idosos saudáveis e idosos doentes para a consistência líquida quanto aos resíduos oral e faríngeo

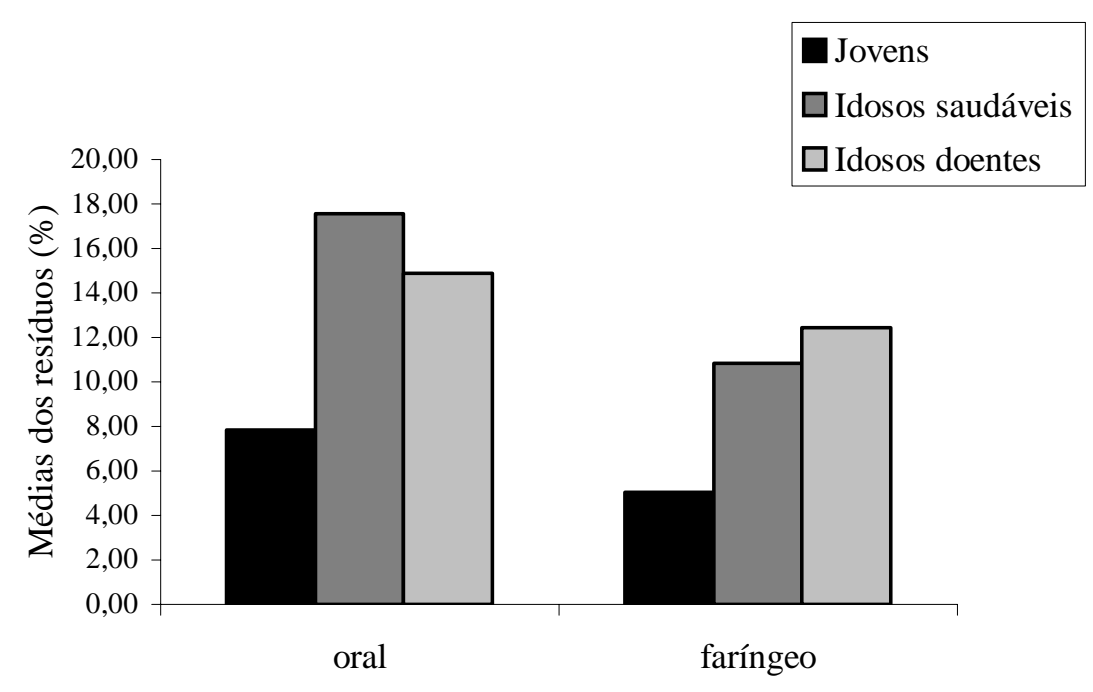

Gráfico 4: Comparação entre os grupos de jovens, idosos saudáveis e idosos doentes para a consistência líquida quanto aos tempos de trânsito, clearance e entrada no esôfago proximal



Na tabela 2 comparamos a deglutição do bolo pastoso entre os três grupos estudados. 
Tabela 2 - COMPARAÇÃO ENTRE OS GRUPOS DE JOVENS, IDOSOS SAUDÁVEIS E DOENTES PARA A CONSISTÊNCIA PASTOSA

\begin{tabular}{|c|c|c|c|c|c|c|c|c|}
\hline Grupos & $\mathrm{n}$ & \multicolumn{2}{|c|}{$\begin{array}{l}\text { Trânsito } \\
\text { oral (s) }\end{array}$} & $\begin{array}{l}\text { Resíduo } \\
\text { oral (\%) }\end{array}$ & $\begin{array}{l}\text { Trânsito } \\
\text { oral (s) }\end{array}$ & $\begin{array}{l}\text { Clearance } \\
\text { oral (s) }\end{array}$ & $\begin{array}{c}\text { Resíduo } \\
\text { faríngeo (\%) }\end{array}$ & $\begin{array}{c}\text { Entrada no } \\
\text { esôfago }\end{array}$ \\
\hline \multirow[t]{3}{*}{ Jovens } & 20 & média & 0,63 & 9,13 & 0,49 & 0,88 & 10,95 & 0,51 \\
\hline & & DP & 0,45 & 6,09 & 0,26 & 0,28 & 6,59 & 0,13 \\
\hline & & med. & 0,45 & 7,76 & 0,45 & 0,82 & 9,10 & 0,50 \\
\hline \multirow{3}{*}{$\begin{array}{c}\text { Idosos } \\
\text { saudáveis }\end{array}$} & 10 & média & 0,84 & 15,40 & 0,47 & 0,91 & 10,88 & 0,42 \\
\hline & & DP & 0,47 & 15,48 & 0,15 & 0,35 & 7,37 & 0,16 \\
\hline & & med. & 0,62 & 12,05 & 0,45 & 0,85 & 13,06 & 0,45 \\
\hline \multirow{3}{*}{$\begin{array}{l}\text { Idosos } \\
\text { doentes }\end{array}$} & 29 & média & 0,75 & 19,48 & 0,44 & 0,93 & 19,08 & 0,61 \\
\hline & & $\mathrm{DP}$ & 0,43 & 10,64 & 0,14 & 0,46 & 11,29 & 0,30 \\
\hline & & med. & 0,65 & 17,32 & 0,40 & 0,80 & 17,89 & 0,55 \\
\hline $\mathrm{p}$ & & \multicolumn{2}{|c|}{0,1831 (ns) } & $0,0013(*)$ & 0,7563 (ns) & 0,9625 (ns) & $0,0156(*)$ & 0,1625 (ns) \\
\hline
\end{tabular}

Observamos que os resíduos oral e faríngeo também apresentam diferença estatística, não sendo observado a mesma no tempo de entrada no esôfago proximal, como visto na deglutição do bolo líquido.

O resíduo oral foi considerado diferente, com alta significância entre os grupos de jovens vs idosos doentes $(\mathrm{p}<0,001)$. Apesar de não haver diferença estatística, houve tendência deste ser maior em idosos saudáveis do que em jovens e maior em idosos doentes do que em idosos saudáveis (gráfico 5).

Quanto ao resíduo faríngeo, houve diferença estatística entre o grupo de jovens e idosos doentes, não havendo diferença significante entre jovens e idosos saudáveis e entre idosos saudáveis e idosos doentes. 


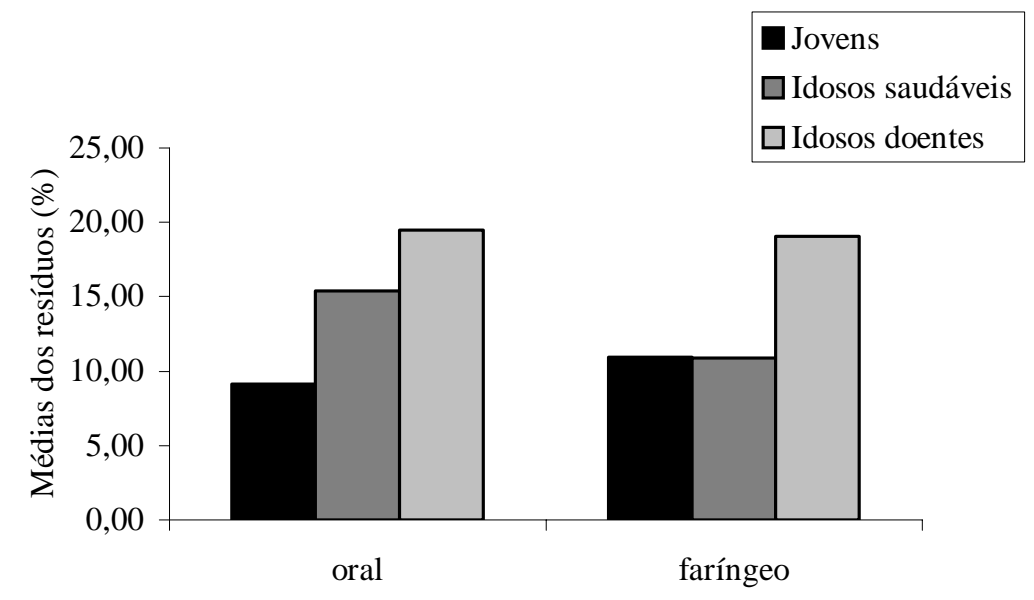

Gráfico 5: Comparação entre os grupos de jovens, idosos saudáveis e idosos doentes para a consistência pastosa quanto aos resíduos oral e faríngeo

Embora não tenha sido verificada diferença estatisticamente significante durante os tempos de trânsito analisados, o gráfico 6 mostra a variação entre os grupos.

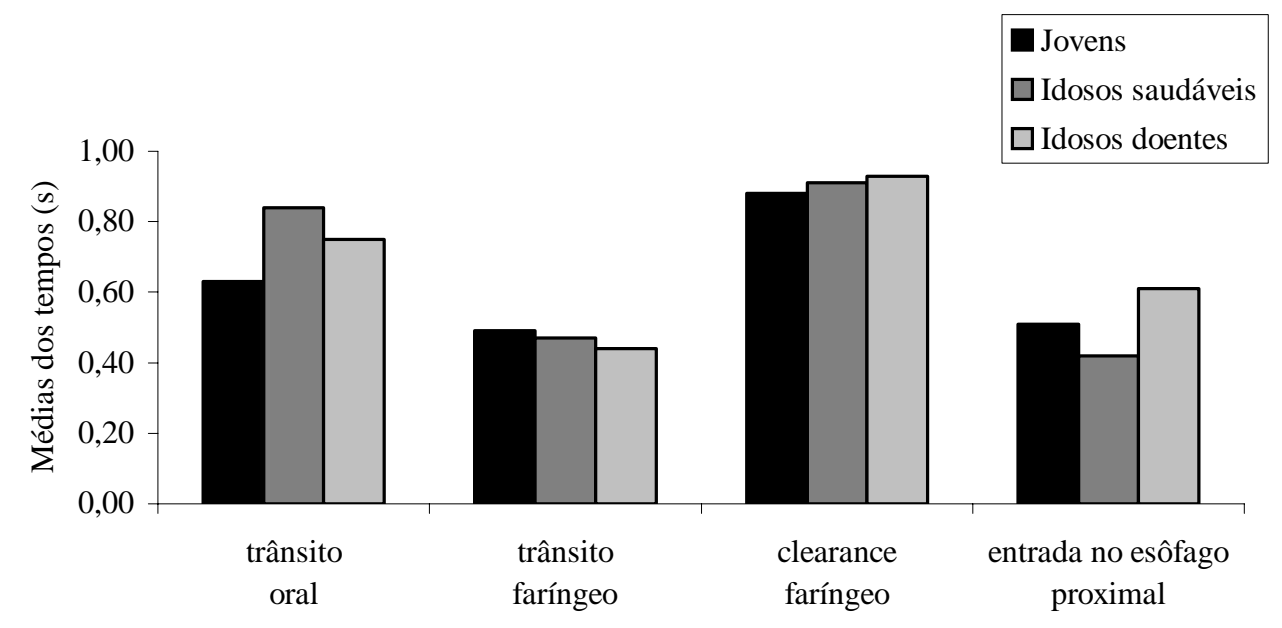

Gráfico 6: Comparação entre os grupos de jovens, idosos saudáveis e idosos doentes para a consistência pastosa quanto aos tempos de trânsito, clearance e entrada no esôfago proximal

A partir da tabela 3, será comparado para cada grupo e para cada fase da deglutição, os dados obtidos na avaliação cintilográfica da deglutição de bolos com 
diferentes consistências. Após serem demonstradas todas as tabelas de cada grupo, será exposto um gráfico ilustrativo, para melhor compreensão.

No grupo de jovens, apesar do tempo de trânsito e resíduo serem maiores para o alimento na consistência pastosa, não há diferença estatística quanto aos parâmetros estudados na fase oral (tabela 3).

Tabela 3 - COMPARAÇÃO DA FASE ORAL ENTRE AS CONSISTÊNCIAS (BOLOS) NO GRUPO DE JOVENS

\begin{tabular}{lcccccc}
\hline \multicolumn{3}{c}{ Trânsito (s) } & \multicolumn{3}{c}{ Resíduo (\%) } \\
\hline Bolos & média & DP & med. & média & DP & med. \\
Líquido & 0,55 & 0,28 & 0,45 & 7,43 & 5,35 & 5,92 \\
Pastoso & 0,63 & 0,45 & 0,45 & 9,13 & 6,09 & 7,76 \\
\hline p & 0,6705 (ns) & \multicolumn{3}{c}{0,4898 (ns) } \\
\hline DP = desvio padrão; med. = mediana
\end{tabular}

Quanto à fase faríngea, houve diferença significante no tempo de clearance e no resíduo, sendo estes maiores quando deglutido o bolo pastoso (tabela 4).

\section{Tabela 4 - COMPARAÇÃO DA FASE FARÍNGEA ENTRE AS CONSISTÊNCIAS (BOLOS) NO GRUPO DE JOVENS}

\begin{tabular}{lccccccccc}
\hline & \multicolumn{4}{c}{ Trânsito (s) } & \multicolumn{3}{c}{ Clearance (s) } & \multicolumn{3}{c}{ Resíduo (\%) } \\
\hline Bolos & média & DP & med. & média & DP & Med. & média & DP & med. \\
Líquido & 0,44 & 0,09 & 0,45 & 0,71 & 0,18 & 0,70 & 5,04 & 3,74 & 3,73 \\
Pastoso & 0,49 & 0,26 & 0,45 & 0,88 & 0,28 & 0,82 & 10,95 & 6,59 & 9,10 \\
\hline p & \multicolumn{4}{c}{0,3508 (ns) } & \multicolumn{3}{c}{$0,0016(*)$} & \multicolumn{3}{c}{$0,0003\left(^{*}\right)$} \\
\hline DP = desvio padrão; med. = mediana; * = significante & \multicolumn{3}{c}{}
\end{tabular}

O mesmo fato pode ser visto quanto ao tempo de entrada no esôfago proximal, havendo uma diferença significativa, sendo este maior para o bolo pastoso. 
Tabela 5 - COMPARAÇÃO DA ENTRADA NO ESÔFAGO PROXIMAL ENTRE AS CONSISTÊNCIAS (BOLOS) NO GRUPO DE JOVENS

\begin{tabular}{lccc}
\hline \multicolumn{4}{c}{ Entrada no esôfago proximal (s) } \\
\hline Bolos & média & DP & med. \\
Líquido & 0,20 & 0,07 & 0,20 \\
Pastoso & 0,51 & 0,13 & 0,50 \\
\hline $\mathrm{P}$ & $<0,0001\left(^{*}\right)$ \\
\hline $\mathrm{DP}=$ desvio padrão; med. = mediana; * = significante
\end{tabular}

O gráfico 7 demonstra os tempos de trânsitos e resíduos oral e faríngeo, clearance faríngeo e tempo de entrada no esôfago proximal quando comparados à deglutição dos bolos líquido e pastoso em jovens, e em seguida, há a representação gráfica da comparação dos resíduos oral e faríngeo durante a deglutição dos dois bolos (gráfico 8).



Gráfico 7: Comparação entre os tempos de trânsito oral e faríngeo, clearance faríngeo e entrada no esôfago proximal durante a deglutição de líquido e pastoso no grupo de jovens 


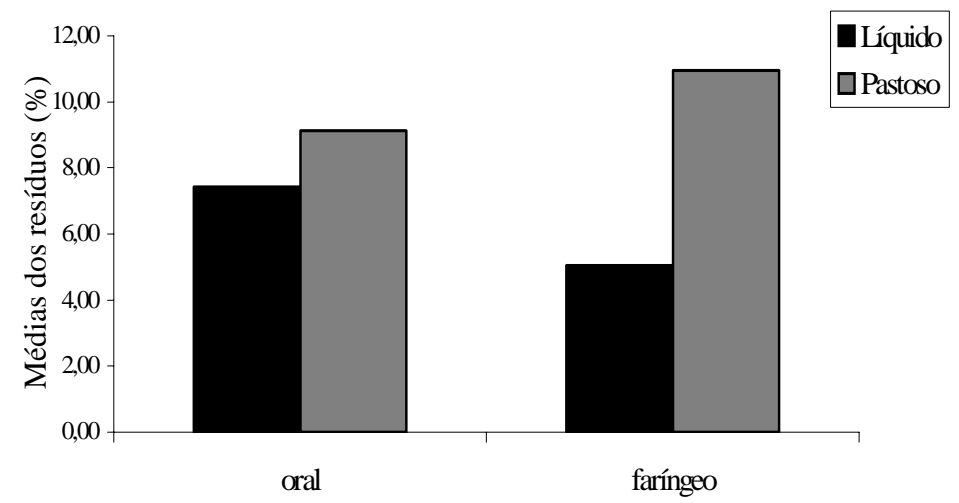

Gráfico 8: Comparação entre os resíduos oral e faríngeo na deglutição dos bolos líquido e pastoso no grupo de jovens

As tabelas 6, 7 e 8 referem-se às comparações das deglutições dos diferentes bolos (líquido e pastoso) no grupo de idosos saudáveis nas três respectivas fases, oral, faríngea e esofageana.

Assim como no grupo de jovens, não foi observada diferença estatística na fase oral da deglutição. Entretanto, diferentemente do grupo de jovens, houve uma menor porcentagem de resíduo para o alimento pastoso. Cumpre salientar que isto se deve a um resíduo já aumentado, em relação ao grupo jovem, à deglutição de líquido.

Tabela 6 - COMPARAÇÃO DA FASE ORAL ENTRE AS CONSISTÊNCIAS (BOLOS) NO GRUPO DE IDOSOS SAUDÁVEIS

\begin{tabular}{lcccccc}
\hline \multicolumn{3}{c}{ Trânsito (s) } & \multicolumn{3}{c}{ Resíduo (\%) } \\
\hline Bolos & média & DP & med. & média & DP & med. \\
Líquido & 0,61 & 0,26 & 0,62 & 17,56 & 10,14 & 14,03 \\
Pastoso & 0,84 & 0,47 & 0,62 & 15,40 & 15,28 & 12,05 \\
\hline P & 0,1641 (ns) & & 0,3750 (ns) \\
\hline DP = desvio padrão; med. = mediana
\end{tabular}

A diferença entre os parâmetros observados na fase faríngea foi pequena quando comparada às deglutições dos dois bolos, não havendo diferença com significância estatística. 
Tabela 7 - COMPARAÇÃO DA FASE FARÍNGEA ENTRE AS CONSISTÊNCIAS (BOLOS) NO GRUPO DE IDOSOS SAUDÁVEIS

\begin{tabular}{lccccccccc}
\hline & \multicolumn{3}{c}{ Trânsito (s) } & \multicolumn{3}{c}{ Clearance (s) } & \multicolumn{3}{c}{ Resíduo (\%) } \\
\hline Bolos & média & DP & med. & média & DP & med. & média & DP & med. \\
Líquido & 0,46 & 0,13 & 0,50 & 0,81 & 0,18 & 0,80 & 10,86 & 8,53 & 7,01 \\
Pastoso & 0,47 & 0,15 & 0,45 & 0,91 & 0,35 & 0,85 & 10,88 & 7,37 & 13,06 \\
\hline p & \multicolumn{3}{c}{0,5000 (ns) } & \multicolumn{4}{c}{0,2129 (ns) } & \multicolumn{3}{c}{0,4609 (ns) } \\
\hline
\end{tabular}

$\mathrm{DP}$ = desvio padrão; med. = mediana

Não houve diferença estatisticamente significante entre o tempo de entrada no esôfago para o bolo líquido e para o pastoso no grupo de idosos saudáveis.

Estes são melhores observados nos gráficos que seguem (gráficos 9 e 10).

Tabela 8 - COMPARAÇÃO DA ENTRADA NO ESÔFAGO PROXIMAL ENTRE AS CONSISTÊNCIAS (BOLOS) NO GRUPO DE IDOSOS SAUDÁVEIS

\begin{tabular}{lccc}
\hline & \multicolumn{3}{c}{ Entrada no esôfago proximal (s) } \\
\hline Bolos & média & DP & med. \\
Líquido & 0,37 & 0,16 & 0,35 \\
Pastoso & 0,42 & 0,16 & 0,45 \\
\hline p & \multicolumn{3}{c}{0,6953 (ns) } \\
\hline DP = desvio padrão; med. = mediana
\end{tabular}




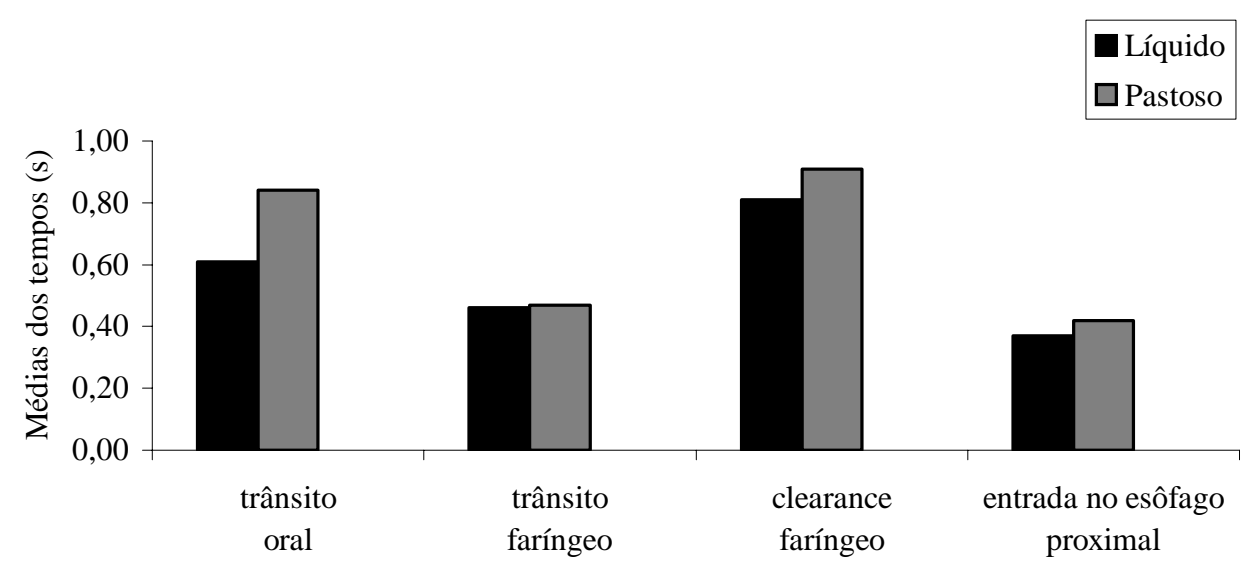

Gráfico 9: Comparação entre os tempos de trânsito oral e faríngeo, clearance faríngeo e entrada no esôfago proximal durante a deglutição de líquido e pastoso no grupo de idosos saudáveis

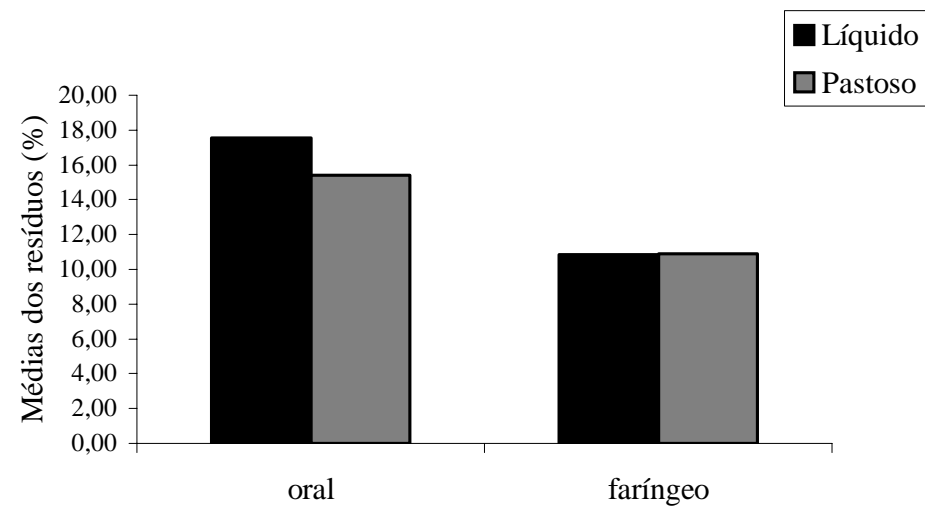

Gráfico 10: Comparação entre os resíduos oral e faríngeo na deglutição dos bolos líquido e pastoso em idosos saudáveis

Por fim, as tabelas de 9 a 11 apresentam as fases oral, faríngea e esofageana obtidos pela avaliação cintilográfica do grupo de idosos internados, os quais denominamos de idosos doentes. 
Para o trânsito oral houve um aumento de tempo durante a deglutição do bolo pastoso, não significativa. Porém, a diferença entre o resíduo oral para as consistências foi significativa (tabela 9).

Tabela 9 - COMPARAÇÃO DA FASE ORAL ENTRE AS CONSISTÊNCIAS (BOLOS) NO GRUPO DE IDOSOS DOENTES

\begin{tabular}{lcccccc}
\hline & \multicolumn{3}{c}{ Trânsito (s) } & \multicolumn{3}{c}{ Resíduo (\%) } \\
\hline Bolos & média & DP & med. & média & DP & med. \\
Líquido & 0,71 & 0,39 & 0,65 & 14,88 & 12,72 & 10,48 \\
Pastoso & 0,75 & 0,43 & 0,65 & 19,48 & 10,64 & 17,32 \\
\hline p & \multicolumn{3}{c}{0,4310 (ns) } & & & $0,0061\left(^{*}\right)$
\end{tabular}

$\mathrm{DP}$ = desvio padrão; med. = mediana; * = significante

Houve um trânsito mais rápido do alimento na consistência pastosa, com um tempo de clearance maior e uma permanência de resíduos também maior (tabela 10).

Tabela 10 - COMPARAÇÃO DA FASE FARÍNGEA ENTRE AS CONSISTÊNCIAS (BOLOS) NO GRUPO DE IDOSOS DOENTES

\begin{tabular}{lccccccccc}
\hline & \multicolumn{4}{c}{ Trânsito (s) } & \multicolumn{3}{c}{ Clearance (s) } & \multicolumn{3}{c}{ Resíduo (\%) } \\
\hline Bolos & média & DP & med. & média & DP & med. & média & DP & med. \\
Líquido & 0,48 & 0,16 & 0,45 & 0,90 & 0,34 & 0,80 & 12,45 & 7,75 & 11,72 \\
Pastoso & 0,44 & 0,14 & 0,40 & 0,93 & 0,46 & 0,80 & 19,08 & 11,29 & 17,89 \\
\hline p & \multicolumn{4}{c}{0,1234 (ns) } & \multicolumn{3}{c}{0,2814 (ns) } & \multicolumn{3}{c}{$0,0020\left(^{*}\right)$} \\
\hline DP = desvio padrão; med. = mediana; * = significante & &
\end{tabular}

Quando à entrada dos bolos no esôfago proximal, no grupo de idosos doentes, registrou-se um tempo maior para a consistência pastosa. 
Tabela 11 - COMPARAÇÃO DA ENTRADA NO ESÔFAGO PROXIMAL ENTRE AS CONSISTÊNCIAS (BOLOS) NO GRUPO DE IDOSOS DOENTES

\begin{tabular}{lccc}
\hline \multicolumn{3}{c}{ Entrada no esôfago proximal (s) } \\
\hline Bolos & Média & DP & med. \\
Líquido & 0,47 & 0,51 & 0,30 \\
Pastoso & 0,61 & 0,30 & 0,55 \\
\hline P & $0,0164(*)$ & \\
\hline DP = desvio padrão; med. = mediana; * = significante
\end{tabular}

Os dados gráficos da deglutição de idosos doentes quando comparados quanto as duas consistências utilizadas, seguem abaixo (gráficos 11 e 12).

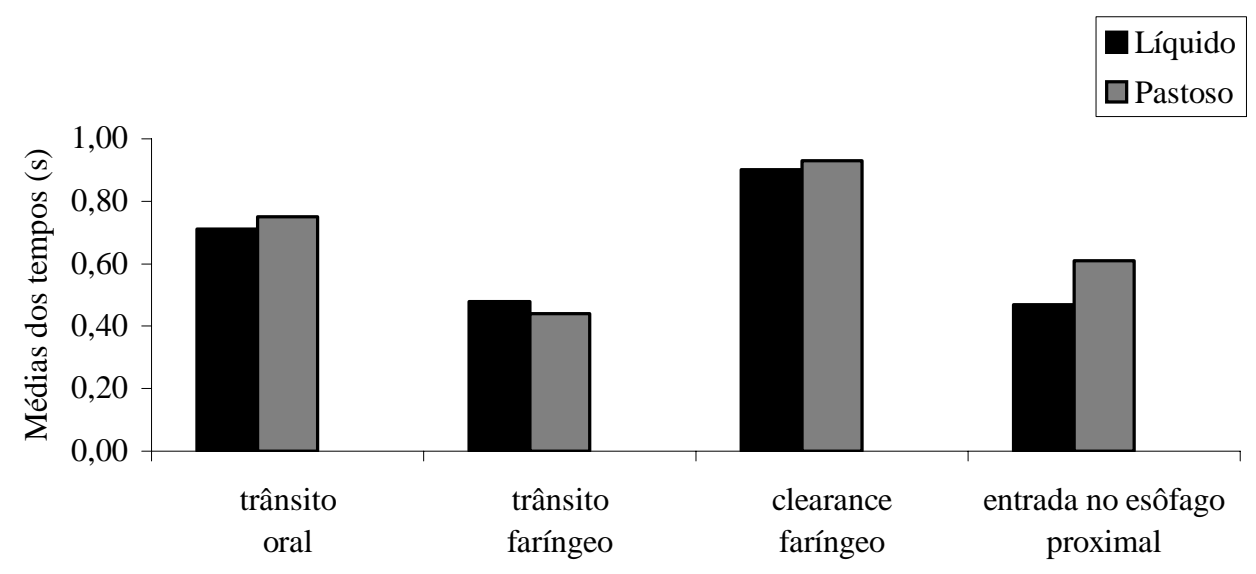

Gráfico 11: Comparação entre os tempos de trânsito oral e faríngeo, clearance faríngeo e entrada no esôfago proximal durante a deglutição de líquido e pastoso no grupo de idosos doentes 




Gráfico 13: Comparação entre os resíduos oral e faríngeo na deglutição dos bolos líquido e pastoso no grupo de idosos doentes 


\section{DISCUSSÃO}


Sabe-se que a disfagia aumenta com o avanço da idade e, acima de $10 \%$ daqueles, com 50 anos ou mais de idade a experimentarão. Entretanto, o processo de envelhecimento, por si só, não causa esse sintoma, o qual sempre requer investigação. Uma doença que pode causar disfagia no jovem pode causá-la também nos idosos, assim como muitas outras doenças que ocorrem neles exclusivamente. Estas pessoas, uma vez que apresentem doenças agudas, podem ter seu estado piorado por aspirações e até mesmo por quadros de desnutrição e desidratação, devido à modificação dos hábitos alimentares, deixando, assim, o indivíduo mais suscetível a adquirir outras doenças, como pneumonias (FARRELL \& FRIEDMAN, 2001).

Diversos estudos sobre a deglutição em idosos descrevem alterações no mecanismo da deglutição decorrentes do processo de envelhecimento. ROBBINS et al (1992), em seus estudos com diferentes faixas etárias, através da videofluoroscopia e manometria, observaram um atraso no início da excursão hiolaríngea, descrevendo-a com um tempo de duração mais longo com o aumento da idade. Relataram também que o tempo de transição entre as fases da deglutição, tempo de trânsito faríngeo, de abertura do esfíncter esofágico superior (E.E.S.) e de duração total da deglutição aumentam com a idade.

Outros autores revisaram exames de videofluoroscopia de 50 pacientes idosos que aspiravam. As análises mostraram que em 23 desses pacientes a aspiração foi devida a anormalidades do estágio oral: 10 a apresentaram no estágio faríngeo e 17 em ambos os estágios. A disfunção no estágio oral foi devida à ingestão rápida do alimento ou de um volume grande, dificuldade na contenção oral do alimento (dificuldade na manipulação do bolo, dissociação da propulsão e início da deglutição na fase transicional). A disfunção no estágio faríngeo foi devida à alteração no trânsito, com retenção alimentar e fechamento inadequado do vestíbulo laríngeo. A aspiração foi a anormalidade mais observada durante o exame radiológico (FEINBERG \& EKBERG, 1991).

VIDIGAL et al (2001), descreveram que a deglutição orofaríngea torna-se mais lenta nos idosos à medida em que o disparo da deglutição está atrasado. O aumento da penetração no vestíbulo laríngeo e as mudanças na geração da pressão faríngea também são observados. Além disso, ocorrem mudanças no movimento da língua como o aumento destes e o posicionamento do bolo em região posterior. 
Este estudo teve por objetivo avaliar os pacientes internados em uma enfermaria de geriatria, com a intenção de verificar a presença de alterações não relatadas que pudessem, potencialmente, interferir de forma negativa na evolução das doenças e em seu prognóstico. Para tanto, avaliamos o paciente clinicamente, quanto às estruturas envolvidas na deglutição e sua função propriamente ditas. Abordamos, assim, a fase orofaríngea da deglutição.

Utilizou-se um protocolo de avaliação (anexo C), onde se pode obter alguns dados sobre possíveis alterações de deglutição e, posteriormente, correlaciona-los à avaliação instrumental, pela cintilografia da deglutição.

Para a avaliação estrutural da deglutição, incluiu-se um grupo controle de voluntários idosos (apêndice 5), e para a avaliação cintilográfica, incluiu-se o mesmo grupo de voluntários idosos e um terceiro de voluntários jovens (apêndices 3 e 4). A função da deglutição foi considerada normal para ambos os grupos, sendo este o critério de inclusão dos voluntários na pesquisa.

Algumas considerações quanto aos métodos objetivos de avaliação da disfagia e o utilizado no estudo devem ser feitas.

Muitos métodos de avaliação da deglutição existem, desde os clínicos aos exames complementares. Entre estes, pode-se citar a ausculta cervical, a eletromiografia, a ultrasonografia, a oximetria de pulso, a endoscopia digestiva alta, a videofluoroscopia, a nasovideoendoscopia, a manometria e a cintilografia. Todos estes métodos apresentam vantagens e desvantagens, havendo, muitas vezes, necessidade de realização de mais de um deles para elucidação diagnóstica.

Os métodos objetivos mais solicitados e utilizados habitualmente por profissionais que trabalham com disfagia alta (orofaríngea) são a nasovideoendoscopia e a videofluoroscopia, que avaliam a dinâmica da deglutição, estruturas anatômicas, possibilitam ao profissional a verificação do resultado das manobras facilitadoras posturais e de limpeza de recessos faríngeos, assim como escolha da consistência de alimento mais adequada ao paciente. A avaliação endoscópica tem por finalidade observar as características da mucosa, avaliação estrutural e funcional da deglutição, sensibilidade. Tem por objetivo localizar, topograficamente, as alterações mais evidentes e significantes durante a função da deglutição (MANRIQUE, 1999). A videofluoroscopia é importante para o 
esclarecimento da presença de aspiração ou microaspiração, observação dinâmica das estruturas associadas à deglutição durante suas fases (GONÇALVES e VIDIGAL, 1999).

Outro método freqüentemente solicitado é a manometria, para elucidação diagnóstica de fenômenos motores que ocorrem no esôfago, espontaneamente ou em conseqüência de estímulos. Sua maior indicação ocorre para o paciente com disfagia quando os exames radiológicos e endoscópico não foram completamente esclarecedores (DANTAS, 1998b).

Este estudo não visava a realização de exames invasivos para a detecção de alterações anatômicas em pacientes com sintomatologia bem definida, mas sim verificar aspectos da fisiologia da deglutição em diferentes grupos, em sua grande maioria, pessoas assintomáticas. Por esta razão optou-se pelo uso da cintilografia da deglutição que, apesar de não ser um método freqüentemente utilizado por profissionais, é um método seguro, não é invasivo, e permite a quantificação do tempo do trânsito do alimento quando deglutido, sendo este o objetivo do estudo. A dose de radiação utilizada no exame é rapidamente eliminada de todo o corpo, sendo que a meia vida do tecnécio é de 6 horas e a quantidade de radioatividade para cada sujeito é inferior a um terço do exame radiológico. É uma técnica suficientemente sensível para detectar, funcionalmente, mudanças fisiológicas relevantes na deglutição em sujeitos assintomáticos (KAZEM, 1972; RUSSEL et al, 1981; HOLT et al, 1990; COOK et al, 1994; ZOHAR et al, 1998; QUINTELLA et al, 1999; NOBRE E SOUZA et al, 2000).

Imprecisões podem ocorrer na avaliação cintilográfica da progressão do bolo através da orofaringe, porque os sujeitos podem não realizar uma deglutição apenas. Entretanto, um ensaio prévio da retenção do bolo e deglutição minimiza a tendência para uma deglutição incompleta e a inspeção da forma da curva do tempo de atividade gerada de regiões de interesse auxilia na detecção de artefatos. Outros fatores, como movimentos do paciente, na tentativa consciente de variar o tamanho e velocidade do trânsito do bolo na faringe, podem introduzir imprecisões, mas os pacientes não podem ser completamente controlados durante exames cintilográficos e, até mesmo, em outros exames. Estudos cintilográficos têm as mesmas dificuldades 
de dados de aquisição que são encontrados em outros procedimentos (HOLT et al, 1990).

Apesar de haver algumas dificuldades durante a realização da cintilografia, é com ela que há possibilidade de se aproximar mais do sabor natural da comida em relação às demais técnicas de avaliação como as com uso de bário, pois o alimento é marcado com o radionúcleo que não altera o sabor do mesmo (HAMLET et al, 1996).

Inicialmente, quando os pacientes foram avaliados no leito, eram questionados sobre se teriam ou não dificuldades ao se alimentarem. A minoria dos pacientes (10\%) responderam afirmativamente, caracterizando suas dificuldades variavelmente, com exceção à referência quanto ao aumento do tempo de alimentação e à perda de peso, que foram afirmados pelos três pacientes. Alguns sintomas que são considerados como indícios de disfagia (refluxo nasal do alimento, presença de pigarro depois que comem ou bebem algo, presença de tosse antes, durante ou após a deglutição e presença de infecções respiratórias freqüentes) foram, na maioria das vezes, negados pelos pacientes incluídos na pesquisa, o que leva a se ter maior cuidado durante a avaliação lembrando-se da possibilidade de poderem apresentar alterações de deglutição sem sinais clínicos evidentes. Além disso, como já citado, pacientes se adaptam aos pequenos defeitos da deglutição e só têm queixa quando ocorrem alterações mais importantes.

Quando se deu atenção às doenças de base apresentadas por esses pacientes com queixas, viu-se que apresentavam doenças neurológicas (acidente vascular cerebral e síndrome pseudobulbar), doenças cardiovasculares, asma brônquica, depressão e desnutrição, que são doenças que cursam com possíveis dificuldades de deglutição, condizendo com as doenças mais freqüentemente encontradas em estudo realizado por BILTON et al (1999), de idosos fragilizados em uma enfermaria geriátrica.

Ao término da avaliação clínica, observou-se que dois desses pacientes apresentaram alterações na deglutição (os pacientes com doenças neurológicas), e um não teve alteração, sendo este o paciente com quadro de asma brônquica. O fato desse último paciente não ter apresentado alteração poderia ser explicado pela possibilidade de tal queixa não ser constante pois, embora não tenha apresentado alterações clínicas 
da deglutição, deve-se considerar a queixa do paciente quando nos remetemos ao seu quadro, sendo que, provavelmente, suas dificuldades ocorrem em momentos de crises ou descompensações, sabendo-se que os sistemas respiratório e digestivo alto apresentam estruturas comuns. Como, no momento da avaliação, o paciente mostravase estável, não foram observadas alterações. Além disso, caso esse paciente apresentasse penetração do alimento e/ou aspiração silenciosa, não seria possível detectar devido ao fato do exame não permitir essa análise e, como descrito anteriormente, o objetivo do estudo foi o de detectar os aspectos fisiológicos da deglutição em diferentes grupos. Comparando-se os resultados da avaliação clínica alterada dos dois pacientes com queixa com o exame cintilográfico, nos parâmetros de estudo utilizados (tabela 5, pacientes 1 e 15, com síndrome pseudo bulbar e A.V.C., respectivamente), observou-se que estes também apresentaram tempos consideravelmente altos em relação à média encontrada. Para o paciente 15 não se conseguiu obter dados, pois o paciente não deglutiu o alimento no tempo máximo de aquisição padronizado no exame. No paciente 1, para a consistência pastosa, também não foram obtidos valores no tempo máximo (20 segundos), evidenciando-se suas dificuldades.

A terceira paciente (paciente 17) que relatou queixas, mas avaliação clínica normal, apresentou apenas aumento na entrada do alimento pastoso no esôfago proximal, com análise cintilográfica orofaríngea normal.

Confirma-se assim, a correlação entre avaliação clínica e instrumental nos três casos descritos.

Direcionando-se aos demais pacientes observa-se que, apesar de não terem queixas de disfagia, a maioria (74,9\%), quando perguntados sobre sua alimentação, referiram, subjetivamente, aspectos que remetem à presença de dificuldades e que, sob suas perspectivas, não caracterizaram como tal. Cita-se, como exemplo, o relato de presença de engasgos, pigarro, sensação de alimento parado e recusa ao se alimentarem. Ressalta-se também, os relatos quanto à perda de apetite e de peso que, embora estejam presentes em sua maioria, não são remetidas a nenhum fato específico. Dos 27 pacientes, apenas 25,9\% não descreveram algo sobre sua alimentação, afirmando, mais uma vez, que estava normal. 
Observando-se os dados de anamnese e caracterização da função da deglutição pelos pacientes avaliados, utiliza-se mais uma vez, a descrição de ROSSMAN (1986) referindo que a queixa de pacientes idosos não deve ser ignorada porque ela é realmente um sintoma de suas dificuldades; entretanto, deve-se dispor de certo cuidado quando se referem a localização da dificuldade, pois os idosos não são os melhores observadores de suas funções.

Os relatos do grupo de estudo quando se referiam sobre sua alimentação, reforçavam a constatação do autor principalmente quanto as observações dos idosos pois, como visto, os pacientes não referem dificuldades e estas são, indiretamente, remetidas durante as perguntas dirigidas.

As doenças mais freqüentementes apresentadas pelos pacientes (doenças cardio-vasculares, obstipação intestinal, úlcera gástrica, divertículo) sabidamente levam a certo desconforto ou mudanças de hábitos alimentares, possivelmente justificando os sintomas descritos. Alguns quadros, como os demenciais, apresentam alterações quanto à alimentação por desordens cognitivas (dependência, esquecimento, alteração de apetite e comportamento) (SANTINI, 1999, SCHINDLER \& KELLY, 2002).

Como descrito anteriormente, a função da deglutição é um processo em que diversos fatores estão inter-relacionados, com fases e estruturas envolvidas que, uma vez incoordenados ou falhos, podem alterar todo esse processo, acarretando conseqüências. Serão destacados, então, os achados da avaliação clínica após a aplicação do protocolo.

Para uma adequada avaliação fonoaudiológica, é necessário que o estado em que o paciente se encontra ofereça condições mínimas para que essa avaliação seja adequada (FURKIM, 1999), caso contrário pode-se obter alterações que não condizem com o quadro real do paciente. Além disso, o nível de alerta é um dos preditores ao desenvolvimento de problemas na deglutição (LANGMORE et al, 2002). Esta foi uma dificuldade pouco freqüente, pois $86,7 \%$ encontravam-se em estado de alerta.

Alguns pacientes estudados apresentavam leve alteração de compreensão oral, que prejudicou a avaliação de outros aspectos, como a força de língua e a sensibilidade oral. Por outro lado, a alteração de expressão oral apresentada pelos pacientes do estudo caracterizou-se como a presença de disartrias (quadros de A.V.C. 
e paralisia pseudo bulbar progressiva), onde nesse quadro de alteração de fala ocorre um comprometimento do seu controle motor (MURDOCH, 1997), fato este que pode levar a disfunções de deglutição, principalmente na fase oral desta, devido à participação de estruturas comuns. Como exemplo ressalta-se a importância da língua na fala, na preparação e na retropropulsão do bolo alimentar.

Problemas na mastigação e deglutição podem decorrer não somente de danos neurológicos ou estruturais, mas também de alterações na fisiologia das estruturas envolvidas como a dentição: próteses mal adaptadas, redução da força e efetividade mastigatória, redução no volume da saliva e alterações perceptuais táteis e gustativas (ANDERSON, 1971; HEATH, 1982; WAYLER et al, 1984; LOGEMANN, 1990; ROBBINS, 1992; ROLANDELLI \& ULLRICH, 1994; COOK et al, 1994; SHAY \& SHIP, 1995; PLANT, 1998; WEETCH, 2001).

A maioria dos pacientes idosos não apresentavam dentes naturais. Alguns utilizavam próteses dentárias superiores e/ou inferiores, outros não a usavam. Houve alta prevalência de próteses mal adaptadas (próteses “folgadas”, que se movimentam constantemente na cavidade oral). Essas más adaptações, devido ao emagrecimento ou inadequação no momento da confecção da prótese, podem dificultar a fala devido ao jogo realizado entre prótese e mobilidade de órgãos fonoarticulatórios e também pode acarretar dificuldades de manipulação, trituração e formação do bolo alimentar.

A ausência de dentes encontrada em pessoas idosas, levando-as ao uso de próteses dentárias, é muito freqüente. Pode-se confrontar este aspecto com a incidência do uso de próteses no grupo controle de idosos do estudo, onde a maioria dos voluntários a utilizavam. Entretanto, essas próteses dentárias eram adequadamente adaptadas, com exceção feita a um voluntário (apêndice 5).

Neste estudo, não foram observados ulcerações na cavidade oral, que poderiam levar a desconforto durante a mastigação.

A maioria dos pacientes (90\%) tinha salivação aparentemente normal e todos a deglutiam espontaneamente, sendo compatível com os dados obtidos no grupo de voluntários idosos. A porcentagem elevada de pacientes apresentando salivação normal não condiz com a literatura, que refere alta incidência de xerostomia em pacientes idosos, contribuindo para um maior prejuízo na deglutição (MANDEL, 1989; SHAY \& SHIP, 1995; WEETCH, 2001; SCHINDLER \& KELLY, 2002). Não 
se pode justificar a discordância deste achado pela forma de avaliação, pois os autores não descrevem como a realizaram.

A higiene, como referido, é importante na manutenção da saúde oral e, principalmente, na conservação de dentes e prevenção de problemas periodontais. Apesar de não terem sido encontrados pacientes que não realizavam a higiene oral, foi observada a presença de resíduos alimentares nessa cavidade, demonstrando uma higienização inadequada. Isso também é visto devido ao fato de pacientes retirarem a prótese dentária para lavá-la, mas não realizaram a limpeza da boca, onde também ficam os restos alimentares. Esse fator foi visto e, algumas vezes, referido por pacientes e cuidadores.

A avaliação das estruturas envolvidas na ação esfinctérica durante a deglutição é importante devido ao fato dos tratos alimentar, respiratório e fonatório poderem ser conceitualizados como um tubo com válvulas localizadas nos lábios, véu palatino, laringe e esfíncter esofágico superior (E.E.S.). O fechamento incompleto de alguma válvula poderia, teoricamente, afetar o transporte do bolo, sendo importante considerar que todas as válvulas, exceto o E.E.S., devem permanecer fechadas durante a deglutição. O sistema fisiológico pode afetar a função com uma certa variabilidade no fechamento completo e eficiente de cada válvula, mas uma vez que uma válvula crítica é alterada, a função é comprometida (PEARLMAN et al, 1993).

Com exceção de um paciente, a oclusão de lábios dos idosos internados estava adequada durante o repouso.

Junto à presença da função esfínctérica para obtenção de pressão durante a alimentação, é importante a força da língua na formação do bolo alimentar e retropropulsão deste para a faringe.

A língua é dividida em terços, onde os dois terços anteriores são de extrema importância durante a alimentação e deglutição, pois é nessa região que o bolo é posicionado, e em seguida, com a força do terço anterior contra a região alveolar, é propelido posteriormente, somado ao movimento ondulatório da língua, dando início à fase faríngea da deglutição.

Estudos demostraram que os dois terços anteriores da língua apresentam maior força e melhor modulação do que a base da língua. A pressão de clareamento e força propulsora nas partes anterior e média da língua têm maior amplitude de 
movimento e capacidade de adaptação do que a parte posterior ou base da língua, mostrando a importância primária da língua frente ao palato duro para uma propulsão adequada do bolo em direção à faringe e ao esôfago durante a deglutição (POUDEROUX \& KAHRILAS, 1995).

Neste estudo, a maior parte dos pacientes (66,7\%) apresentaram força de língua nos terços médio e posterior $(60,0 \%)$ ou somente no terço posterior $(6,7 \%)$, confirmando dados de alterações freqüentes na fase oral da deglutição da população idosa, além da presença de resíduos alimentares na cavidade, entre outras alterações decorrentes de uma fase oral inadequada. Confirma-se que a perda de força no terço anterior da língua seja um dado observado na população idosa, e não somente nos portadores de doenças, pois houve também alta incidência (60\%) de ausência de força na região anterior da língua nos voluntários idosos participantes.

FEINBERG \& EKBERG (1991), em seus estudos de videofluoroscopia da deglutição de pacientes idosos que aspiram, concluíram que anormalidades do estágio oral isoladas são as mais comuns causas do mal direcionamento do bolo e, quando a atividade lingual apresenta-se grosseiramente anormal, fica difícil determinar se pacientes estão formando o bolo ou tentando iniciar a deglutição.

Ainda na avaliação da cavidade oral, a deglutição, abertura de mandíbula e sensibilidade oral se mostraram adequadas na maioria dos pacientes. Em relação à avaliação da sensibilidade, não foi testada a sensibilidade gustativa, apenas tátil com solicitação para que o paciente indicasse a região referida. Os achados quanto a este último, diferem da literatura que relatam modificações nas sensações perceptuais de idosos (LEEMING et al, 1975; ROLANDELLI \& ULLRICH, 1994; MARTIN et al, 1994; FARRELL \& FRIEDMAN, 2001). Apenas 20\% dos pacientes a apresentaram alterada, devido à impossibilidade de avaliação descrita anteriormente.

Ainda em relação à sensibilidade em idosos, WEETCH (2001), demonstrou que alguns deles podem segurar a comida em suas bocas por um longo tempo sem iniciar a deglutição por não sentir o alimento na boca. A comida irá adquirir a mesma temperatura que a boca e a pessoa pode esquecê-la.

Dentro dessa avaliação, a sensibilidade de palato mole apresentou-se adequada em 73,3\% dos pacientes. E, por fim, todos os pacientes apresentavam tosse voluntária. A maioria dos voluntários idosos (70,0\%) apresentaram sensibilidade de 
palato mole adequada, confirmando que esta, em sua maioria, não sofre modificações com o processo de envelhecimento. Acredita-se que a ausência de sensibilidade de palato mole nos participantes possa ser um dado isolado ou associado a outros fatores como, por exemplo, doença.

Quanto às perguntas direcionadas à alimentação e deglutição, quase todos os pacientes referiram apresentarem freqüência, tempo e postura normais durante as refeições, negando o uso de manobras compensatórias. Entretanto, 20,0\% dos pacientes relataram a presença de resíduos de alimento na cavidade oral após alimentação.

Engasgos, tosse e fadiga durante a alimentação foram negados pela maioria dos pacientes, não sendo relatados por ausência de observação pelos próprios pacientes, embora 20,0\% as apresentassem à avaliação.

Todos os voluntários do grupo de idosos apresentaram referências de ausência de alterações de deglutição, sendo este um dos critérios de inclusão no estudo.

Dois pacientes apresentaram a ausculta cervical alterada antes da deglutição e, logo após, a apresentaram normal. Este fato pode ser devido à estase de saliva em hipofaringe com o clareamento após a deglutição da mesma. Esses pacientes apresentaram avaliação clínica funcional normal.

Em contrapartida, os pacientes com mudança na qualidade vocal após o oferecimento do alimento (10,0\%), apresentaram avaliação alterada.

Dois pacientes apresentaram manobras compensatórias (mudança de postura) embora todos as negassem. Em relação à presença de resíduos após a deglutição, a freqüência também não foi igual à dos relatos dos pacientes. A ausência de resíduo durante a avaliação funcional pode ter sido reduzida devido ao tipo de alimento, pois foi utilizado alimento pastoso e líquido, que podem deixar menos resíduos que os alimentos sólidos, rotineiramente consumidos pelos pacientes.

Em uma análise geral, 83,3\% dos pacientes não apresentaram alterações clínicas da deglutição. Desses, apenas um apresentou, inicialmente, queixa de disfagia durante a anamnese, que não foi constatada, posteriormente, quando oferecido o alimento. Esta paciente referida anteriormente, apresentava como diagnóstico médico asma brônquica. Possivelmente suas dificuldades estão 
relacionadas a momentos de crise (incoordenação pneumofônica), ou não estar conseguindo caracterizar, especificamente, as dificuldades de respiração e alimentação. Esses 25 pacientes que apresentaram avaliação clínica normal, tinham como diagnóstico médico, diabetes, depressão, doença pulmonar obstrutiva crônica (apenas dois deles) e, em sua maioria, doenças cardio vasculares e outras doenças crônicas.

Dos cinco pacientes $(16,7 \%)$ que apresentaram alterações clínicas de deglutição, apenas dois tinham a queixa inicial (pacientes 1 e 15). Os pacientes 11, 16 e 22 (apêndice 1), não referiram dificuldades.

Estes últimos pacientes (11, 16 e 22), apresentaram diagnóstico de síndrome demencial. A paciente 11 apresentava também fibrilação atrial e pneumonia tratada; o paciente 16, flutuação no estado de consciência, hipertensão arterial sistêmica e doença pulmonar crônica; o paciente 22, hipertensão arterial crônica, diabetes, derrame pleural, perda de peso e rouquidão a esclarecer. Pelas patologias apresentadas, deve-se atentar para possíveis complicações, principalmente, devido aos quadros neurológicos e pulmonares.

Destaca-se aqui que, dentro dos critérios de inclusão descritos no estudo, os pacientes que apresentavam alterações evidentes de disfagia como, por exemplo, uso de sondas nasoentéricas para a alimentação, foram, inicialmente, excluídos. Assim, evidencia-se que os pacientes eram, em sua maioria, assintomáticos devendo ser dada maior significância à porcentagem encontrada.

A presença de deglutições múltiplas não foi considerada, isoladamente, como fator de alteração. Entretanto, sua presença foi constatada e registrada durante as avaliações, podendo ser observada em 20,0\% dos pacientes com avaliação normal, sendo este um dado importante a ser considerado. NILSSON et al (1996), estudaram a deglutição oral e faríngea, quantitativamente, em 53 sujeitos não disfágicos. Dos idosos, 74\% precisaram mais de uma deglutição para limpar a cavidade oral após a ingestão de alimento.

Na análise cintilográfica, os pacientes que apresentaram tempos de trânsito maiores, registraram resíduos alimentares menores. Os resultados são concordantes com NOBRE E SOUZA et al (2000), em seus estudos com pacientes com doença de Chagas e doença esofageana, avaliando o trânsito orofaríngeo através da 
cintilografia. Os autores concluíram que pacientes apresentando disfagia têm trânsito oral mais longo do que voluntários sadios. Referiram que anormalidades do trânsito encontradas no estudo eram devidas a um comportamento desenvolvido para minimizar a disfagia, em que pacientes com disfagia aprenderiam a evitá-la através de uma lentificação da fase oral da deglutição, deste modo reduzindo o preenchimento esofageano e aumentando o clearance faríngeo.

Durante a cintilografia da deglutição, o paciente 11 apresentou grande aumento do trânsito oral em ambas as consistências, aumento no trânsito faríngeo, com aumento do resíduo oral do alimento na consistência pastosa quando comparados com a média dos tempos obtidos. Houve apenas aumento no tempo de entrada do alimento pastoso no esôfago proximal. O paciente 16 apresentou redução do trânsito oral de alimento líquido com aumento de resíduo oral do mesmo, sem alterações nas fases faríngea e entrada no esôfago proximal para a consistência líquida. Para o alimento pastoso, o tempo do trânsito oral e faríngeo do alimento foi próximo à média, com aumento do resíduo na boca e faringe e tempo de entrada no esôfago proximal próximo à média. Durante a realização da avaliação clínica, foi necessário solicitar que a paciente deglutisse várias vezes devido à grande estase de alimento na cavidade oral.

Os dados cintilográficos dos pacientes com queixa (pacientes 1 e 15) já foram referidos anteriormente. O paciente 22 apresentou aumento do trânsito oral, trânsito e clearance faríngeo do alimento líquido, com grande resíduo em faringe, tempo de entrada no esôfago proximal normal (em relação à média), redução no tempo de trânsito e resíduo oral, redução no tempo de trânsito e clearance faríngeo para o alimento na consistência pastosa, com aumento de resíduo do alimento em faringe, sem alterações quanto ao tempo de entrada no esôfago proximal. Somando-se à avaliação clínica, esse paciente apresentou deglutições múltiplas para ambas as consistências com piora para o líquido (de acordo com a cintilografia), com presença de estridor durante a ausculta cervical, excursão laríngea limitada e presença de soluços após a deglutição. Estes dados esclareceram a presença de estase alimentar na faringe quando houve uma limitação na excursão laríngea.

Os resultados descritos permitem afirmar que os dados de avaliação clínica e instrumental foram compatíveis e complementares. 
Quanto aos tempos decorridos nas fases da deglutição, LOGEMANN (1990), descreveu que a fase faríngea, normalmente, ocorre em um tempo de 0,3 a 1 segundo em adultos. KAZEM (1972), em seu estudo demonstrou que uma bebida (água ou chá) requer um período de 3 a 5 segundos para passar pelo esôfago; entretanto, não foi referido o tempo requerido apenas para a entrada no mesmo. HAMLET et al (1996), através de dados cintilográficos de voluntários com idades variando de 39 a 65 anos, na deglutição de $10 \mathrm{ml}$ de água e $10 \mathrm{ml}$ de alimento mais viscoso (suco de maçã engrossado), verificaram que o tempo de trânsito oral e trânsito faríngeo são, respectivamente, para o líquido e para o líquido engrossado, 0,38 e 0,31 segundos e o resíduo oral e faríngeo são, respectivamente, 7,3\% e 4,0\% para o líquido; 18,9\% e 10,5\% para o líquido engrossado.

NILSSON et al (1996), quantificaram a deglutição de 53 idosos não disfágicos, com uma média de idade de 76 anos através do teste de ROSS ("Repetitive Oral Suction Swallow"), comparando com um grupo de jovens voluntários com idade média de 39 anos durante a deglutição de $200 \mathrm{ml}$ de água, e concluíram que o tempo de trânsito faríngeo foi de 0,59 segundos nos idosos e 0,56 segundos nos jovens, não tendo uma diferença estatisticamente significante.

COOK et al (1994), estudaram a deglutição de 30 voluntários, sendo 21 idosos (idade média de 68 anos) e 9 jovens (idade média de 28 anos), através da cintilografia, visando determinar a influência do envelhecimento normal do trânsito regional e clearance oral e faríngeo, com a deglutição de água em dois volumes, 5 e $10 \mathrm{ml}$. Observaram que o resíduo oral para $5 \mathrm{ml}$ em idosos foi de 7,6\%, em jovens de 9,6\%; para $10 \mathrm{ml}$ foi de 6,3\% em idosos e 7,7\% em jovens. Na fase faríngea obtiveram resíduo de 5,4\% em idosos e 1,3\% em jovens para $5 \mathrm{ml}$. Para $10 \mathrm{ml}$, foi de 3,5\% em idosos e 0,7\% em jovens.Os tempos de trânsito oral, trânsito faríngeo e clearance faríngeo são, respectivamente, para $5 \mathrm{ml}, 0,7,0,6$ e 1,3 segundos em idosos e 0,46, 0,38 e 0,76 segundos em jovens; para $10 \mathrm{ml}$ são 0,6, 0,6 e 1,2 segundos em idosos e 0,44, 0,33 e 0,71 segundos em jovens.

Neste estudo, o grupo de jovens (de 20 a 30 anos) apresentou um tempo médio de trânsito oral de líquidos de 0,55 segundos, média de porcentagem de resíduo oral de 7,84\%; para a fase faríngea, a média do tempo foi de 0,44 segundos, 0,71 segundos para o clearance e resíduo de 5,04\%. O tempo de entrada no esôfago 
proximal foi de 0,20 segundos. Para a consistência pastosa, os valores resultantes são, de maneira geral, maiores. Foram, respectivamente, 0,63 segundos, 9,13\%; 0,49 segundos, 0,88 segundos e 10,95\%; 0,51 segundos. As variações existentes entre os tempos (mínimo e máximo) podem ser vistos no apêndice 4.

A compreensão de parâmetros da deglutição normal no grupo de idosos é importante para a interpretação de medidas em estágios patológicos (COOK et al, 1994). No grupo de idosos saudáveis (acima de 60 anos), para a consistência líquida, o tempo médio de trânsito oral foi de 0,61 segundos, a média de porcentagem de resíduo oral é de 17,56\%; para a fase faríngea, a média do tempo de trânsito foi de 0,46 segundos, 0,81 segundos para o clearance e resíduo de 10,86\%. O tempo de entrada no esôfago proximal foi de 0,37 segundos. Os valores resultantes para o alimento na consistência pastosa foram, respectivamente, de 0,84 segundos, 15,40\%; 0,47 segundos, 0,91 segundos e 10,88\%; 0,42 segundos. As variações também constam no apêndice 3.

Para a consistência pastosa, os valores de tempos de trânsito foram maiores; entretanto os resíduos foram menores, principalmente na boca, provavelmente devido à facilidade maior em manipulação do bolo pastoso (coeso) em relação ao líquido, onde não há possibilidade de formação do bolo alimentar, havendo também necessidade de controle motor mais refinado. A textura é necessária para estimular a sensação oral, estimulando a boca e a língua (WEETCH, 2001). O aumento da viscosidade do bolo induz a um aumento na força propulsora da língua e na pressão de clareamento pela língua na fase oral, sendo este controle voluntário (PEARLMAN et al, 1993). Outros autores, em estudo cintilográfico, com diferentes consistências (líquido e pastoso fino), com pacientes adultos mais velhos (entre 35 e 65 anos), observaram que o tempo de trânsito oral foi mais curto para o material viscoso do que para a água, mas o tempo de trânsito faríngeo não foi significativamente diferente para as duas consistências (HAMLET et al, 1996).

Autores referem, diferentemente, sobre a importância e influência da performance na função da deglutição em relação ao volume e consistência do bolo alimentar. KENDALL et al (2001), KIM et al (1994), não encontraram diferenças estatisticamente significantes no tempo do trânsito faríngeo com variações das consistências dos bolos. PEARLMAN et al (1993), concluíram que o efeito do volume 
do bolo alimentar afeta, significativamente, a duração da pressão “intrabolo” (pressão exercida pela língua no bolo e precedendo a geração de pressão faríngea). POUDEROUX \& KAHRILAS (1995), afirmaram que não há força de adaptação quanto à mudança de volume. A duração, mas não a extensão, do movimento do osso hióide, é influenciada pelo volume do bolo alimentar (PLANT, 1998). Não foi observado um efeito em características quantitativas da fase oral e faríngea da deglutição para volume diferentes de bolos, entretanto, o tempo de trânsito oral e faríngeo e clearance faríngeo foi, significativamente, maior para uma consistência mais espessa do que para o líquido (COOK et al, 1989; DANTAS et al, 1990; COOK et al, 1994).

ROBBINS et al (1992), referiram que o fluxo líquido requer um aumento do tempo para passar pelo E.E.S., enquanto que uma massa mais coesa requer um tempo mais breve na passagem, em contraposição, DANTAS et al (1990), referiram que o tempo de abertura do esfíncter é maior para pasta de bário que para o líquido.

HAMLET et al (1996), encontraram poucas diferenças no tempo de trânsito comparando deglutições de diferentes consistências.

ROBBINS et al (1992), ainda referiram que a duração do estágio de transição, duração da excursão velar, duração do trânsito faríngeo foram todas significantemente mais longas para o bolo semi-sólido do que para o bolo líquido.

FERRIOLLI et al (1996), em estudo da motilidade esofágica, não encontraram diferença significante na duração da onda de contração, velocidade e relaxamento do esfíncter esofágico inferior quando utilizados bolos líquidos com viscosidades distintas.

CHI-FISHMAN \& SONIES (2002), examinaram os efeitos de mudanças na viscosidade do bolo durante o movimento do osso hióide em 30 sujeitos saudáveis em 3 grupos de idade, e concluíram que mudanças sistemáticas na propriedade do bolo realmente afetaram o movimento do hióide. A variação de viscosidade afetou, significativamente, a fase voluntária da deglutição, no material menos espesso tendo um período de movimento do hióide mais longo no início da deglutição. Em contraste, o volume do bolo afetou, significativamente, muitos parâmetros de movimento, com um maior volume deglutido tendo amplitudes máximas maiores na trajetória do 
movimento de elevação, distância total de elevação, retorno à posição de repouso mais longa e maior velocidade no pico de elevação.

DODDS et al (1990a), relataram que o volume do bolo alimentar altera muito as variáveis da seqüência da deglutição, tal como o tempo e duração da abertura do E.E.S., mas isso não altera outras variáveis tais como a magnitude da contração faríngea.

SHAKER et al (1994), em seus estudos sobre os eventos biomecânicos da deglutição faríngea e primária, concluíram que o volume limiar de deglutição faríngea é significantemente mais alto em idosos do que em jovens, mas isso não é afetado pela posição do corpo ou temperatura do bolo alimentar.

DANTAS et al (1990), em seus estudos, utilizaram volumes de 2, 5, 10 e 20 ml, julgando-os como estarem dentro do alcance fisiológico. COOK et al (1989), descreveram que um volume de 20 ou $30 \mathrm{ml}$ quando utilizado pode causar stress no mecanismo da deglutição.

COOK et al (1994), encontraram, em seus estudos, uma diferença quanto ao clearance em diferentes volumes (5 e $10 \mathrm{ml}$ ), referindo que a diferença relacionada ao volume tenha sido devido à maior diluição da constância da dose de isótopo dentro de um bolo maior.

NILSSON et al (1996), descreveram que um volume de bolo maior tem mais dificuldade para entrar na faringe. CHI-FISHMAN \& SONIES (2002), afirmaram que a deglutição de um volume maior de alimento afeta a excursão do hióide, sendo que um volume maior tem um pico de velocidade maior (10 ml) na elevação do que um volume menor $(5 \mathrm{ml})$.

SHAKER et al (1994), afirmaram que um volume significantemente maior de líquido é requerido para disparar o reflexo da deglutição faríngea em idosos.

Poucos estudos retrataram diferenças na função da deglutição entre homens e mulheres. CHI-FISHMAN \& SONIES (2002), referiram duração mais longa do movimento do hióide no início da deglutição mais longa e uma redução geral de seu movimento para a deglutição orofaríngea em mulheres. ROBBINS et al (1992), referiram que a duração da abertura do E.E.S. foi, significantemente, maior em mulheres do que em homens, mas homens e mulheres apresentam performance 
similares em termos de duração e características de pressão da duração da deglutição orofaríngea.

Neste estudo, foi mantido um mesmo volume oferecido, com consistências variadas, com a finalidade de serem observadas mudanças na acomodação de bolos diferentes. Não foram avaliadas as possíveis diferenças entre sexos.

Na comparação entre os grupos durante a deglutição de alimento na consistência líquida (tabela 1), não houve diferença estatisticamente significante do trânsito oral do alimento entre os grupos, havendo diferença estatisticamente significante no resíduo oral entre o grupo de jovens e idosos sadios, não havendo diferença significante entre idosos sadios e doentes, e jovens e idosos doentes.

Na fase faríngea, também observa-se diferença estatisticamente significante apenas quanto ao resíduo, sendo estes resultados discordantes de dados de literatura que não referem um aumento normal na quantidade de resíduo faríngeo após a deglutição em adultos idosos (LOGEMANN, 1990). Não foi observado diferenças significativas entre trânsito e clearance; entretanto há um aumento no tempo dos mesmos entre jovens e idosos (sadios e doentes). A diferença estatisticamente significante ocorreu, mais uma vez, quanto ao resíduo de jovens e idosos sadios.

Ainda em relação à consistência líquida temos uma diferença significante no tempo de entrada do alimento no esôfago proximal entre jovens e idosos sadios.

Alguns autores relataram ser a duração da pressão faríngea afetada pela idade, com uma duração mais longa em idosos do que em jovens, referindo que a contração e o relaxamento do músculo podem estar relacionados a mudanças das propriedades viscoelásticas do tecido que são associadas com a idade (PEARLMAN et al, 1993).

Portanto, baseando-se em uma pressão reduzida na faringe, havendo um aumento no tempo de trânsito, esse bolo entrará com uma pressão menor no esôfago, aumentando assim, seu tempo de chegada. Autores referem um relaxamento insuficiente do esfíncter cricofaríngeo em idosos que poderia prejudicar o clearance da faringe após a deglutição (COOK et al, 1994; WEETCH, 2001), aumentando também o tempo de entrada do bolo no esôfago.

Quanto aos resultados para o alimento de consistência pastosa, as mesmas diferenças estatísticas foram observadas com diferença significante quanto ao resíduo oral e faríngeo do alimento. Entretanto, a diferença foi muito significante entre os 
grupos de jovens e idosos doentes, não havendo diferenças estatisticamente significantes entre os demais grupos.

A diferença dos tempos de entrada no esôfago proximal entre os grupos, para a consistência pastosa não foi significativa.

Os dados obtidos permitem concluir que o grupo de jovens apresenta um tempo reduzido de deglutição do alimento líquido em relação aos grupos de idosos sadios e doentes. Já estes últimos, apesar de também apresentarem tempos distintos entre as consistências (maior para o pastoso), não são tão discrepantes como o de jovens. Este fato justifica a diferença significativa entre jovens e idosos doentes por apresentarem médias mais distantes, provavelmente também porque entre os pacientes idosos alguns apresentaram alterações de deglutição comprovadas, o que, possivelmente, elevou seus tempos de trânsito, clearance e porcentagem de resíduo.

Alguns dados discordam com a literatura quanto à presença de resíduo oral maior em idosos observada durante estudo cintilográfico realizado com grupos de jovens e idosos saudáveis. COOK et al (1994), em seus estudos obtiveram que a contagem do resíduo faríngeo foi significativamente maior em idosos do que no grupo controle, não tendo influência no resíduo oral. Porém, este trabalho está em concordância com o autor quando refere que o tempo do trânsito oral na velhice é significativamente prolongado, assim como os tempos de trânsito e de clearance faríngeo.

LOGEMANN (1990), referiu que todas as mudanças temporais observadas com a idade são pequenas na magnitude, mas são estatisticamente significantes quando os valores de adultos idosos são comparados com o de adultos jovens.

Além disso, o envelhecimento normal, prejudicando a eficiência do clearance durante a deglutição, leva a pessoa a um tempo maior de exposição do bolo alimentar na hipofaringe. O clearance faríngeo prolongado e o aumento residual do bolo faríngeo poderiam causar problemas sutis nos idosos (COOK et al, 1994). Provavelmente, esses dados isolados não levam, necessariamente, o paciente a apresentar uma aspiração, mas estes são fatores passíveis de serem considerados quando se fala sobre alterações de deglutição em idosos.

Ao se comparar os parâmetros de estudo em cada grupo, isoladamente, quanto a cada consistência alimentar utilizada, obteve-se que no grupo de jovens não 
há diferenças estatisticamente significantes entre o trânsito e resíduo oral, mesmo sendo observados que o tempo de trânsito e a porcentagem de resíduo tenham sido maiores para a consistência pastosa.

Na fase faríngea, não foram obtidas diferenças significativas no trânsito do alimento, mas quando se faz referência ao clearance e resíduo, observa-se diferença estatisticamente significante, assim como no tempo de entrada do esôfago proximal (início da fase esofágica da deglutição). Mais uma vez pode-se reafirmar que a diferença encontrada deve-se à deglutição mais rápida do alimento líquido nessa faixa etária.

KENDALL et al, 2001, identificaram em seus estudos um aumento na velocidade do trânsito orofaríngeo para um bolo líquido, acreditando-se que esse bolo mova mais rapidamente devido à aplicação de uma força muscular dirigida menor, mas esse dado não foi estatisticamente significante.

No grupo de idosos sadios, não houve nenhuma diferença estatisticamente significante quando comparadas a deglutição de alimentos líquido e pastoso. Em contraposição, COOK et al (1994), descreveram que o processo normal de envelhecimento prejudica o clearance faríngeo de um bolo líquido durante a deglutição. Neste caso, pode-se pensar na pressão faríngea reduzida que o bolo líquido exerce.

Os dados do estudo mostraram que pacientes idosos não apresentam modificações na deglutição quando ingerem alimentos com diferentes viscosidades, o que, normalmente, deveria ocorrer, devido às características já descritas das diferenças quanto ao material ingerido. Autores descreveram que durante a deglutição o trato aerodigestivo alto humano responde a mudanças no volume do bolo e consistência de forma a manter um trânsito eficiente do bolo da cavidade oral ao esôfago proximal. A coordenação e força da acomodação da deglutição pode ser alterada de acordo com as características do bolo, tendo impacto direto em seu trânsito (KENDALL et al, 2001).

HAMLET et al (1996), estudaram a deglutição de diferentes viscosidades em adultos normais, e concluíram que o resíduo oral e faríngeo foi maior para o material viscoso após a primeira deglutição comparada com os resíduos seguidos da deglutição única feita para o líquido, discordando com os presentes dados, quanto ao 
grupo de idosos sadios, havendo, entretanto, esta correlação para os idosos doentes (internados).

As alterações de sensibilidade decorrentes do processo de envelhecimento, levando à não percepção adequada dos bolos, somados a mudanças fisiológicas, alterando toda a função, poderiam explicar a ausência de diferenças. Sabe-se, pois, que o tempo de trânsito do bolo, tempo de acomodação da deglutição, geração de pressão faríngea e força de contração muscular orofaríngea representam uma função de acomodação ao bolo durante a deglutição (KENDALL et al, 2001), o que está prejudicado no idoso.

Na comparação das fases, separadamente, quanto às consistências estudadas no grupo de pacientes idosos internados na enfermaria, obteve-se que na fase oral e faríngea, a diferença entre a porcentagem de resíduo apresenta ser estatisticamente significante entre os alimentos líquido e pastoso, não sendo observada diferença significante para os tempos de trânsito oral e faríngeo e clearance faríngeo.

Diferenças estatisticamente significantes também foram encontradas durante a entrada de alimento no esôfago proximal quando comparadas às duas consistências.

Essa diferença significativa pode ter sido causada pelo fato de, nesse grupo específico, existirem pacientes com patologias que acometem diretamente a função da deglutição, apresentando alterações. E, como descrito, há um aumento nas médias que, quando analisadas estatisticamente, resultaram em diferenças significantes, contrapondo NILSSON et al (1996), que referiram que idosos sintomáticos têm discreta alteração na função da deglutição quando comparados com jovens. É possível concluir que essas alterações não são discretas quando devidamente avaliadas.

A acomodação da deglutição com a análise do bolo, os efeitos de mudanças pela consistência do bolo em relação ao tempo de acomodação da deglutição e extensão e no trânsito do bolos, identifica casos nos quais o tempo e acomodação é alterado como resultado de doença ou usado como estratégia para vencer anormalidades funcionais (KENDALL et al, 2001).

Dessa forma, é visto que existem diferenças entre a deglutição nas faixas etárias distintas e que essa diferença se faz entre jovens e idosos. 
Um fato observado durante o trabalho foi a variabilidade entre os sujeitos idosos como sendo maior que em jovens quanto aos seus desempenhos, sendo necessário a obtenção de uma amostra maior de sujeitos.

Idosos têm menor capacidade de reserva, isto é, eles estão, durante condições normais, usando toda (ou próximo disso) sua própria capacidade funcional máxima (NILSSON et al, 1996). Portanto, uma simples referência quanto ao seu hábito alimentar deve ser bastante considerada.

O que se ressalta é que em pacientes idosos com predisposição a apresentarem dificuldades de deglutição, deve-se atentar para as patologias evidenciadas e diagnósticos em investigação. Isso significa que para pessoas que trabalham com pacientes geriátricos, demasiada atenção nunca será excesso de cuidado mas, com certeza, prevenção. Um simples quadro pode e deve ser questionado e investigado quanto à alimentação e deglutição pois, quando ocorrem doenças em um processo de deglutição fisiologicamente alterado, os sintomas decorrentes da disfagia tornam-se mais proeminentes. As doenças relacionadas com a idade podem pôr pacientes geriátricos num risco maior para a disfagia, comprometendo seu estado geral.

O objetivo deste trabalho foi avaliar a fase orofaríngea da deglutição de pacientes idosos, independentemente da presença de queixa de dificuldade de deglutição (disfagia). A justificativa para tanto era verificar se os idosos apresentavam mudanças de hábitos alimentares, adaptações aos pequenos defeitos da deglutição ou alterações durante a alimentação, ainda que não a designassem como dificuldades, pois a presença de disfagia pode levar ao desenvolvimento de quadros clínicos com agravamento de seu tratamento, piora na qualidade de vida e nos aspectos funcionais.

Observou-se, durante o estudo, que o processo da deglutição é afetado como um todo pela idade, com mudanças quanto às características gerais da função. Isto significa que, apesar dos idosos manterem, funcionalmente, todos os aspectos relacionados à deglutição, estes ocorrem diferentemente do observado em pessoas mais jovens, o que, comprovadamente, ocorre devido a mudanças fisiológicas e estruturais do organismo em processo de envelhecimento. Pessoas que têm mais idade deglutem mais lentamente, sendo o desempenho da deglutição em pessoas 
idosas saudáveis mais lento quando comparado ao dos indivíduos mais jovens. Em termos de implicações clínicas, pode-se afirmar que a deglutição permanece segura nos idosos sadios. O fato de lentificar a deglutição pode permitir um tempo para garantir que a deglutição ocorra eficientemente. Isto significa que os idosos podem e devem se esforçar para se alimentarem de forma segura e sem desconfortos.

A deglutição de um idoso internado não se torna pior pela condição de estar fragilizado (fato este que o levou à internação). As mudanças ocorrem naturalmente no processo de envelhecimento. Entretanto, isso não exime o médico ou outro profissional a não se atentar às alterações de deglutição pois, uma vez que elas existam dentro de um quadro que não oferece condições clínicas favoráveis, terão, certamente, conseqüências bastante prejudiciais ao mesmo. 
CONCLUSÃO 
- $\quad$ As queixas de disfagia foram raras na população estudada (10\%).

- Idosos doentes, quando não apresentam queixas de disfagia e não tiveram doenças que cursam com possíveis dificuldades de deglutição, não tiveram parâmetros da deglutição significativamente diferentes em relação a idosos saudáveis.

- A deglutição é afetada como um todo pela idade, com mudanças quanto às características gerais da função, diferenciando-se da deglutição observada em pessoas mais jovens. Pessoas idosas deglutem mais lentamente, entretanto, a deglutição permanece segura nos idosos pois, o fato de lentificar a deglutição pode permitir um tempo para garantir que a deglutição ocorra eficientemente.

- Referências relacionadas às mudanças no hábito alimentar em idosos devem ser cuidadosamente questionadas pelos profissionais que trabalham com a população geriátrica, devido ao fato desses pacientes apresentarem histórias pouco esclarecedoras.

- A avaliação clínica fonoaudiológica da deglutição, em idosos internados, deve fazer parte da definição do diagnóstico diferencial, principalmente em quadros que sugerem dificuldades de deglutição e que apresentam sinais discretos de alterações.

- As dificuldades de deglutição, quando referidas e adequadamente caracterizadas pelos idosos, já fazem parte de um quadro complexo de um estado patológico e, muitas vezes, irreversível, devido ao fato dessa população, pelo próprio processo do envelhecimento, já ser fragilizada.

- A técnica cintilográfica da deglutição é sensível a sutis mudanças relacionadas ao trânsito, clearance e resíduo alimentar.

- Idosos saudáveis apresentam maior resíduo oral e faríngeo de alimento na consistência líquida quando comparados com jovens, sendo o tempo de entrada no esôfago proximal maior nos dois grupos de idosos, pacientes e voluntários, em relação aos jovens, não havendo diferença significativa quando idosos saudáveis e doentes são comparados entre si.

- O resíduo oral para o alimento na consistência pastosa apresenta uma tendência em ser maior no grupo de idosos saudáveis quando comparado ao grupo de jovens. Com significância estatística, o resíduo faríngeo é maior no grupo de idosos 
doentes em relação aos jovens. Não há diferença estatisticamente significante entre os grupos estudados, durante o tempo de entrada no esôfago proximal.

- Embora as diferenças de trânsito oral e faríngeo para ambas as consistências não sejam significativas, observa-se uma variação entre os grupos.

- Jovens deglutem mais rapidamente para a consistência líquida apresentando menor resíduo oral, sem significância estatística. O tempo de clearance, o resíduo faríngeo e o tempo de entrada no esôfago proximal foram maiores para o alimento na consistência pastosa.

- Para o grupo de voluntários idosos, há maior tempo de trânsito oral e faríngeo e de clearance, maior resíduo oral e faríngeo, tempo maior de entrada no esôfago proximal para o alimento na consistência pastosa, sem significância estatística.

- No grupo de idosos internados, há um aumento no tempo de trânsito oral para o alimento pastoso sem significância estatística, com maior resíduo para esta consistência sendo estatisticamente significante. Na fase faríngea, o trânsito ocorre mais rapidamente para o alimento pastoso com tempo de clearance maior e maior tempo de entrada no esôfago proximal.

- O tempo de trânsito oral em jovens para um volume de $5 \mathrm{ml}$ de alimento na consistência líquida foi de 0,55 segundos com uma média de 7,84\% de resíduo oral; 0,44 segundos de trânsito, 0,71 segundos de clearance e 5,04\% de resíduo faríngeo; 0,20 segundos de tempo de entrada no esôfago proximal. Para a consistência pastosa foi, respectivamente, 0,63 segundos e 9,13\%; 0,49 segundos, 0,88 segundos e 10,95\%; e 0,51 segundos.

- O tempo de trânsito oral em idosos para um volume de $5 \mathrm{ml}$ de alimento na consistência líquida foi de 0,61 segundos com uma média de 17,56\% de resíduo oral; 0,46 segundos de trânsito, 0,81 segundos de clearance e 10,86\% de resíduo faríngeo; 0,37 segundos de tempo de entrada no esôfago proximal. Para a consistência pastosa foi, respectivamente, 0,84 segundos e 15,40\%; 0,47 segundos, 0,91 segundos e $10,88 \%$; e 0,42 segundos. 
ANEXOS 


\section{ANEXO A: Carta de Aprovação do Comitê de Ética em Pesquisa}

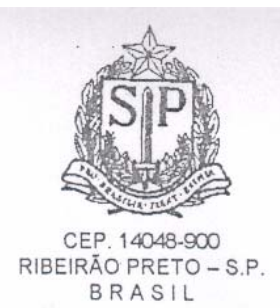

HOSPITAL DAS CLINICAS DA FACULDADE DE MEDICINA DE RIBEIRÃO PRETO DA UNIVERSIDADE DE SÃO PAULO

Ribeirão Preto, 26
CAMPUS UNIVERSITÁRIO - MONTE ALEGRE FONE: $62-1000$ - FAX (016) $33-1144$

Oficio $n^{\circ} 1540 / 2001$

$\mathrm{CEP} / \mathrm{SPC}$

Prezada Senhora:

O trabalho intitulado "AVALIAÇÃo

ESTRUTURAL E FUNCIONAL DA DEGLUTIÇÃO DE IDOSOS, COM E SEM QUEIXAS DE DISFAGIA, INTERNADOS EM UMA ENFERMARIA GERIÁTRICA", foi analisado pelo Comitê de Ética em Pesquisa, em sua $110^{a}$ Reunião Ordinária realizada em 04/06/2001, e enquadrado na categoria: APROVADO, de acordo com o Processo HCRP n³ 3766/2001.

Aproveito a oportunidade para apresentar a Vossa Senhoria protestos de estima e consideração.

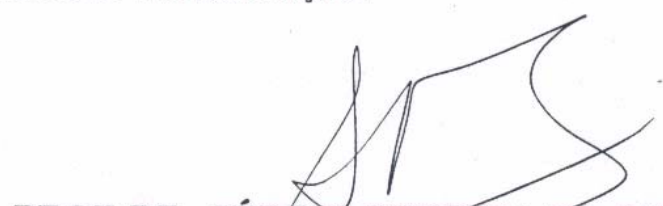

PROF.DR. SÉRGIO PEREIRA DA CUNHA

Coordenador do Comitê de Ética em Pesquisa do HCFMRP-USP 
ANEXO B: Termo de Consentimento Livre e Esclarecido

HOSPITAL DAS CLÍNICAS DA FACULDADE DE MEDICINA

DE RIBEIRÃO PRETO DA UNIVERSIDADE DE SÃO PAULO

\section{TERMO DE CONSENTIMENTO LIVRE E ESCLARECIDO}

EU

abaixo assinado, tendo sido devidamente esclarecido sobre todas as condições que constam do documento "ESCLARECIMENTOS AO SUJEITO DA PESQUISA", de que trata o Projeto de Pesquisa intitulado "Avaliação Estrutural e Funcional da Deglutição de Idosos, com e sem queixas de disfagia, internados em uma Enfermaria Geriátrica" que tem como pesquisador responsável o(a) Sr.(a) PAULA DE CARVALHO MACEDO ISSA especialmente no que diz respeito ao objetivo da pesquisa, aos procedimentos que serei submetido, aos riscos e aos benefícios, à forma de ressarcimento no caso de eventuais despesas, bem como a forma de indenização por danos decorrentes da pesquisa, declaro que tenho pleno conhecimento dos direitos e das condições que me foram assegurados, a seguir relacionados:

1. A garantia de receber a resposta a qualquer pergunta ou esclarecimento de qualquer dúvida a respeito dos procedimentos, riscos, benefícios e de outras situações relacionadas com a pesquisa e o tratamento a que serei submetido.

2. A liberdade de retirar o meu consentimento e deixar de participar do estudo, a qualquer momento, sem que isso traga prejuízo à continuidade do meu tratamento.

3. A segurança de que não serei identificado e que será mantido o caráter confidencial da informação relacionada a minha privacidade.

4. O compromisso de que me será prestada informação atualizada durante o estudo, ainda que esta possa afetar a minha vontade de continuar dele participando.

5. O compromisso de que serei devidamente acompanhado e assistido durante todo o período de minha participação no projeto, bem como de que será garantida a continuidade do meu tratamento, após a conclusão dos trabalhos da pesquisa.

Declaro, ainda, que concordo inteiramente com as condições que me foram apresentadas e que, livremente, manifesto a minha vontade em participar do referido projeto.

Ribeirão Preto, de de 


\section{ANEXO C: Avaliação Clínica da Deglutição \\ Fga Paula de Carvalho Macedo Issa}

\section{Dados de identificação}

Nome:

$\mathrm{n}^{\mathrm{o}}$ :

D.N.:

idade:

Data da internação:

Data da alta:

Acompanhante:

Data da avaliação:

Médico Responsável:

\section{Dados de Anamnese}

Etiologia: HD:

\section{História Clínica}

- Quanto tempo leva, habitualmente, para comer uma refeição e como era antes?

- Houve modificação na dieta? Qual a consistência que habitualmente está utilizando?

( ) sem restrição a qualquer consistência; ( ) líquida; ( ) pastosa fina (iogurte); pastosa engrossada (pudim); ( ) sólida; ( ) outros

- Existe dificuldade para iniciar a deglutição?

- Há necessidade de deglutir mais de uma vez? Quantas?

- Sobra resíduos na língua ou nos vestíbulos após deglutir?

- Há refluxo nasal?

- Há sensação de parada do alimento?

- Teve perda de peso atualmente?

- Há pigarro depois que come ou bebe algo?

- Há presença de tosse antes, durante ou após a deglutição? Quando?

- Há mudança na qualidade vocal após a deglutição?

- Apresenta infecções respiratórias freqüentes?

- Ocorreram quadros de pneumonia?

- Faz uso de medicamentos? Quais?

- Apresenta outras doenças? Quais?

\section{Avaliação Estrutural}

- Estado do paciente
( ) sonolento
( ) alerta
( ) outro 
- Compreensão

( ) adequada

( ) alterada

- Expressão

( ) adequada

( ) alterada

- Dentição

( ) presença

- Estado de conservação:

( ) BEC

( ) ausência

- Prótese dentária:

( ) não usa

( ) MEC

( ) parcial inferior ( ) total superior

( ) parcial superior ( ) não está com a prótese

( ) bem adaptada ( ) inferior ( ) superior

( ) mal adaptada ( ) inferior ( ) superior

- Retirada da prótese na internação:

( ) $\operatorname{sim}$

( ) não

- Presença de ulcerações na cavidade oral:

( ) $\operatorname{sim}$

( ) não

- Saliva:

( ) pouca

( ) normal

( ) excessiva

- Condições de higienização: ( ) paciente realiza sozinho (a)

( ) higiene com supervisão

( ) não realiza higiene oral

( ) cuidador realiza a higiene

- Deglutição espontânea de saliva: ( ) sim

( ) não

- Oclusão de lábios:

( ) $\operatorname{sim}$

( ) não

- Força de língua:

( ) 1/3 médio ( ) 1/3 anterior ( ) 1/3 posterior

( ) ausência ( ) impossível avaliar

- Mobilidade para deglutição:

( ) $\operatorname{sim} \quad$ ( ) não

( ) reduzida ( ) impossível avaliar

- Sensibilidade:

( ) $\operatorname{sim}$ ( ) não

( ) alterada ( ) impossível avaliar

- Abertura de mandíbula:

( ) $\operatorname{sim}$

( ) não

- Sensibilidade de palato mole:

( ) $\operatorname{sim}$

( ) não

- Tosse:

( ) $\operatorname{sim}$

( ) não

( ) impossível avaliar

- Dieta:

Tipo de alimentação de entrada: ( ) nasoenteral

( ) insuficiente

( ) gastrostomia

( ) oral

( ) parenteral

( ) jejunostomia

( ) total

Consistência:

( ) líquido

( ) parcial

( ) pastoso fino

( ) pastoso grosso

( ) sólido

( ) nutricional caseira (prescrita)

( ) sem restrições

Postura durante alimentação:

Usa manobras compensatórias:

Resíduo na cavidade oral:

Resíduo na cavidade oral: ( ) sim

Presença de engasgos: ( ) sim

( ) não

( ) sem dados

( ) não

( ) sem dados 


$\begin{array}{llll}\text { Presença de tosse: } & \text { ( ) sim } & \text { ( ) não } & \text { ( ) sem dados } \\ \text { Presença de fadiga: } & \text { ( ) sim } & \text { ( ) não } & \text { ( ) sem dados }\end{array}$

\section{Avaliação funcional ( $5 \mathrm{ml}$ de líquido e $5 \mathrm{ml}$ de pastoso):}

- Postura durante a alimentação:

- Ausculta cervical sem a oferta do alimento: ( )positiva ( ) negativa

- Qualidade vocal após a deglutição: ( ) sem alteração ( ) com alteração ( ) impossível avaliar

- Ausculta cervical com a oferta do alimento ( ) positiva ( ) negativa

- Abre a boca voluntariamente? ( ) sim ( ) não

- Apresenta reflexo de mordida? ( ) sim ( ) não

- Vedamento labial adequado? ( ) sim ( ) não

- Apresenta movimentação compensatória ao deglutir? ( ) sim ( ) não Qual?

- Resíduo na cavidade oral/estase?( ) sim
( ) não
OBS:

- Apresentou engasgos?

( ) $\operatorname{sim}$

( ) não

OBS:

- Apresentou tosse?

( ) $\operatorname{sim}$

( ) não

OBS:

- Apresentou fadiga?

( ) $\operatorname{sim}$

( ) não

OBS:

5. Conclusão da avaliação clínica (funcional): ( ) normal （ ）alterada 
REFERÊNCIAS BIBLIOGRÁFICAS 
ALBERTO, E. A. Psicologia da saúde e o idoso hospitalizado: resgate de uma vida esquecida. In: ANGERAMI-CAMON, V.A. (org.). Urgências Psicológicas no Hospital. Pioneira Psicologia, São Paulo, cap. 7, pp. 123-70, 1998.

ALENCAR, Y. M. G.; CURIATI, J. A. E. Envelhecimento do aparelho digestivo. In: FILHO, E. T. C.; NETTO, M. P. Geriatria: Fundamentos, Clínica e Terapêutica, ed Atheneu, São Paulo, cap.14, pp. 203-08, 1998.

AMANCIO, A. Problemas neurológicos na velhice. In: AMANCIO, A.; CAVALCANTI, P. C. U. Clínica Geriátrica. Livraria Atheneu, cap. 9, pp. 57-71, 1975.

ANDERSON, E. L. Eating patterns before and after dentures. Journal of The American Dietetic Association, vol. 58, pp. 421-26, may 1971.

BESDINE, R. W. Introdução. In: ABRAMS, B. A.; BERKOW, R. Manual Merk de Geriatria, ed. Roca, pp. 2-4, 1995.

BILTON T.; SOARES, L. T.; TEGA, L. V.; SANTOS, C. A. F. Acompanhamento interdisciplinar de idosos fragilizados. Distúrbios da Comunicação, São Paulo, 11(1): 85-110, 1999.

BRANDT, L. J. Gastrointestinal disorders in the elderly. In: ROSSMAN, I. Clinical Geriatrics, $3^{\text {rd }}$ edition, pp. 260-77, 1986.

CALHOUN, K. H.; GIBSON, B.; HARTLEY, L.; MINTON, J.; HOKANSON, J. A. Age-related changes in oral sensation. Laryngoscope 102, pp. 109-16, feb 1992.

CASTELL, D. O. Distúrbios do trato gastrointestinal. In: ABRAMS, B. A.; BERKOW, R. Manual Merk de Geriatria, ed. Roca, pp. 530-41, 1995. 
CHI-FISHMAN, G.; SONIES, B. C. Effects of systematic bolus viscosity and volume changes on hyoid movement kinematics. Dysphagia 17: 278-87, 2002.

COOK, I. J.; DODDS, W. J.; DANTAS, R. O.; KERN, M. K.; MASSEY, B. T.; SHAKER, R.; HOGAN, W. J. Timing of videofluoroscopic, manometric events, and bolus transit during the oral and pharyngeal phases of swallowing. Dysphagia, 4: 815, 1989.

COOK, I. J.; WELTMAN, M. D.; WALLACE, K.; SHAW, D. W.; McKAY, E.; SMART, R. C.; BUTLER, S. P. Influence of aging on oral-pharyngeal bolus transit and clearance during swallowing: scintigraphic study. American Journal of Physiology, 266: G 972-77, 1994.

CUNHA, C. C.; ZUCCOLOTTO, M. C. C. Prótese total: avaliação e tratamento dos usuários. In: FELÍCIO, C. M. Fonoaudiologia aplicada a casos odontológicos: motricidade oral e audiologia, ed. Pancast, pp. 198-222, 1999.

CURIATI, J. A. E. Principais afecções do aparelho digestivo. In: FILHO, E. T. C.; NETTO, M. P. Geriatria - Fundamentos, Clínica e Terapêutica, ed. Atheneu, São Paulo, pp. 209-19, 1998.

DANTAS, R. O. Papel da manometria no diagnóstico das doenças motoras do esôfago. In: MACEDO-FILHO, E. M.; PISSANI, J. C.; CARNEIRO, J.; GOMES, G. Disfagia: Abordagem Multidisciplinar. 2a ed. Frontis editorial, pp.139-142, 1998b.

DANTAS, R. O.; KERN, M. K.; MASSEY, B. T.; DODDS, W. J.; KAHRILAS, P. J.; BRASSEUR, J. G.; COOK, I. J.; LANG, I. M. Effect of swallowed bolus variables on oral and paharyngeal phases of swallowing. American Journal Physiology. 258: G675 - G681, 1990. 
DODDS, W. J.; STEWART, E. T.; LOGEMANN, J. A. Physiology and radiology of the normal oral and phayngeal phases of swallowing. American Journal of Radiology, 154: 953-963, may 1990a.

DODDS, W. J.; LOGEMANN, J. A.; STEWART, E. T. Radiologic assessment of abnormal oral and pharyngeal phases of swallowing. American Journal of Radiology, 154: 965-74, may 1990b.

EKBERG, O.; FEINBERG, M. J. Altered swallowing function in elderly patients without dysphagia, radiology findings in 56 cases. American Journal Roentgenology 156: 1181-84, 1991.

EKBERG, O.; OLSSON, R. Dynamic radiology of swallowing disorders. Endoscopy, 29: 439-446, 1997.

FARRELL, J. J.; FRIEDMAN, L. S. Esophageal diseases in the elderly. Clinical Perspectives in Gastroenterology, 4 (6): 363-68, 2001.

FEIJÓ, A. V.; RIEDER, C. R. M. Distúrbios da deglutição em idosos. In: JACOBI, J. S.; LEVY, D. S.; CORREA DA SILVA, L. M. Disfagia: Avaliação e Tratamento. Ed. Revinter, pp. 225-32, 2003.

FEINBERG, M. J.; EKBERG, O. Videofluoroscopy in the elderly patients with aspirations: importance of evaluating both oral and pharyngeal stages of deglutition. American Journal Roentgenology 156: 293-96, 1991.

FERRIOLLI, E.; DANTAS, R. O.; OLIVEIRA, R. B.; BRAGA, F. J. N. H. The influence of ageing after ingestion of liquids with different viscosities. European Journal of Gastroenterology \& Hepatology, 8: 793-98, 1996. 
FURKIM, A. M. Fonoterapia nas disfagias orofaríngeas. In: FURKIM, A. M; SANTINI, C. S. Disfagias Orofaríngeas. Carapicuiba, SP: Pró-Fono, pp. 229-58, 1999.

GONÇALVES, M. I. R.; VIDIGAL, M. L. N. Avaliação videofluoroscópica das disfagias. In: FURKIM, A. M; SANTINI, C. S. Disfagias Orofaríngeas. Carapicuiba, SP: Pró-Fono, pp. 189-202, 1999.

GORMAN, R. C.; MORRIS, J. B.; KAISER, L. R. Esophageal disease in the elderly patient. In: ZENIL-MAN, M.; ROSLYN, J. J. The Surgical Clinics of North America 74: 93-112, 1994.

GROHER, M. E. Distúrbios de deglutição em idosos. In: FURKIM, A. M.; SANTINI, C. S. Disfagias Orofaríngeas. Pró-Fono, pp. 97-107, 1999.

HAMLET, S.; CHOI, J.; ZORMEIER, M.; SHAMSA, F.; STACHLER, R.; MUZ, J.; JONES, L. Normal adult swallowing of liquid and viscous material: scintigraphic data on bolus transit and oropharyngeal residues. Dysphagia 11: 41-47, 1996.

HEATH, M. R. The effect of maximun biting force and bone loss upon masticatory function and dietary selection of the elderly. Int Dent J 32 (4): 345-56, 1982.

HOLLINSHED, H.. Anatomy of the phariynx and esophagus, English, vol. 3, cap. 3, 1994.

HOLT, S.; MIRON, S. D.; DIAZ, M. C.; SHIELDS, R.; INGRAHAM, D.; BELLON, E. M. Scintigraphic measurement of oropharyngeal transit in man. Digestive Diseases and Sciences, 35 (10): 1198-204, 1990.

KAZEM, I. A new scintigraphic technique for the study of the study of the esophagus. The American Journal of Roentgenology, Radium Therapy and Nuclear Medicine, vol 115(4): pp. 681-88, 1972. 
KENDALL, K. A.; LEONARD, R. J.; McKenZIE, S. W. Accommodation to changes in bolus viscosity in normal deglutition: a videofluoroscopic study. Annals Otology, Rhinology and Laryngology 110: 1059-65, 2001.

KIM, C. H.; HSU, J. J.; O’CONNOR, M. K.; WEAVER, A. L.; BROWN, M. L.; ZINSMEISTER, A. R. Effect of viscosity on oropharyngeal and esophageal emptying in man. Digestive Diseases and Sciences, vol 39, $\mathrm{n}^{\circ} 1$, pp. 189-92, jan 1994.

LANGMORE, S. E.; TERPENNING, M. S.; SCHORK, A.; CHEN, Y.; MURRAY, J. T.; LOPATIN, D.; LOESCHE, W. J. Predictors of aspiration pneumonia: how important is dysphagia? Dysphagia 13: 69-81, 1998.

LANGMORE, S. E.; SKARUPSKI, K. A.; PARK, P. S.; FRIES, B. E. Predictors of aspiration pneumonia in nursing home residents. Dysphagia 17: 298-307, 2002.

LEÃO, R. Recorte e Sobreposição de Imagens Originais de 1983 e 1990 dos Avós Alexandrina, Issa e Julia. beto@ardesigner.com.br, 2003.

LEEMING, J. T.; WEBSTER, S. P. G.; DYMOCK, I. W. Aparato digestivo. In: BROCKLEHURST, J. C. Tratado de Clínica Geriátrica y Gerontologia. Editorial Médica Panamericana, pp. 314-20, 1975.

LOGEMANN, J. A. Effects of aging on the swallowing mechanism. Otolaryngologic Clinic of North America, 23 (6): 1045-56, 1990.

MACEDO-FILHO, E. D. Conceitos e fisiologia aplicada da deglutição. In: MACEDO-FILHO, E.; PISSANI, J. C.; CARNEIRO, J.; GOMES, G. Disfagia: Abordagem Multidisciplinar, Centro de Pesquisa e Tratamento da Disfagia. Frôntis Editorial, 2a ed., pp. 3-18, 1998. 
MANDEL, I. D. The role of saliva in maintaining oral homeostasis. The Journal of American Dental Association, vol. 119, pp. 298-304, aug. 1989.

MANRIQUE, D. Avaliação otorrinolaringológica da deglutição. In: FURKIM, A. M; SANTINI, C. S. Disfagias Orofaríngeas. Carapicuiba, SP: Pró-Fono, pp. 49-60, 1999.

MARCHESAN, I. Q. Disfagia. In: MARCHESAN, I. Q.; BOLAFFI, C.; GOMES, I. C. D.; ZORZI, J. L. Tópicos em Fonoaudiologia, vol. II - CEFAC, ed. Lovise, pp.161-6, 1995.

MARTIN, B. J. W.; LOGEMANN, J.; SHAKER, R.; DOODS, W. The coordenation between respiration and swallow; respiratory relationships and temporal integration. Journal of Applied Physiology 72: 714, 1994.

MORLEY, J. E. Weight problems. In: YOSHIKAWA, T. T.; COBBS, E. L.; BRUMMEL-SMITH, K. Ambulatory Geriatric Care, pp. 437-47, 1993.

MURDOCH, B.E. Desenvolvimento da Fala e Distúrbios da Linguagem: uma Visão Neuroanatômica e Funcional, ed. Revinter, 1997.

NASI, A.; CARVALHO, L. E. B.; CECCONELLO, I.; PINOTTI, H. W. Disfagia no indivíduo idoso. In: FILHO, E. M.; PISSANI, J. C.; CARNEIRO, J.; GOMES, G. Disfagia: Abordagem Multidisciplinar. 2a ed. Frontis editorial, pp.47-62, 1998.

NILSSON, H.; EKBERG, O.; OLSSON, R.; HINDFELT, B. Quantitative aspects of swallowing in en elderly nondysphagic population. Dysphagia 11: 180-84, 1996.

NOBRE E SOUZA, M. A.; DANTAS, R. O.; OLIVEIRA, R. B.; BRAGA, F. J. H. N. A scintigraphic study of oropharyngeal swallowing dynamics in Chagas' disease. Neurogastroenterology Motility, 12(4): 335-41, 2000. 
PEARLMAN, A. L.; SCHULTZ, J. G.; VANDAELE, D. J. Effects of age, gender, bolus volume, and bolus viscosity on oropharyngeal pressure during swallowing. Journal Applied Physiology 75: pp. 33-7, 1993.

PLANT, R. L. Anatomy and physiology of swallowing in adults and geriatrics. Otolaryngologic Clinics of North America, vol. 31, nº 3, pp. 477-88, june 1998.

POUDEROUX, P.; KAHRILAS, P. J. Deglutitive tongue force modulation by volition, volume and viscosity in humans. Gastroenterology. 108: p. 1418-1426, 1995.

QUINTELLA, T.; SILVA, A. A.; BOTELHO, M. I. M. R. Distúrbios da deglutição (e aspiração) na infância. In: FURKIM, A. M.; SANTINI, C. S. Disfagias Orofaríngeas. Pró-Fono, pp. 61-96, 1999.

RIBEIRO, A. Aspectos biológicos do envelhecimento. In: RUSSO, I. P. Intervenção Fonoaudiológica na Terceira Idade. Ed. Revinter, pp. 1-11, 1999.

ROBBINS, J.; HAMILTON, J.; LOF, G. L.; KEMPSTER, G. B. Oropharyngeal swallowing in normal adults of different ages. Gastroenterology, 103: 823-29, 1992.

ROLANDELLI, R. H.; ULLRICH, J. R. Nutricional suppot in the frail elderly surgical patient. In: ZENILMAN, M.; ROSLYN, J. J. The Surgical Clinics of North America. Guest editors, vol. 74(1), pp. 79-92, 1994.

ROSSMAN, I. Common symptoms and complaints. Clinical Geriatrics, $3^{\text {rd }}$ edition, pp. 138-49, 1986.

RUSSEL, C. O. H.; HILL, L. D.; HOLMES III, E. R.; HULL, D. A.; GANNON, R.; POPE II, C. E. Radionuclide transit: a sensitive screening test for esophageal dysfunction. Gastroenterology, 80: 887-92, 1981. 
SANTINI, C. S. Disfagia Neurogênica. In: FURKIM, A. M; SANTINI, C. S. Disfagias Orofaríngeas. Carapicuiba, SP: Pró-Fono, pp. 19-34, 1999.

SCHINDLER, J. S.; KELLY, J. H. Swallowing disorders in the elderly. Laryngoscope, 112 (4): p. 589-602, april 2002.

SCHNEIDER, J. Manual de Geriatria, ed Roca, São Paulo, 1985.

SHAKER, R.; LANG, I. M. Aging and deglutitive motor function, effect of aging on the deglutitive oral, pharyngeal and esophageal motor function. Dysphagia, 9: 221, 1994.

SHAKER, R.; REN, J.; ZAMIR, Z.; SARNA, A.; LIU, J.; SUI, Z.. Effect of aging, position and temperature on the threshold volume triggering pharyngeal swallows. Gastroenterology. 107: 306-402, 1994.

SHAY, K; SHIP, J. A. The importance of oral health in the older patient. Journal of American Geriatrics Society. 43: 1414-1422, 1995.

SILVA-NETTO, C. R. S. Deglutição na Criança, no Adulto e no Idoso: Fundamentos para Odontologia e Fonoaudiologia, ed. Lovise, 2003.

STEELE, C. M.; GREENWOOD, C.; ENS, I.; ROBERSTSON, C.; SEIDMANCARLSON, R. Mealtime difficulties in a home for the aged: not just dysphagia. Dysphagia, 12: 43-50, 1997.

VIDIGAL, M. L. N.; RODRIGUES, K. A.; NASRI, F. Efeitos do envelhecimento sadio na deglutição. In: HERNANDEZ, A. M.; MARCHESAN, I. Atuação Fonoaudiológica no Ambiente Hospitalar, Ed. Revinter, pp. 61-66, 2001.

WAYLER, A. H.; MUENCH, M. E.; KAPUR, K. K.; CHAUNCEY, H. H.. Masticatory performance and food acceptability in persons with removable partial 
dentures, full dentures and intact natural dentition. Journal of Gerontology, vol. 39, no 3, pp. 284-89, 1984.

WEETCH, R. Fedding problems in elderly patients. Nursing Times, 97(16): 60-1, april 2001.

ZOHAR, Y.; GRUSKO, I.; SULKES, J.; MELLOUL, M. M. Oropharyngeal scintigraphy: a computerized analysis of swallowing in patients with obstructive sleep apnea. The Laryngoscope 108, pp. 37-41, 1998. 
BIBLIOGRAFIA CONSULTADA 
American gastroenterological association medical position statement of oropharyngeal dysphagia. Gastroenterology. 116: 452-454, 1999.

Anatomy of the phariynnx and esophagus. vol 3, cap.3, 1994.

Presbyesophagus cineradiografic manifestation. Radiology 82: 463-7, 1964.

. Universidade de São Paulo. Sistema integrado de bibliotecas / Centro de Computação de São Carlos. Diretrizes para apresentação de teses e dissertações à USP: documento eletrônico ou impresso - São Paulo: SIBi/USP, 16p., 2001.

BASTIAN, R. W.; RIGGS, L. C. Role of sensation in swallowing function. Laryngoscope, 109: 1974-1977, dec. 1999.

BLOEM, B. R.; LAGAAY, A. M.; VANBECK, W.; HANN, J.; ROOS, R. A. C.; WINTZEN, A. R. Prevalence of subjective dysphagia in comunity residents aged over 87. British Medical Journal, 300: 271, 1990.

CASTELL, D. O. Eating and swallowing disorders in the elderly. Practic Gastroenterol 12: 32-37, s/a.

CASTELL, D. O. Esophageal disorders in the elderly. Gastroenterology Clinics of North America 19: 235-55, 1990.

CHAUHAN, J.; HAWRYSH, Z.; GEE, M.; VOLICER, R. M.; ADELMAN, R. G. Age related olfactory and taste changes and interrelationships between taste and nutrition. Journal of American Dietetic Association 87: 1543, 1987.

DANTAS, R. O. Disfagia orofaríngea. In: MACEDO-FILHO, E. M.; PISSANI, J. C.; CARNEIRO, J.; GOMES, G. Disfagia: Abordagem Multidisciplinar. $2^{a}$ ed. Frontis editorial, pp.19-27, 1998a. 
FEINBERG, M. J.; KNEBL, J.; TULLY, J. Prandial aspiration and pneumonia in an elderly population followed over 3 years. Dysphagia, 11: 104, 1996.

FINEGOLD, M. S. Aspiration pneumonia. Reviews of Infection Diseases, 13 (supp. 9), 5737-42, 1991.

FURKIM, A. M.; SILVA, R. G. Programas de reabilitação em disfagia neurogênica. Frontis editorial, 1999.

HOLLIS, J. B.; CASTELL, D. O. Esophageal function in elderly men - A new look at “presbyesophagus”. Annals of Internal Medicine 80: 371-4, 1974.

MARTIN, J. H.; DIAMOND, B.; AVIV, J. E.; JONES, M. E.; KEEN, M. S.; BLITZER, A.. Age-related changes in pharyngeal and supraglottic sensation. Annals of Otology, Rinology and Laryngology 103: pp. 749-52, 1994.

McKAIG, T. N. Ausculta cervical e torácica. In: FURKIM, A. M.; SANTINI, C. S. Disfagias Orofaríngeas. Pró-Fono, pp. 61-96, 1999.

MOLD, J. W.; REED, L. E.; DAVIS, A. B.; ALLEN, M. L.; DECKTOR, D. L.; ROBINSON, M.. Prevalence of gastroesophageal reflux in elderly patient in a primary care setting. The American Journal of Gastroenterology, 86 (8): pp. 96570, 1991.

PATERSON, W. G. Dysphagia in the elderly. Canadian Family Physician 42: 92532, 1996.

ROTHER, E. T.; BRAGA, M. E. R. Como elaborar sua tese: estrutura e referências, São Paulo, 86 p., 2001.

SHITH, N.; DINER, W. C. Swallowing problems in the elderly. Dysphagia, 4: 209, 1988. 
SIEBENS, H.; TRIPE, E.; SIEBENS, A. A.; COOK, F.; ANSHEN, S.; HANAUER, R.; OSTER, G. Correlates and consequences of eating dependency in institucionalized elderly. The Journal American Geriatric Society, 34: 192, 1986.

SILVA, R. G.; VIEIRA, M. M. Disfagia Orofaríngea Neurogênica em Adultos PósAcidente Vascular Encefálico: Identificação e Classificação. In: FILHO, E. M.; PISSANI, J. C.; CARNEIRO, J.; GOMES, G. Disfagia: Abordagem Multidisciplinar. $2^{\text {a }}$ ed. Frontis editorial, pp.29-46, 1998.

SOERGEL, K. H.; ZBORALSKE, F. F.; AMBERG, J. R. Presbyesophagus: esophageal motility in nonagerians. Journal of Clinical Investigation, 43(7):14729, 1964.

SONIES, B. L.; PARENT, L. J.; MORRISH; BAUM, B. Duration aspects of the oropharyngeal phase of swallowing in normal adults. Dysphagia, 3: 1, 1988.

TRACY, J. F.; LOGEMANN, J. A.; KAHRILAS, P. I.; JACOB, P.; KOBARA, M.; KRUGLER, C. Preliminary observations on the effects of the age on oropharyngeal deglution. Dysphagia. 4: 90-4, 1989.

WALLACE, J. I.; SCHWARTZ, R. S.; LACROIX, A. Z.; UHLMANN, R. F.; PEARLMAN, R. A.. Involuntary weight loss in older outpatients: incidence and clinical significance. Journal of The American Geriatrics Society, 43 (4): pp. 329337, 1995.

ZBORALSKE, F. F.; AMBERG, J. R.; SOERGEL, K. H. Presbyesophagus cineradiographic manifestations. Radiology, 82: 463, 1964. 
APÊNDICE 
APÊNDICE 1: Perfil dos 30 pacientes internados na enfermaria de geriatria

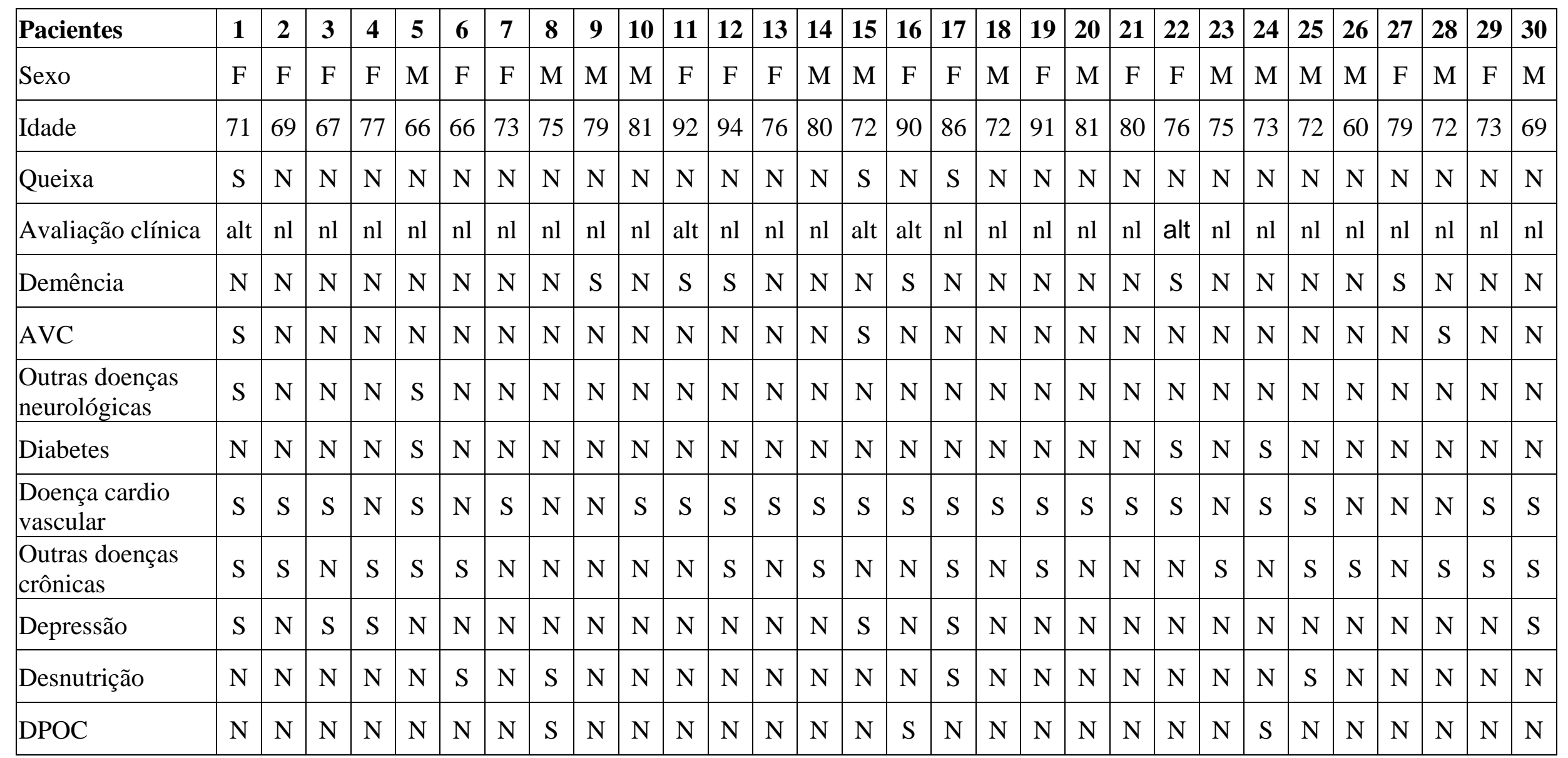

F: feminino; M: masculino; S: sim; N: não; alt: alterada; nl: normal 
APÊNDICE 2: Parâmetros dos dados cintilográficos da deglutição de idosos internados na enfermaria de geriatria

\begin{tabular}{|c|c|c|c|c|c|c|c|c|c|c|c|c|}
\hline \multirow{3}{*}{\begin{tabular}{|c|}
$\mathrm{S}$ \\
$\mathbf{u}$ \\
$\mathbf{j}$ \\
$\mathbf{e}$ \\
$\mathbf{i}$ \\
$\mathbf{t}$ \\
$\mathbf{o}$
\end{tabular}} & \multicolumn{6}{|c|}{ Consistência Líquida } & \multicolumn{6}{|c|}{ Consistência Pastosa } \\
\hline & \multicolumn{2}{|c|}{ Boca } & \multicolumn{3}{|c|}{ Faringe } & \multirow{2}{*}{\begin{tabular}{|c|}
$\begin{array}{c}\text { Esôfago } \\
\text { Proximal }\end{array}$ \\
$\begin{array}{c}\text { Entrada } \\
\text { (seg.) }\end{array}$ \\
\end{tabular}} & \multicolumn{2}{|c|}{ Boca } & \multicolumn{3}{|c|}{ Faringe } & \multirow{2}{*}{$\begin{array}{c}\begin{array}{c}\text { Esôfago } \\
\text { Proximal }\end{array} \\
\text { Entrada } \\
\text { (seg.) }\end{array}$} \\
\hline & $\begin{array}{l}\text { Trânsito } \\
\text { (seg.) }\end{array}$ & $\begin{array}{c}\text { Resíduo } \\
\text { (\%) }\end{array}$ & $\begin{array}{l}\text { Trânsito } \\
\text { (seg.) }\end{array}$ & $\begin{array}{c}\text { Clearance } \\
\text { (seg.) }\end{array}$ & \begin{tabular}{|c} 
Resíduo \\
(\%)
\end{tabular} & & $\begin{array}{l}\text { Trânsito } \\
\text { (seg.) }\end{array}$ & $\begin{array}{c}\text { Resíduo } \\
\text { (\%) }\end{array}$ & $\begin{array}{l}\text { Trânsito } \\
\text { (seg.) }\end{array}$ & \begin{tabular}{|c}
$\begin{array}{c}\text { Clearance } \\
\text { (seg.) }\end{array}$ \\
\end{tabular} & $\begin{array}{c}\text { Resíduo } \\
\text { (\%) }\end{array}$ & \\
\hline 1 & 1,65 & 58,00 & 0,20 & 2,00 & 22,00 & 0,25 & - & - & - & - & - & - \\
\hline 2 & 1,15 & 9,21 & 0,35 & 0,65 & 5,35 & 0,55 & 0,70 & 17,43 & 0,50 & 0,85 & 2,33 & 0,40 \\
\hline 3 & 0,60 & \begin{tabular}{|l|}
20,39 \\
\end{tabular} & 0,25 & 0,55 & 33,36 & 2,95 & 0,55 & 20,91 & 0,25 & 0,55 & 11,11 & 0,45 \\
\hline 4 & 0,30 & 14,18 & 0,55 & 0,80 & 15,84 & 0,85 & 0,50 & 8,08 & 0,70 & 0,95 & 0,95 & 0,35 \\
\hline 5 & 0,60 & 12,74 & 0,75 & 1,60 & 13,00 & 0,55 & 0,60 & 15,93 & 0,45 & 0,70 & 14,69 & 0,50 \\
\hline 6 & 0,45 & 5,26 & 0,60 & 0,75 & 8,51 & 0,60 & 0,35 & 26,87 & 0,50 & 0,80 & 19,15 & 1,20 \\
\hline 7 & 0,80 & 15,89 & 0,45 & 0,90 & 12,16 & 0,50 & 0,45 & 31,14 & 0,35 & 0,60 & 5,19 & 0,40 \\
\hline 8 & 0,25 & 8,41 & 0,45 & 0,70 & 16,67 & 0,30 & 0,95 & 9,09 & 0,35 & 0,75 & 23,08 & 1,10 \\
\hline 9 & 0,70 & 33,11 & 0,60 & 0,80 & 14,29 & 0,30 & * & 20,21 & 0,40 & 0,65 & 18,87 & 0,35 \\
\hline 10 & 0,65 & 20,00 & 0,50 & 0,90 & 4,54 & 0,35 & 1,85 & 5,83 & 0,30 & 0,80 & 24,53 & 0,30 \\
\hline 11 & 1,00 & \begin{tabular}{|l|}
28,27 \\
\end{tabular} & 0,60 & 1,20 & 16,32 & 0,45 & 0,65 & 40,27 & 0,30 & 0,85 & 33,33 & 0,65 \\
\hline 12 & 1,90 & 9,68 & 0,50 & 0,85 & 8,54 & 0,30 & 1,05 & 23,06 & 0,45 & 0,70 & 18,03 & 0,70 \\
\hline 13 & 0,70 & 2,81 & 0,50 & 0,85 & 20,00 & 0,40 & 0,90 & 29,38 & 0,50 & 1,70 & 40,00 & 1,20 \\
\hline 14 & 0,50 & 18,83 & 1,00 & 1,60 & 6,92 & 0,30 & 0,75 & 23,64 & 0,50 & 0,80 & 15,24 & 0,65 \\
\hline 15 & - & - & - & - & - & - & - & - & - & - & - & - \\
\hline 16 & 0,25 & 17,24 & 0,35 & 0,65 & 19,18 & 0,20 & 0,50 & 30,49 & 0,35 & 0,70 & 20,41 & 0,65 \\
\hline 17 & 0,55 & 6,25 & 0,35 & 0,55 & 4,65 & 0,20 & 0,60 & 17,22 & 0,35 & 0,75 & 6,10 & 0,70 \\
\hline 18 & 0,70 & 10,48 & 0,35 & 0,60 & 3,57 & 0,20 & 0,85 & 11,54 & 0,30 & 0,60 & 14,29 & 0,30 \\
\hline 19 & 0,80 & 6,92 & 0,65 & 1,05 & 7,64 & 0,25 & 1,70 & 14,67 & 0,30 & 1,35 & 36,07 & 0,70 \\
\hline 20 & 0,15 & 29,21 & 0,55 & 1,05 & 11,72 & 0,40 & 0,50 & 43,4 & 0,80 & 0,20 & 31,71 & 0,30 \\
\hline 21 & 1,05 & 40,72 & 0,40 & 0,75 & 9,43 & 0,30 & 0,90 & 11,17 & 0,65 & 1,30 & 10,20 & 0,75 \\
\hline 22 & 0,80 & 4,28 & 0,60 & 1,05 & 28,09 & 0,40 & 0,70 & 5,00 & 0,30 & 0,80 & 48,35 & 0,40 \\
\hline 23 & 0,85 & \begin{tabular}{|l|}
14,73 \\
\end{tabular} & 0,50 & 0,65 & 0,00 & 0,55 & 1,40 & 14,29 & 0,40 & 1,40 & 15,97 & 1,50 \\
\hline 24 & 0,65 & \begin{tabular}{|l|}
12,57 \\
\end{tabular} & 0,25 & 0,80 & 10,71 & 0,20 & 0,25 & 22,52 & 0,60 & 1,25 & 23,08 & 0,55 \\
\hline 25 & 0,60 & 9,01 & 0,35 & 0,65 & 19,01 & 0,25 & 0,30 & 15,91 & 0,55 & 1,15 & 17,76 & 0,50 \\
\hline 26 & 0,40 & 9,42 & 0,40 & 0,85 & 12,37 & 0,50 & 0,30 & 37,73 & 0,40 & 0,70 & 19,61 & 0,65 \\
\hline 27 & 0,90 & 3,61 & 0,45 & 1,15 & 10,58 & 0,90 & 1,45 & 2,84 & 0,65 & 2,60 & 11,84 & 0,55 \\
\hline 28 & 0,20 & 5,00 & 0,45 & 0,65 & 5,55 & 0,15 & 0,40 & 13,44 & 0,40 & 0,65 & 27,78 & 0,45 \\
\hline 29 & 0,75 & 1,86 & 0,35 & 0,75 & 19,32 & 0,30 & 0,25 & 23,42 & 0,30 & 0,60 & 16,18 & 0,30 \\
\hline 30 & 0,60 & 3,35 & 0,60 & 0,90 & 1,85 & 0,20 & 1,00 & 10,00 & 0,40 & 1,45 & 8,45 & 0,60 \\
\hline
\end{tabular}


APÊNDICE 3: Parâmetros dos dados cintilográficos da deglutição de idosos normais (grupo controle)

\begin{tabular}{|c|c|c|c|c|c|c|c|c|c|c|c|c|}
\hline $\mathrm{S}$ & \multicolumn{6}{|c|}{ Consistência Líquida } & \multicolumn{6}{|c|}{ Consistência Pastosa } \\
\hline e & \multicolumn{2}{|c|}{ Boca } & \multicolumn{3}{|c|}{ Faringe } & \multirow{2}{*}{\begin{tabular}{|c|c|}
$\begin{array}{c}\text { Esôfago } \\
\text { Proximal }\end{array}$ \\
Entrada \\
\end{tabular}} & \multicolumn{2}{|c|}{ Boca } & \multicolumn{3}{|c|}{ Faringe } & \multirow{2}{*}{\begin{tabular}{|r|}
$\begin{array}{r}\text { Esôfago } \\
\text { Proxima }\end{array}$ \\
Entrada \\
\end{tabular}} \\
\hline o & Trânsito & Resíduo & Trânsito & Clearance & Resíduo & & Trânsito & Resíduo & Trânsito & \begin{tabular}{|l|} 
Clearance \\
\end{tabular} & Resíduo & \\
\hline & (seg.) & (\%) & (seg.) & (seg.) & (\%) & (seg.) & (seg.) & (\%) & (seg.) & (seg.) & (\%) & (seg.) \\
\hline 1 & 0,45 & 10,08 & 0,35 & 0,55 & 15,68 & 0,30 & 0,65 & 5,06 & 0,35 & 5 & 1 &, 50 \\
\hline 2 & 0,50 & 32,85 & 0,30 & 65 & 18,64 & 0,35 & 0,50 & 13,36 & 0,50 & 0,95 & 14,63 & 0,60 \\
\hline 3 & 0,35 & 26,74 & 0,50 & 75 & 1,02 & 0,15 & 0,60 & 11,67 & 0,35 & 0,70 & 22,86 & 0,35 \\
\hline 4 & 1,10 & 22,13 & 0,65 & 20 & 6,25 & 0,30 & 1,55 & 19,76 & 0,50 & 1,80 & 17,35 & 0,70 \\
\hline 5 & 0,65 & 12,82 & 0,65 & & 1,59 & & 1,20 & 3,73 & 30 & 0,65 & 5,43 & 0,45 \\
\hline 6 & 0,90 & 4,73 & 0,50 & 0,85 & 7,04 & 0,35 & 0,95 & 17,31 & 0,40 & 0,60 & 15,69 & 0,45 \\
\hline 7 & 0,75 & 15,25 & 0,30 & 0,70 & 5,08 & 0,40 & 0,60 & 12,43 & 0,75 & 1,00 & 1,71 & 0,20 \\
\hline 8 & 0,65 & 8,75 & 0,50 & 0,80 & 22,96 & 0,40 & 0,60 & 10,77 & 0,55 & 0,80 & 11,84 & 0,45 \\
\hline 9 & 0,20 & 10,26 & 0,50 & 0,80 & 6,98 & 0,75 & 1,60 & 3,85 & 0,35 & 0,65 & 2,30 & 0,35 \\
\hline 10 & 0,60 & 32,00 & 0,40 & 0,95 & 23,4 & 0,45 & 0,20 & 56,06 & 0,70 & 0,90 & 2,70 & 0,20 \\
\hline
\end{tabular}


APÊNDICE 4: Parâmetros dos dados cintilográficos da deglutição de jovens (grupo controle)

\begin{tabular}{|c|c|c|c|c|c|c|c|c|c|c|c|c|}
\hline \multirow{3}{*}{$\begin{array}{l}\mathbf{S} \\
\mathbf{u} \\
\mathbf{j} \\
\mathbf{e} \\
\mathbf{i} \\
\mathbf{t} \\
\mathbf{0}\end{array}$} & \multicolumn{6}{|c|}{ Consistência Líquida } & \multicolumn{6}{|c|}{ Consistência Pastosa } \\
\hline & \multicolumn{2}{|c|}{ Boca } & \multicolumn{3}{|c|}{ Faringe } & \multirow{2}{*}{\begin{tabular}{|c|c|}
$\begin{array}{c}\text { Esôfago } \\
\text { Proximal }\end{array}$ \\
$\begin{array}{c}\text { Entrada } \\
\text { (seg.) }\end{array}$ \\
\end{tabular}} & \multicolumn{2}{|c|}{ Boca } & \multicolumn{3}{|c|}{ Faringe } & \multirow{2}{*}{\begin{tabular}{|c|}
$\begin{array}{c}\text { Esôfago } \\
\text { Proximal }\end{array}$ \\
$\begin{array}{c}\text { Entrada } \\
\text { (seg.) }\end{array}$ \\
\end{tabular}} \\
\hline & $\begin{array}{c}\text { Trânsito } \\
\text { (seg.) }\end{array}$ & \begin{tabular}{|c} 
Resíduo \\
$(\%)$
\end{tabular} & \begin{tabular}{|c|} 
Trânsito \\
(seg.)
\end{tabular} & \begin{tabular}{|c|}
$\begin{array}{c}\text { Clearance } \\
\text { (seg.) }\end{array}$ \\
\end{tabular} & \begin{tabular}{|c|} 
Resíduo \\
$(\%)$
\end{tabular} & & \begin{tabular}{|c|} 
Trânsito \\
(seg.)
\end{tabular} & $\begin{array}{c}\text { Resíduo } \\
(\%)\end{array}$ & \begin{tabular}{|c|} 
Trânsito \\
(seg.)
\end{tabular} & \begin{tabular}{|c|} 
Clearance \\
(seg.)
\end{tabular} & $\begin{array}{c}\text { Resíduo } \\
\text { (\%) }\end{array}$ & \\
\hline 1 & 0,45 & 11,54 & 0,45 & 0,85 & 5,26 & 0,10 & 1,30 & 1,25 & 0,60 & 1,20 & 8,95 & 0,50 \\
\hline 2 & 1,00 & 6,12 & 0,55 & 0,90 & 3,51 & 0,25 & 1,50 & 2,26 & 0,40 & 0,80 & 16,67 & 0,50 \\
\hline 3 & 0,75 & 5,29 & 0,50 & 0,70 & 3,07 & 0,15 & 1,40 & 4,52 & 0,50 & 0,85 & 6,74 & 0,50 \\
\hline 4 & 0,60 & 12,87 & 0,55 & 0,70 & 2,70 & 0,20 & 0,35 & 12,02 & 0,35 & 0,70 & 17,20 & 0,45 \\
\hline 5 & 1,05 & 7,18 & 0,40 & 0,60 & 3,90 & 0,15 & 0,50 & 17,14 & 0,45 & 0,95 & 8,20 & 0,55 \\
\hline 6 & 0,45 & 11,22 & 0,50 & 0,70 & 0,00 & 0,25 & 0,35 & 7,21 & 0,30 & 0,85 & 11,29 & 0,40 \\
\hline 7 & 0,65 & 3,85 & 0,35 & 0,60 & 3,45 & 0,20 & 0,65 & 2,88 & 0,50 & 0,75 & 1,86 & 0,50 \\
\hline 8 & 0,40 & 5,97 & 0,35 & 0,40 & 6,33 & 0,15 & 0,40 & 11,63 & 0,30 & 0,65 & 9,26 & 0,45 \\
\hline 9 & 0,30 & 2,78 & 0,35 & 0,60 & \begin{tabular}{|l|}
3,57 \\
\end{tabular} & 0,30 & 0,20 & 6,74 & 0,30 & 0,65 & 6,67 & 0,65 \\
\hline 10 & 0,50 & 5,03 & 0,60 & 1,10 & \begin{tabular}{|l|}
1,87 \\
\end{tabular} & 0,25 & 0,35 & 12,64 & \begin{tabular}{|l|}
0,50 \\
\end{tabular} & 1,20 & 20,55 & 0,70 \\
\hline 11 & 0,40 & 3,33 & 0,30 & 0,75 & 4,72 & 0,20 & 0,30 & 5,19 & 0,35 & 0,75 & 20,00 & 0,50 \\
\hline 12 & 0,30 & 20,78 & 0,50 & 0,80 & 11,11 & 0,15 & 0,35 & 13,73 & 0,35 & 0,45 & 16,66 & 0,50 \\
\hline 13 & 1,20 & 4,81 & 0,35 & 0,55 & \begin{tabular}{|l|}
99 \\
\end{tabular} & 0,20 & 0,55 & 4,35 & 0,55 & 0,70 & 18,64 & 0,50 \\
\hline 14 & 0,45 & 3,51 & 0,40 & 0,75 & 15,15 & 0,15 & 1,60 & 7,83 & 1,45 & 1,70 & 21,67 & 0,55 \\
\hline 15 & 0,70 & 8,70 & 0,30 & 0,45 & 8,57 & 0,20 & 0,15 & 27,00 & 0,50 & 0,65 & 13,16 & 0,30 \\
\hline 16 & 0,30 & 5,43 & 0,30 & 0,45 & \begin{tabular}{|l|}
6,86 \\
\end{tabular} & 0,15 & 0,40 & 9,15 & 0,40 & 0,80 & 3,54 & 0,30 \\
\hline 17 & 0,65 & 6,10 & 0,45 & 0,65 & 5,75 & 0,25 & 0,70 & 5,71 & 0,55 & 0,85 & 3,19 & 0,65 \\
\hline 18 & 0,30 & 21,7 & 0,50 & 1,00 & 0,94 & 0,30 & 0,55 & 7,70 & 0,80 & 1,25 & 7,14 & 0,75 \\
\hline 19 & 0,35 & 4,76 & 0,50 & 0,85 & \begin{tabular}{|l|}
3,37 \\
\end{tabular} & 0,35 & 0,60 & 8,33 & \begin{tabular}{|l|}
0,25 \\
\end{tabular} & 0,85 & 2,65 & 0,30 \\
\hline 20 & 0,20 & 5,88 & 0,55 & 0,85 & 1,11 & 0,10 & 0,35 & 15,38 & 0,45 & 1,05 & 5,00 & 0,65 \\
\hline
\end{tabular}


APÊNDICE 5: Avaliação estrutural da deglutição do grupo dos 10 voluntários idosos.

\begin{tabular}{|c|c|c|c|c|}
\hline Aspecto Avaliado & \multicolumn{2}{|l|}{ Descrição } & Pacientes & $(\%)$ \\
\hline \multirow[t]{3}{*}{ Estado do paciente } & \multicolumn{2}{|l|}{ Sonolento } & 0 & 0,0 \\
\hline & \multicolumn{2}{|l|}{ Alerta } & 10 & 100,0 \\
\hline & \multicolumn{2}{|l|}{ Confusional } & 0 & 0,0 \\
\hline \multirow[t]{2}{*}{ Compreensão } & \multicolumn{2}{|l|}{ Adequada } & 10 & 100,0 \\
\hline & \multicolumn{2}{|l|}{ Alterada } & 0 & 0,0 \\
\hline \multirow[t]{2}{*}{ Expressão } & \multicolumn{2}{|l|}{ Adequada } & 10 & 100,0 \\
\hline & \multicolumn{2}{|l|}{ Alterada } & 0 & 0,0 \\
\hline \multirow[t]{5}{*}{ Dentição } & \multicolumn{2}{|l|}{ Presença } & 3 & 30,0 \\
\hline & \multicolumn{2}{|c|}{ Falta de elementos dentários } & 0 & 0,0 \\
\hline & \multicolumn{2}{|c|}{ Bom estado de conservação } & 2 & 20,0 \\
\hline & \multicolumn{2}{|c|}{ Mau estado de conservação } & 1 & 10,0 \\
\hline & \multicolumn{2}{|l|}{ Ausência } & 6 & 60,0 \\
\hline \multirow[t]{5}{*}{ Prótese dentária } & \multicolumn{2}{|l|}{\begin{tabular}{|l|} 
Não usa \\
\end{tabular}} & 0 & 0,0 \\
\hline & \multicolumn{2}{|l|}{ Parcial inferior } & 1 & 10,0 \\
\hline & \multicolumn{2}{|l|}{ Parcial superior } & 1 & 10,0 \\
\hline & \multicolumn{2}{|l|}{ Total inferior } & 5 & 50,0 \\
\hline & \multicolumn{2}{|l|}{ Total superior } & 6 & 60,0 \\
\hline \multirow[t]{4}{*}{ Adaptação da prótese } & \multirow[t]{2}{*}{ Bem adaptada } & Inferior & 5 & 50,0 \\
\hline & & Superior & 6 & 60,0 \\
\hline & \multirow[t]{2}{*}{ Mal adaptada } & Inferior & 0 & 0,0 \\
\hline & & Superior & 0 & 0,0 \\
\hline \multirow{2}{*}{\begin{tabular}{|llll}
$\begin{array}{l}\text { Retirada } \\
\text { internação }\end{array}$ & da & prótese & na \\
\end{tabular}} & \multicolumn{2}{|l|}{ Sim } & $-*$ & $-*$ \\
\hline & Não & & $-*$ & $-*$ \\
\hline Ulcerações na cavidade oral & Sim & & 0 & 0,0 \\
\hline & Não & & 10 & 100,0 \\
\hline Saliva & Pouca & & 0 & 0,0 \\
\hline & Normal & & 10 & 100,0 \\
\hline & Excessiva & & 0 & 0,0 \\
\hline Condições de higienização & Paciente realiz & sozinho (a) & 10 & 100,0 \\
\hline & Higiene com $\mathrm{s}$ & eervisão & $-*$ & $-*$ \\
\hline & Não realiza hį̧ & ene oral & 0 & 0,0 \\
\hline & Cuidador reali & a higiene & $-*$ & $-*$ \\
\hline Deglutição espontânea de saliva & Sim & & 10 & 100,0 \\
\hline & Não & & 0 & 0,0 \\
\hline Oclusão de lábios & Sim & & 10 & 100,0 \\
\hline & Não & & 0 & 0,0 \\
\hline
\end{tabular}




\begin{tabular}{|c|c|c|c|}
\hline \multirow[t]{5}{*}{ Força de língua } & 1/3 posterior & 1 & 10,0 \\
\hline & $1 / 3$ médio e $1 / 3$ posterior & 5 & 50,0 \\
\hline & $\begin{array}{l}\text { 1/3 anterior, } 1 / 3 \text { médio e } 1 / 3 \\
\text { posterior }\end{array}$ & 4 & 40,0 \\
\hline & Ausência & 0 & 0,0 \\
\hline & Impossível avaliar & 0 & 0,0 \\
\hline \multirow[t]{4}{*}{ Mobilidade para a deglutição } & Sim & 10 & 100,0 \\
\hline & Não & 0 & 0,0 \\
\hline & Reduzida (alterada) & 0 & 0,0 \\
\hline & Impossível avaliar & 0 & 0,0 \\
\hline \multirow[t]{3}{*}{ Sensibilidade } & Sim & 10 & 0,0 \\
\hline & Não & 0 & 0,0 \\
\hline & Alterada & 0 & 0,0 \\
\hline \multirow[t]{2}{*}{ Abertura de mandíbula } & Sim & 10 & 100,0 \\
\hline & Não & 0 & 0,0 \\
\hline \multirow[t]{3}{*}{ Sensibilidade de palato mole } & Sim & 7 & 70,0 \\
\hline & Não & 3 & 30,0 \\
\hline & Impossível avaliar & 0 & 0,0 \\
\hline \multirow[t]{3}{*}{ Tosse } & Sim & 10 & 100,0 \\
\hline & Não & 0 & 0,0 \\
\hline & Insuficiente & 0 & 0,0 \\
\hline \multirow[t]{2}{*}{ Freqüência da alimentação } & Normal & 10 & 100,0 \\
\hline & Reduzida & 0 & 0,0 \\
\hline \multirow[t]{2}{*}{ Tempo da refeição } & Normal & 10 & 100,0 \\
\hline & Aumentado & 0 & 0,0 \\
\hline Postura durante a alimentação & Sentado & 10 & 100,0 \\
\hline \multirow[t]{2}{*}{ Usa manobras compensatórias } & Sim & 0 & 0,0 \\
\hline & Não & 10 & 100,0 \\
\hline \multirow[t]{3}{*}{ Resíduo na cavidade oral } & Sim & 0 & 0,0 \\
\hline & Não & 10 & 100,0 \\
\hline & Sem dados & 0 & 0,0 \\
\hline \multirow[t]{3}{*}{ Presença de engasgos } & Sim & 0 & 0,0 \\
\hline & Não & 10 & 100,0 \\
\hline & Sem dados & 0 & 0,0 \\
\hline \multirow[t]{3}{*}{ Presença de tosse } & Sim & 0 & 0,0 \\
\hline & Não & 10 & 100,0 \\
\hline & Sem dados & 0 & 0,0 \\
\hline \multirow[t]{3}{*}{ Presença de fadiga } & Sim & 0 & 0,0 \\
\hline & Não & 10 & 100,0 \\
\hline & Sem dados & 0 & 0,0 \\
\hline
\end{tabular}

*: itens não incluídos na avaliação do grupo controle 